\author{
UNIVERSIDADE DE SÃO PAULO \\ Escola de Engenharia de São Carlos \\ Departamento de Engenharia de Transportes \\ Programa de Pós-Graduação em Engenharia de Transportes
}

Gabriel Jurado Martins de Oliveira

\title{
CALIBRAÇÃO DA RELAÇÃO FLUXO-VELOCIDADE PARA AUTOESTRADAS E RODOVIAS DE PISTA DUPLA
}



Gabriel Jurado Martins de Oliveira

\section{CALIBRAÇÃO DA RELAÇÃO FLUXO-VELOCIDADE PARA AUTOESTRADAS E RODOVIAS DE PISTA DUPLA}

Dissertação de Mestrado submetida à Escola de Engenharia de São Carlos, da Universidade de São Paulo, como parte dos requisitos para a obtenção do título de Mestre em Ciências, Programa de Pós-Graduação em Engenharia de Transportes. Área de Concentração: Planejamento e Operação de Sistemas de Transportes

Orientador: Prof. Dr. André Luiz Barbosa Nunes da Cunha

São Carlos 

Aos meus pais,

Altamir e Marta. 



\section{Agradecimentos}

Agradeço a Deus.

Aos meus amados pais Altamir e Marta pelo amor, ensinamentos, incentivos, paciência e pelos esforços nunca medidos.

Ao meu primo Diego, pela amizade, união, companheirismo de vida e de trabalho.

Aos meus familiares, em especial, a Ariel, Arlete, Lauriberto, Carol, Almir, Marcel, os quais ao longo de todo processo, sempre estiveram do meu lado.

Ao Departamento de Engenharia de Transportes e a Escola de Engenharia de São Carlos STT/EESC/USP, pela oportunidade de realização do curso. Ao Dr. André Luiz Barbosa Nunes da Cunha, pelo aceite na minha orientação e, principalmente, pelos conselhos e incentivos, bem como pela confiança depositada na realização deste trabalho.

Aos professores e funcionários do Departamento de Engenharia de Transportes, pela contribuição para minha evolução profissional e atenção dispensada ao longo do curso, em especial ao Dr. José Reynaldo Setti e Dra. Cira Souza Pitombo, pelas opiniões e disponibilidade.

Aos meus queridos amigos, que de uma forma ou de outra, sempre me apoiaram. Aos amigos do grupo de pesquisa: Elaine, Leandro, Mariana, Natália, Bruna, André e Adriano pela amizade e ótima convivência. As conversas e sugestões foram importantíssimas para o desenvolvimento deste trabalho.

A todos os colegas e amigos do departamento, que conviveram no dia a dia comigo, e que, direta ou indiretamente, sempre estiveram dispostos a me ajudar e contribuíram para a realização e êxito deste trabalho, em especial, ao Francisco e Luan. 
Agradeço também ao Gustavo Riente pelas conversas e disponibilidade. 


\section{Resumo}

Martins de Oliveira, G. J. CALIBRAÇÃO DA RELAÇÃO FLUXO-VELOCIDADE PARA AUTOESTRADAS E RODOVIAS DE PISTA DUPLA. 108 p. Dissertação de Mestrado - Escola de Engenharia de São Carlos, Universidade de São Paulo, 2018.

Esta pesquisa apresenta um método de calibração da relação fluxo-velocidade do Highway Capacity Manual, HCM, para autoestradas e rodovias de pista dupla, a partir de recomendações tecidas pelos autores envolvidos na elaboração do manual. Para tanto, foi utilizado uma amostra com mais de 1.700 .000 observações, coletadas por 34 sensores de tráfego, localizados em quatros rodovias do Estado de São Paulo: SP-280, SP-348, SP-270 e SP-021. O tratamento do banco de dados foi realizado por meio da filtragem dos dados originais através da aplicação de três critérios, que têm como finalidade remover observações consideradas inadequadas para a calibração do modelo. Os critérios baseiam-se em obter uma corrente de tráfego formada somente por veículos leves, com condições de operação normal e com observações referentes apenas ao regime de fluxo livre. A separação entre os regimes de fluxo livre e congestionado foi realizada por meio da densidade na capacidade. Para tanto, foi proposto um método de estimação da capacidade por meio da análise da variação da velocidade média da corrente em função do fluxo de tráfego. O pressuposto do método parte do conceito de que o colapso da corrente de tráfego é um fenômeno estocástico, caracterizado pela queda abrupta da velocidade média em função do aumento do fluxo de tráfego. O momento em que ocorre mudança abrupta de velocidade é associado ao colapso da corrente de tráfego e consequentemente à capacidade da via. Após a estimação da capacidade, a velocidade na capacidade foi determinada como a média das velocidades associadas ao fluxo na capacidade, enquanto que a densidade na 
capacidade foi obtida por meio da relação fundamental de tráfego. O método foi aplicado em um conjunto de 18 trechos de rodovias que atingem a capacidade e os resultados foram considerados satisfatórios após a comparação com valores encontrados na literatura. A calibração da relação fluxo-velocidade foi realizada individualmente para cada trecho de rodovia utilizado no estudo. A análise dos resultados mostra que as rodovias rurais apresentam em média valores maiores para velocidade de fluxo livre, capacidade, coeficiente de calibração, velocidade na capacidade e ponto de transição em relação as rodovias urbanas. Alem disso, o ponto de transição, que consiste em um patamar de velocidade de fluxo livre constante, apresenta valores significativamente menores em relação a literatura.

Palavras-chave: rodovias. autoestradas. rodovias de pista dupla. relação fluxo-velocidade. capacidade. HCM. calibração. inferência bayesiana. 


\section{Abstract}

Martins de Oliveira, G. J. CALIBRATION OF SPEED-FLOW RELATIONSHIP FOR FREEWAYS AND MULTILANE HIGHWAYS. 108 p. Master Thesis - São Carlos School of Engineering, University of São Paulo, 2018.

The following research aims to outline a calibration method of the speed-flow relationship presented in the Highway Capacity Manual (HCM). The method is applied on freeways and multilane highways, leveraging the guidelines made by the authors that developed the manual. In order to support the calibration, a sample with more than 1.700 .000 observations was used, collected by 34 traffic sensors on four highways at São Paulo state (SP-280, SP-348, SP270, and SP-021). Furthermore, the data treatment and cleaning process aimed to remove observations considered inappropriate from a model calibration perspective by filtering the original data through three main criteria: traffic flow only composed by passenger car, traffic under normal operations condition, and only containing observations which free flow regime applies. The third filtering criteria was applied by splitting free flow and congested regime through the threshold of density at capacity. To this extent, a capacity estimation method was proposed, aiming to analyse the average speed variation in function of the traffic flow. The assumption of the method relies in the concept that the traffic flow breakdown is a stochastic process, characterized by the abrupt drop in the average speed as function of the traffic flow increase. The moment that abrupt drop occurs is related to traffic breakdown and, consequently, to the capacity freeway capacity. Once the capacity was estimated, the speed at capacity was defined as the average of the speed associated with the flow at capacity while the density at capacity was estimated through the fundamental relationship of the traffic flow. The method was ap- 
plied in 18 delimited highway traffic perimeter that reached their corresponding capacity and the results were considered satisfactory after comparing against values found in the literature. Furthermore, the speed-flow relationships calibration was performed for each of them individually. The results show that rural highways have in average higher free flow speed, capacity, calibration coefficient, speed at capacity and breakpoint than urban highways. Moreover, the breakpoint, which consists a constant free flow speed level, presented significant lower values in comparison to the literature.

Keywords: highways. freeways. multilane highways. speed-flow relationship. capacity. HCM. calibration. bayesian inference. 


\section{Sumário}

1 Introdução $\quad 15$

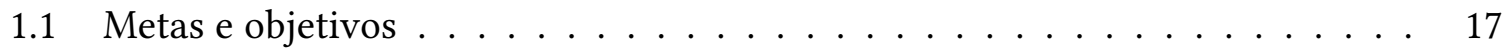

1.2 Justificativa . . . . . . . . . . . . . . . . . . . . 17

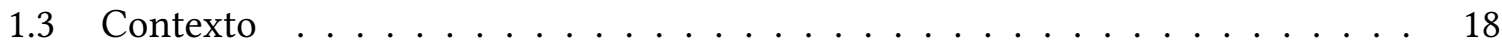

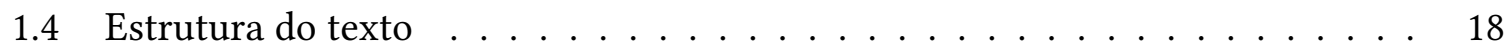

2 Revisão bibliográfica $\quad 19$

2.1 Considerações iniciais . . . . . . . . . . . . . . . . . . . . . . . 19

2.2 Teoria de fluxo de tráfego $\ldots \ldots \ldots \ldots \ldots$

2.2.1 Parâmetros de tráfego . . . . . . . . . . . . . . . . . . 20

2.2.2 Relação fundamental de tráfego . . . . . . . . . . . . . . . . 22

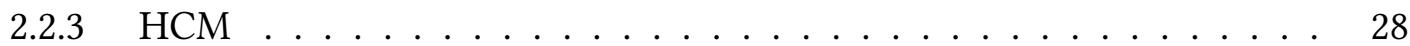

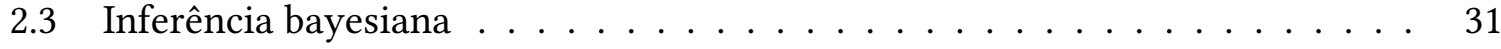

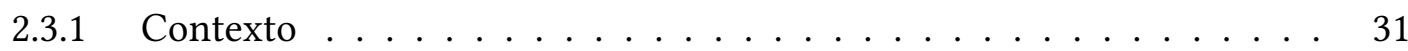

2.3.2 Teorema de Bayes . . . . . . . . . . . . . . . . . . 32

2.3.3 Monte Carlo via cadeias de Markov . . . . . . . . . . . . . . . . . 34

2.4 Considerações finais . . . . . . . . . . . . . . . . . . . . 35 
3.1 Considerações iniciais . . . . . . . . . . . . . . . . . . 37

3.1.1 Dados de Tráfego . . . . . . . . . . . . . . . 37

3.1 .2 Dados geométricos . . . . . . . . . . . . . . . 39

3.2 Tratamento dos dados de tráfego . . . . . . . . . . . . . . . . 40

3.2 .1 Método de tratamento . . . . . . . . . . . . . . . 40

3.3 Resultados . . . . . . . . . . . . . . . . . . . 43

3.4 Considerações finais . . . . . . . . . . . . . . . . . . . . . 44

4 Capacidade em rodovias $\quad 45$

4.1 Considerações iniciais . . . . . . . . . . . . . . . . . 45

4.1.1 Estimação de colapso da corrente de tráfego de forma direta . . . . . 46

4.1.2 Estimação de colapso da corrente de tráfego por meio de modelos es-

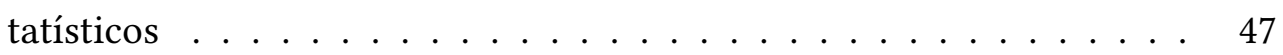

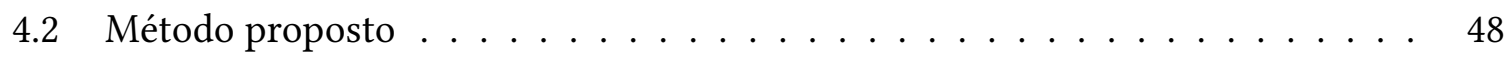

4.2 .1 Descrição do modelo . . . . . . . . . . . . . . . . . . 49

$4.2 .2 \quad$ Banco de dados . . . . . . . . . . . . . . . . . 51

4.2 .3 Distribuição a priori . . . . . . . . . . . . . . . . . 51

4.2.4 Função de verossimilhança . . . . . . . . . . . . . . . . 52

4.2.5 Monte Carlo via cadeias de Markov . . . . . . . . . . . . . . . . 52

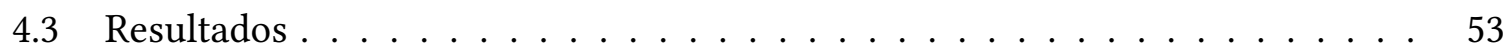

4.3 .1 Distribuição posterior . . . . . . . . . . . . . . . 53

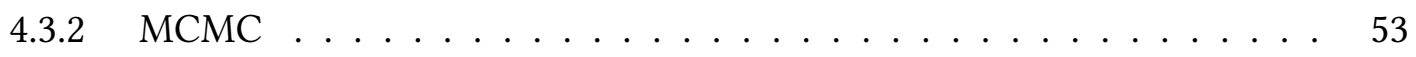

4.4 Considerações Finais . . . . . . . . . . . . . . . . . . . . 55

5 Calibração da curva fluxo-velocidade $\quad 57$

5.1 Considerações iniciais . . . . . . . . . . . . . . . . . 57

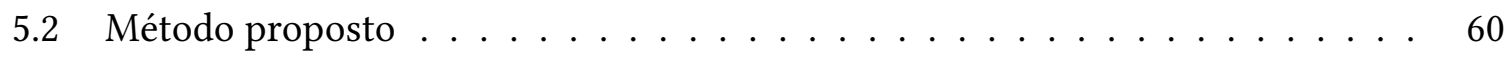

5.2 .1 Banco de dados . . . . . . . . . . . . . . . . . 60

5.2 .2 Classificação dos trechos . . . . . . . . . . . . . . 61

5.2 .3 Distribuições a priori . . . . . . . . . . . . . . . 62

5.2 .4 Função de verossimilhança . . . . . . . . . . . . . . . . . 62 
5.2.5 Monte Carlo via cadeias de Markov . . . . . . . . . . . . . . . . 63

5.3 Resultados . . . . . . . . . . . . . . . . . . . . 63

5.3.1 Distribuição posterior . . . . . . . . . . . . . . . . . 63

$5.3 .2 \quad \mathrm{MCMC} \ldots \ldots \ldots \ldots \ldots \ldots \ldots \ldots$

5.3.3 Comparação entre métodos . . . . . . . . . . . . . . . . . . . . 67

5.3.4 Calibração simultânea . . . . . . . . . . . . . . . . . . . . . 70

5.4 Considerações Finais . . . . . . . . . . . . . . . . . . . . . . 72

6 Conclusões e sugestões $\quad 75$

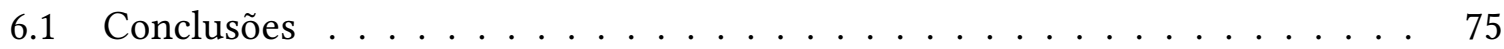

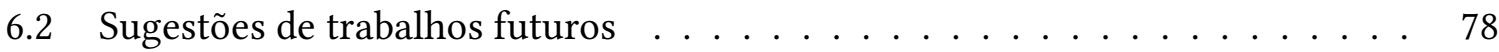

$\begin{array}{ll}\text { Referências } & 81\end{array}$

$\begin{array}{lll}\text { APÊNDICE A } & \text { Gráficos fluxo-velocidade } & 87\end{array}$

$\begin{array}{llr}\text { APÊNDICE B Teste de convergência MCMC } & 105\end{array}$

$\begin{array}{lll}\text { APÊNDICE C Distribuição posterior } & 107\end{array}$ 



\section{Capítulo}

\section{Introdução}

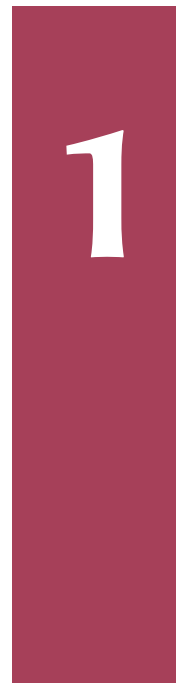

O sistema de transporte é, usualmente, descrito como o "sistema de circulação sanguíneo" de uma nação, em que o complexo sistema de ruas, rodovias, ferrovias, hidrovias, aeroportos, oleodutos, aquedutos e sistemas de transporte urbano, possibilita a circulação de pessoas e mercadorias entre os próprios centros urbanos e remotas regiões. Devido a isso, o sistema de transporte está diretamente atrelado ao nível de desenvolvimento, social e econômico, de uma nação (ROESS; PRASSAS; MCSHANE, 2010).

A engenharia de tráfego é um ramo da engenharia de transporte relacionado ao planejamento, ao desenvolvimento de projetos e a operação de sistemas de transportes rodoviários, como rodovias, terminais e redes viárias. Dentro desse ramo o estudo do tráfego consiste em etapa fundamental e tem como objetivo obter parâmetros que descrevam o comportamento do tráfego e a composição da frota de veículos.

Os parâmetros utilizados para descrever o comportamento do tráfego são classificados em microscópicos e macroscópicos, conforme o seu nível de representação. No nível microscópico, os veículos da corrente de tráfego são representados individualmente, o que permite descrever o comportamento de cada veículo ao longo do tempo e do espaço. Alguns dos parâmetros microscópicos são, headway, espaçamento e tempo de viagem. Sob outra perspectiva, o nível macroscópico, tem interesse na corrente de tráfego como um todo, ou seja, no movimento de grupos de veículos que a constituem. Os parâmetros que descrevem esse nível de representação são: fluxo, velocidade média e densidade da corrente de tráfego.

Os dados de tráfego são obtidos por métodos manuais ou automáticos a partir de pesquisas realizadas em campo. Os procedimentos manuais consistem em levantamentos de campo realizados por um observador o qual registra em documentos os fenômenos do tráfego. Por outro 
lado, os procedimentos automáticos dispensam observadores e são baseados em diversos tipos de sensores (KLEIN, 2001), classificados em intrusivos e não intrusivos. Os sensores denominados intrusivos são embutidos no pavimento, como os laços indutivos, que correspondem ao método de detecção veicular mais utilizado para contagem de tráfego (KLEIN et al., 2006). Já os não intrusivos são baseados em observações remotas, como por meio do processamento de imagens. A partir dos dados de tráfego, diversos modelos foram propostos na literatura para representar o comportamento da corrente de tráfego. Em especial, destaca-se o trabalho pioneiro de Greenshields et al. (1935), que propôs a relação fundamental de tráfego, a qual descreve a interação dos parâmetros macroscópicos, fluxo, velocidade e densidade da corrente.

Em 1950, elaborado nos princípios da relação fundamental de tráfego, o manual norteamericano, Highway Capacity Manual, HCM, consiste em um conjunto de conceitos, diretrizes e procedimentos para a avaliação de sistemas viários. Atualmente, o HCM é a principal referência mundial para a avaliação operacional de rodovias por definir medidas de desempenho, além de sistematizar e uniformizar a qualidade de serviço a qual reflete o desempenho de uma rodovia, segundo a percepção dos usuários.

No entanto, o HCM ressalta que seu desenvolvimento foi realizado a partir de dados de rodovias norte-americanas e que, portanto, refletem características especificas desses locais. Sendo assim, o manual recomenda que seus procedimentos sejam adaptados às condições locais das regiões nas quais forem utilizados (TRB, 2010; TRB, 2016), de forma que a utilização dos seus métodos sem adaptações necessárias pode levar a resultados que estimam incorretamente a qualidade de serviço de uma via.

A adaptação de um manual, método ou modelo a condições diferentes do qual foi concebido consiste na utilização de procedimentos que sejam capazes de captar as características específicas do local em análise. Tais procedimentos refletem a forma de realizar a calibração de um modelo, a qual pode ser obtida por meio de diversas técnicas. Dentre as técnicas tradicionais, destaca-se a regressão baseada no método dos mínimos quadrados. Já em relação a técnicas que vêm ganhando atenção na comunidade científica e empresarial, destacam-se os algoritmos genéticos e a Inferência Bayesiana. Esta última vem se caracterizando como base para diversos métodos de aprendizado de máquina, que consiste em uma subárea de inteligência artificial envolvida no desenvolvimento de algoritmos de auto aprendizado para adquirir conhecimento junto a um conjunto de dados.

No Brasil, o Departamento Nacional de Infraestrutura de Transporte (DNIT) adota o roteiro de cálculo do HCM para estudos de tráfego, servindo de base na avaliação do cenário existente, bem como os efeitos gerados por meio de novas obras de infraestrutura viária (DNIT, 2001). Dentro desse contexto, a Agência Reguladora de Transporte do Estado de São Paulo (ARTESP) determina como obrigatória a utilização do HCM para a verificação do atendimento aos padrões de qualidade de rodovias paulistas em regime de concessão privada (ARTESP, 2004). Regras similares também são encontradas em programas de concessão em outros estados bra- 
sileiros, como em Minas Gerais e em Goiás.

Ressalta-se a importância da adaptação do HCM para condições locais, por meio de uma calibração adequada que represente as características operacionais do local em estudo, uma vez que, diversas tomadas de decisões, nos mais variados âmbitos, estão atreladas diretamente ao correto uso do HCM. No presente estudo, é apresentado um método de calibração das curvas fluxo-velocidade do modelo do HCM para autoestradas e rodovias de pista dupla, a partir de dados empíricos de rodovias paulistas. As curvas são calibradas individualmente e dependem, exclusivamente, do conjunto de dados disponível em cada sensor de tráfego utilizado no trabalho.

\subsection{Metas e objetivos}

Esta pesquisa baseia-se na importância da calibração do HCM para condições diferentes das quais foram concebidas originalmente. Em função disso, a meta desta pesquisa de mestrado foi desenvolver um método de calibração do modelo fluxo-velocidade do HCM para autoestradas e rodovias paulistas de pista dupla, a partir de dados empíricos. Para tanto, foram propostos os seguintes objetivos específicos:

- Obter e tratar um conjunto de dados de tráfego adequado para o estudo;

- Propor um modelo para estimação da capacidade de uma via, bem como a velocidade e a densidade na capacidade; e

- Calibrar os parâmetros do modelo de fluxo-velocidade do HCM.

\subsection{Justificativa}

A necessidade de adaptação de modelos e procedimentos a condições específicas é bem definida na literatura, de forma que se não realizada adequadamente, pode levar a erros sintomáticos (CUNHA, 2007; ANDRADE, 2012). Nesse contexto, encontra-se o Highway Capacity Manual, concebido para condições de rodovias norte-americanas e utilizado na avaliação de sistemas viários ao redor do mundo. A justificativa desta pesquisa baseia-se nos seguintes fatores:

- Necessidade de adaptar o HCM para condições locais de forma rápida e eficiente;

- Aumento na quantidade de dados disponíveis na área de Engenharia de Tráfego; e

- Disponibilidade de bibliotecas e funções para análise de dados, com código aberto e livre. 


\subsection{Contexto}

Este trabalho se insere em uma linha de pesquisa desenvolvida no Departamento de Engenharia de Transportes da Escola de Engenharia de São Carlos (EESC-SP), pelo grupo de professores Doutor André Luiz Barbosa Nunes da Cunha e Doutor José Reynaldo A. Setti, com o propósito de adaptar o HCM para condições locais brasileiras. A calibração dos procedimentos do HCM vem sendo realizada pelo grupo de estudos destes professores e contam com diversos trabalhos em autoestradas e rodovias de pista dupla (DEMARCHI, 2000; CUNHA, 2007; ANDRADE, 2012; PIVA, 2015; BETHONICO, 2016).

\subsection{Estrutura do texto}

Esta dissertação está dividida em seis capítulos. O primeiro consiste nesta introdução.

O Capítulo 2 resume a revisão bibliográfica utilizada, que abrange conceitos da teoria de fluxo de tráfego e da Inferência Bayesiana.

O Capítulo 3 descreve o banco de dados utilizado no desenvolvimento da pesquisa, bem como o procedimento utilizado para o tratamento dos dados de tráfego.

O Capítulo 4 apresenta o conceito de capacidade e as principais formas de estimação, seguido do método proposto.

O Capítulo 5 descreve o modelo de fluxo-velocidade do HCM para autoestradas e rodovias de pista dupla e o método usado para realizar sua calibração.

O Capítulo 6 resume as principais conclusões e recomendações para pesquisas futuras. 


\section{Capítulo}

\section{Revisão bibliográfica}

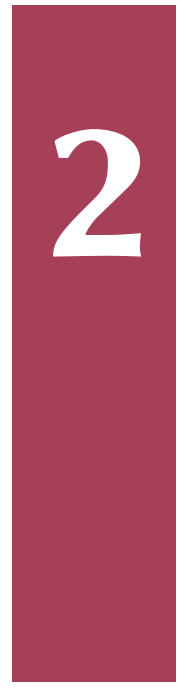

Este capítulo tem por objetivo introduzir os conceitos básicos utilizados no desenvolvimento do presente trabalho, teoria de fluxo de tráfego e Inferência Bayesiana. A teoria de fluxo de tráfego consiste na forma de representação do comportamento do tráfego veicular rodoviário, enquanto a Inferência Bayesiana é um método estatístico utilizado para atualizar a probabilidade de uma hipótese, conforme mais evidências são disponíveis. Os conceitos abordados são necessários para o desenvolvimento do método de estimação dos parâmetros da relação fluxo-velocidade do modelo do HCM para autoestradas e rodovias de pista dupla, meta desta pesquisa.

\subsection{Considerações iniciais}

A corrente de tráfego é formada a partir da interação dos veículos entre si e com o ambiente viário no qual estão inseridos. Como as características dos motoristas e do ambiente variam conforme o local e o tempo, o estudo do comportamento do tráfego apresenta aspectos de variabilidade temporal e espacial. Aliado à isso, há outro fator determinante na análise da corrente de tráfego, que consiste no nível de agrupamento dos parâmetros que a representam.

Os parâmetros de tráfego podem ser classificados conforme o detalhamento da informação que contém sobre a corrente de tráfego. Quando representam os veículos da corrente de forma individual, são classificados como dados microscópicos, enquanto que se representam a corrente de forma agrupada, são classificados como dados macroscópicos.

Os modelos denominados macroscópicos descrevem as características da corrente de tráfego de forma contínua, enquanto os microscópicos abordam a interação veículo a veículo. Já os 
modelos mesoscópicos constituem uma classe intermediária, em que são utilizados ambos os tipos de dados para descrever a corrente de tráfego.

Junto aos modelos que descrevem o comportamento da corrente de tráfego, faz-se necessário estimar os parâmetros internos do modelo, sendo que na literatura existem diversas técnicas e métodos na área de engenharia de tráfego, bem como em outras áreas da ciência. Neste trabalho, apresenta-se um novo método para calibração do modelo macroscópico de fluxovelocidade do HCM, estruturado em séries históricas de dados de tráfego e baseado na Inferência Bayesiana. A seguir, são apresentados alguns dos principais conceitos da teoria de fluxo de tráfego, como parâmetros macroscópicos e microscópicos e relação fundamental de tráfego. Em seguida, são abordados os conceitos, definições e aplicações da Inferência Bayesiana.

\subsection{Teoria de fluxo de tráfego}

\subsubsection{Parâmetros de tráfego}

Para trechos de fluxo não interrompidos os principais parâmetros macroscópicos correspondem a fluxo, velocidade média e densidade, enquanto os principais parâmetros microscópicos são headway, velocidade instantânea e espaçamento. A seguir, são descritos os parâmetros de tráfego em suas diferentes escalas, bem como suas relações.

\subsubsection{Volume, fluxo de tráfego e headway}

Volume de tráfego $(Q)$ é definido como o número total de veículos (n) que passam em uma seção de via em um determinado período de tempo e que pode ser medido por faixas e sentido de tráfego (ROESS; PRASSAS; MCSHANE, 2010). O volume de tráfego é definido pela equação:

$$
Q=\frac{n}{\Delta_{t}}
$$

Relacionado ao volume, encontra-se o fluxo de tráfego, o qual corresponde a uma taxa de passagem de veículos em uma seção em uma unidade de tempo menor que uma hora. Já o headway $(h)$ é o tempo entre a passagem sucessiva de veículos em relação a uma seção de uma via ou a um ponto de referência comum aos veículos. O volume corresponde ao inverso do headway médio, conforme a equação:

$$
Q=\frac{1}{\bar{h}}
$$

\subsubsection{Velocidade e tempo de viagem}

A velocidade $(u)$ é definida como uma taxa de movimento expressa pela razão entre a distância percorrida pelo tempo de viagem $(t)$. Em uma corrente de tráfego, cada veículo viaja a uma velocidade diferente e, assim, a velocidade da corrente é caracterizada por uma distribuição, 
sendo a média da distribuição, usualmente, utilizada como valor representativo. O tempo de viagem é inversamente proporcional à velocidade média da corrente e corresponde ao intervalo de tempo médio para percorrer uma distância entre dois pontos de uma viagem.

A velocidade média pode ser calculada de dois modos: velocidade média no espaço e velocidade média no tempo. Segundo Roess, Prassas e McShane (2010), a velocidade média no tempo $\left(u_{t}\right)$ é definida como a média aritmética das velocidades dos veículos que passam em um ponto fixo da via em um determinado período de tempo. Sendo $n$ a quantidade de veículos que passam por um determinado ponto, a Equação 2.3 representa a relação entre as velocidades instantâneas e a velocidade média no tempo.

$$
u_{t}=\frac{1}{n} \sum_{i}^{n} u_{i}
$$

Já a velocidade média no espaço $\left(u_{s}\right)$ é definida como a média harmônica das velocidades de todos os veículos que ocupam uma secção de via durante um determinado período de tempo. A Equação 2.4 apresenta a relação entre as velocidades instantâneas e as velocidades média no espaço.

$$
u_{s}=\frac{n}{\sum_{i}^{n} \frac{1}{u_{i}}}
$$

A relação entre as velocidades médias no espaço e no tempo é representada pela Equação 2.5, segundo Gerlough e Huber (1975), em que $\sigma$ é a variância das velocidades instantâneas dos veículos. A velocidade no tempo é sempre superior à velocidade no espaço, ou igual, no caso em que todos os veículos estiverem na mesma velocidade, o que corresponde a $\sigma^{2}=0$.

$$
u_{t}=u_{s}+\frac{\sigma^{2}}{u_{s}}
$$

Em essência, a velocidade média no tempo é uma medida pontual, enquanto a velocidade média no espaço é uma medida relacionada a um comprimento de via. Ressalta-se, dentro desse contexto, que para a maioria dos procedimentos do HCM e para diversos outros modelos de tráfego, a velocidade utilizada é a velocidade média no espaço (TRB, 2010; TRB, 2016).

\subsubsection{Densidade e espaçamento}

A densidade $(k)$ é definida como a quantidade de veículos que ocupam um determinado comprimento de rodovia ou faixa e, ao contrário dos parâmetros descritos anteriormente, constitui um parâmetro de difícil mensuração.

A sua estimação por medidas diretas pode ser realizada por meio de sensores baseados em imagens, no entanto, equipamentos de coleta contínuos, que constituem a principal forma de 
obtenção de dados de tráfego atualmente, como laços indutivos, não são capazes de determinala diretamente. Por outro lado, os laços indutivos podem estimar a densidade da corrente de forma indireta por meio de um outro parâmetro, a ocupância.

A ocupância (o) é definida como o percentual do tempo em que uma seção de comprimento $\left(L_{d}\right)$ encontra-se ocupada. A partir de então, por meio da relação expressa pela Equação 2.6, em que $L_{v}$ representa o comprimento dos veículos da corrente de tráfego, determina-se a densidade da corrente. Contudo, em locais que apresentam uma diversidade na frota de veículos, $L_{v}$ varia significantemente, o que pode levar a estimativas errôneas da densidade.

$$
k=\frac{o}{L_{v}+L_{d}}
$$

Apesar da dificuldade de sua estimação de forma direta e confiável, a densidade consiste no parâmetro de tráfego base para análise de nível de serviço em rodovias em diferentes manuais e métodos de engenharia de tráfego, inclusive no HCM. Isto porque a densidade relaciona-se diretamente com a liberdade de manobras e com o conforto psicológico dos motoristas (ROESS; PRASSAS; MCSHANE, 2010). Já a relação entre a densidade e o espaçamento médio (d) entre veículos sucessivos na corrente de tráfego, a partir de um ponto de referência, é expressa por:

$$
k=\frac{1}{\bar{d}}
$$

Dentro desse contexto de dificuldade, a densidade, usualmente, é estimada de forma indireta, por meio da relação fundamental de tráfego, a base da engenharia de tráfego e abordada a seguir.

\subsubsection{Relação fundamental de tráfego}

Os modelos de fluxo de tráfego vêm sendo desenvolvidos e utilizados para compreender, descrever e prever o comportamento do fluxo de tráfego desde o começo do século XX. Os primeiros estudos relacionam-se a aplicação de teoria de probabilidade na descrição do tráfego rodoviário por Adams (1936) e dos pioneiros trabalhos de Bruce D. Greenshields na Yale Bureau of Highway Traffic que propôs uma relação entre os parâmetros de tráfego, fluxo (q), velocidade $(u)$ e densidade $(k)$, representada por:

$$
q=k \cdot u
$$

A relação expressa pela Equação 2.8 é denominada relação fundamental de tráfego e é considerada o ancestral comum aos principais modelos de fluxo de tráfego (WAGENINGEN-KESSELS et al., 2015).

A partir da relação fundamental de tráfego, diversos modelos foram e continuam a ser desenvolvidos para representar o comportamento do tráfego veicular em diferentes formas de 
detalhamento. No entanto, a interação entre as variáveis de tráfego ainda não é totalmente compreendida, de forma que todos os modelos apresentam falhas em representar o comportamento do tráfego em sua totalidade, devido, dentre outros fatores, à variabilidade temporal e espacial referente ao comportamento humano.

Aliado ao desenvolvimento de modelos, encontra-se a necessidade da estimação de seus parâmetros, através de um método de calibração que consiste nas seguintes etapas: definição das variáveis dependentes e independentes; forma algébrica que represente a relação entre as variáveis dependentes e independentes (functional form); função de otimização; e técnica a ser utilizada para computar os parâmetros pela otimização da função objetivo (AERDE; RAKHA, 1995). Dentro desse contexto, diversos métodos de calibração são utilizados para a estimação dos parâmetros de modelos encontrados na literatura.

A seguir, são apresentados alguns dos principais modelos macroscópicos de tráfego existentes na literatura, com suas principais características, vantagens e desvantagens, assim como os métodos de estimação de parâmetros utilizados por seus autores. Os trabalhos que descrevem uma revisão mais detalhada dos principais modelos utilizados na literatura podem ser encontrados em Carey e Bowers (2012), Wageningen-Kessels et al. (2015), Daiheng (2015), Seo et al. (2017).

Ressalta-se que os modelos de fluxo de tráfego macroscópicos apresentam simplificações e limitações que são inerentes aos tipos de dados que utilizam. Apesar das restrições relacionadas a essa classe de modelos, diversos manuais, softwares e procedimentos baseiam-se, principalmente, em modelos macroscópicos em seu desenvolvimento. Como exemplo, o método do HCM para avaliação da capacidade e do nível de serviço em trechos de autoestradas e rodovias de pista dupla, desenvolvido a partir de dados empíricos de rodovias norte-americanas e estruturado em um modelo macroscópico de tráfego.

\subsubsection{Greenshields}

Um dos pioneiros no estudo das teorias de fluxo de tráfego, Greenshields et al. (1935) propuseram um modelo linear para representar a relação entre a velocidade média da corrente de tráfego e a densidade, conforme apresentado na Equação 2.9. A partir da relação linear entre a velocidade média e a densidade, junto com a equação fundamental de tráfego, apresentada na Equação 2.8, deriva-se uma relação parabólica entre o volume e a velocidade média, assim como entre o volume e a densidade da corrente de tráfego, conforme ilustrado na Equação 2.10.

$$
\begin{gathered}
u=u_{f}\left(1-\frac{k}{k_{j}}\right) \\
q=\frac{k_{j}}{u_{f}}\left(u_{f}-u\right) u=k_{j}\left(u-\frac{u^{2}}{u_{f}}\right)
\end{gathered}
$$

Em que: 
- $q$ : Volume de tráfego;

- u: Velocidade média da corrente;

- $k$ : Densidade da corrente;

- $u_{f}$ : Velocidade de fluxo livre; e

- $k_{j}$ : Densidade de congestionamento.

O modelo proposto consiste em um modelo de regime único, ou seja, uma única equação representa os regimes de fluxo livre e congestionado, sendo que sua calibração resume-se à estimação de dois parâmetros, velocidade de fluxo livre e densidade de congestionamento ou capacidade da rodovia. Para tanto, comumente, utiliza-se uma regressão linear que minimiza o erro quadrático médio (RAKHA; CROWTHER, 2002).

Devido à relação linear entre velocidade e densidade da corrente e à parabólica entre as outras variáveis, alguns parâmetros notáveis, como a velocidade na capacidade e a densidade no fluxo máximo, são facilmente determinados e correspondem a, respectivamente, $\frac{u_{f}}{2} \mathrm{e} \frac{k_{j}}{2}$. A Figura 2.1 ilustra as relações de tráfego que correspondem ao modelo de Greenshields.

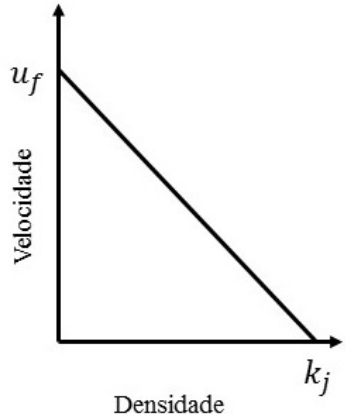

Densidade

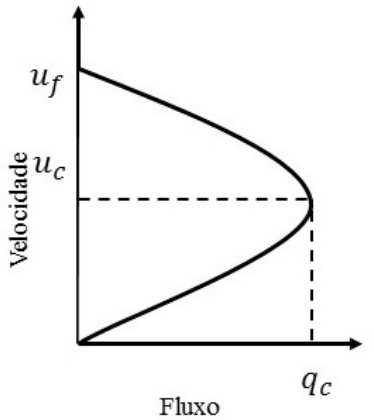

Figura 2.1 - Diagrama Greeshields

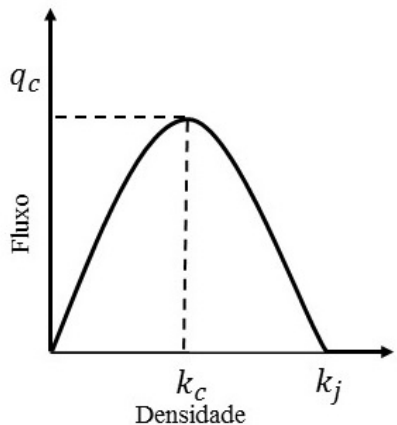

Densidade 
Substituindo a Equação 2.11 na relação fundamental de tráfego, determina-se a equação fluxodensidade, representado pela Equação 2.12, em que $c$ é uma constante estritamente positiva.

$$
\begin{gathered}
u=c \ln \left(\frac{k_{j}}{k}\right) \\
q=c k \ln \left(\frac{k_{j}}{k}\right)
\end{gathered}
$$

Assim como o modelo de Greenshields et al. (1935), o modelo proposto por Greenberg consiste em um modelo de regime único estruturado em dois parâmetros. A calibração do modelo é realizada por meio de uma regressão linear que minimiza o erro quadrático médio (GREENBERG, 1959).

Dentre suas limitações, destaca-se que quando $k=0$, a velocidade de fluxo livre tende ao infinito, o que não representa a realidade (ROSAS-JAIMES; QUEZADA-TÉLLEZ; FERNÁNDEZ-ANAYA, 2017).

\subsubsection{Underwood}

Após o trabalho de Greenberg, Underwood (1961) propôs um modelo exponencial para tentar superar as limitações do modelo proposto por Greenberg (1959). Para tanto, propôs um modelo estruturado na velocidade de fluxo livre e na densidade na capacidade, conforme a Equação 2.13 .

$$
q=u_{f} k \exp \left(\frac{-k}{k_{c}}\right)
$$

Assim como modelo de Greenberg, o modelo proposto por Underwood (1961) consiste em um modelo de regime único com calibração realizada por meio de uma regressão linear que minimiza o erro quadrático médio. Entre as principais limitações, destaca-se que a densidade de congestionamento tende ao infinito.

\subsubsection{Edie}

Edie (1961) propôs um modelo para tentar superar as limitações do modelo de Greenberg (1959) para condições de velocidade de fluxo livre, a qual tende ao infinito. Para tanto, propôs um modelo de dois regimes, em que, para condições de fluxo livre, utiliza o modelo de Underwood (1961) e para condições de tráfego congestionado, utiliza o modelo de Greenberg (1959). A calibração do modelo de Edie (1961) consiste na utilização do método dos mínimos quadrados.

Nos modelos que apresentam mais de um regime, denominado de regimes múltiplos, os dados são categorizados em regimes distintos e mais de um modelo é utilizado para representalos. Nos modelos de regime duplo, os dados são categorizados em não congestionados e con- 
gestionados. Já em modelos de regime triplo, os dados são categorizados em não congestionado, congestionado e de descarga.

\subsubsection{Drew, Pipes e May and Keller}

Os modelos de Drew (1965), Pipes (1967), May e Keller (1967) podem ser compreendidos como extensões do modelo de Greenshields a partir da introdução de novos parâmetros. O modelo de Drew (1965) é representado pela Equação 2.14 e consiste na introdução de um parâmetro $m$, que deve ser maior que zero. Já o modelo de Pipes (1967) é representado pela Equação 2.15 e consiste na introdução de um parâmetro $n$ em sua formulação, o qual também deve ser maior que zero.

$$
\begin{aligned}
& q=k u_{f}\left(1-\left(\frac{k}{k_{j}}\right)^{m}\right) \\
& q=k u_{f}\left(1-\left(\frac{k}{k_{j}}\right)\right)^{n}
\end{aligned}
$$

May e Keller (1967) apresentam um modelo que utiliza os parâmetros introduzidos por Drew (1965) e Pipes (1967) em sua formulação, conforme a Equação 2.16. O modelo de May and Keller se reduz ao modelo de Greenshields, quando $m=1$ e $n=1$. Já quando $n=1$ o modelo se equivale a Drew (1965) e quando $m=1$ o modelo se equivale a Pipes (1967).

$$
q=k u_{f}\left(1-\left(\frac{k}{k_{j}}\right)^{m}\right)^{n}
$$

Os modelos de Drew (1965), Pipes (1967) e May e Keller (1967) constituem modelos de regime único e apresentam maior flexibilidade em relação a Greenshields et al. (1935) e Greenberg (1959), já que apresentam quantidade maior de parâmetros. A estimação dos parâmetros dos modelos é realizada por meio do método dos mínimos quadrados.

\subsubsection{Del Castilho and Benitez}

Castillo e Benitez (1995b) propuseram um modelo de regime único estruturado em três parâmetros, velocidade de fluxo livre, densidade de congestionamento e uma constante $c_{j}$, conforme a Equação 2.17. A calibração do modelo proposta por Castillo e Benitez (1995b) consiste em uma regressão baseada no método dos mínimos quadrados (CASTILLO; BENITEZ, 1995a). Dentre as principais vantagens do modelo, destaca-se a flexibilidade de ajustamento para diferentes configurações de tráfego.

$$
q=k u_{f}\left(1-\exp \left(1-\exp \left(\left(\frac{c_{j}}{u_{f}}\right)\left(\frac{k_{j}}{k}-1\right)\right)\right)\right.
$$




\subsubsection{Van Aerde}

Van Aerde e Rakha (1995) propuseram um modelo mais detalhado para representar a relação fluxo-velocidade da corrente de tráfego que consiste em um modelo de regime único com maior grau de liberdade e de flexibilidade, para capturar diferentes tipos de configurações de tráfego.

O modelo é baseado em quatro parâmetros, velocidade de fluxo livre, capacidade, densidade de congestionamento e velocidade na capacidade, conforme as Equações 2.18, 2.19, 2.20, 2.21 . A Figura 2.2 ilustra as relações de tráfego correspondentes ao modelo.

$$
\begin{gathered}
q=\frac{u}{\left(c_{1}+\frac{c_{2}}{\left(u_{f}-u\right)}+c_{3} u\right)} \\
c_{1}=\frac{u_{f}}{k_{j} u_{c}{ }^{2}}\left(2 u_{c}-u_{f}\right) \\
c_{2}=\frac{u_{f}}{k_{j} u_{c}^{2}}\left(u_{f}-u_{c}\right)^{2} \\
c_{3}=\frac{1}{q_{c}}-\frac{u_{f}}{k_{j} u_{c}{ }^{2}}
\end{gathered}
$$

Em que:

- $q$ : Volume de tráfego;

- $u$ : Velocidade média da corrente;

- $u_{f}$ : Velocidade de fluxo livre;

- $u_{c}$ : Velocidade na capacidade;

- $q_{c}$ : Volume na capacidade; e

- $k_{j}$ : Densidade de congestionamento.

Dentre suas características, o modelo possibilita que a velocidade na capacidade possa ser diferente da velocidade de fluxo livre, comum a diversos modelos existente na literatura, ou da metade da velocidade de fluxo livre, como no caso (GREENSHIELDS et al., 1935). Outra característica de interesse consiste quando o modelo de Van Aerde se equivale ao modelo de Greenshields. Isso ocorre quando $c_{1}=0$, o que corresponde à condição na qual a velocidade e a densidade na capacidade, respectivamente, equivalem a $\frac{u_{f}}{2}$ e $\frac{k_{j}}{2}$.

A calibração do modelo porposto por Van Aerde consiste em estimar os parâmetros por meio de uma regressão dos mínimos quadrados totais, que tem por objetivo minimizar o erro quadrático nas três dimensões do problema, volume, velocidade e densidade da corrente (RAKHA; 

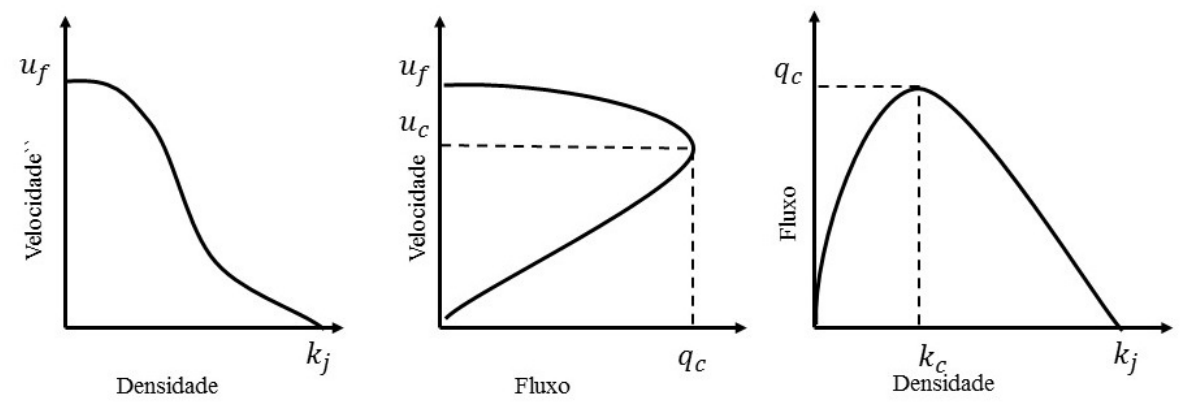

Figura 2.2 - Diagrama Van Aerde

ARAFEH, 2010). Para tanto, os autores utilizam da ferramenta denominada SPDCAL, que consiste em uma solução baseada em um algoritmo de otimização em dois níveis (AERDE; RAKHA, 1995).

\subsubsection{HCM}

Neste item, são apresentados, brevemente, os principais conceitos relacionados ao modelo de fluxo-velocidade do HCM para autoestradas e rodovias de pista dupla. Para tanto, as principais características são elucidadas, bem como as considerações para aplicação do modelo.

\subsubsection{Contexto}

Desde 1950, com a primeira versão do HCM, o manual norte-americano vem sendo a principal referência mundial sobre avaliação operacional de dispositivos viários, cuja principal contribuição é trazer definições das medidas de desempenho e conjuntos de procedimentos uniformizados e sistematizados, a fim de padronizar a medição da qualidade de serviço em dispositivos viários, conforme a percepção do usuário (FDOT, 2013).

De acordo com o HCM, a qualidade de uma viagem pelos usuários é avaliada por meio de uma medida quantitativa e qualitativa, denominada de nível de serviço, a qual caracteriza a condição da corrente de tráfego de uma via. O nível de serviço é dividido em seis categorias e considera fatores como velocidade, tempo de viagem, liberdade de manobras, conforto, interrupções de tráfego e conveniência (TRB, 2010; TRB, 2016). A densidade da corrente de tráfego é a medida utilizada para parametrizar os níveis de serviço em parâmetros de tráfego para autoestradas e rodovias de pista dupla. A estimação da densidade e, consequentemente, do nível de serviço é realizada por meio de curvas fluxo-velocidade calibradas a partir de dados empíricos.

Ao longo do desenvolvimento do HCM, diferentes edições foram elaboradas. Na primeira, de 1950, não existia informação suficiente a respeito de trechos rodoviários de fluxo não interrompido, sendo destinado à segunda edição, de 1965, a introdução de características fundamentais e de métodos para análise de autoestradas e rodovias de pista dupla, como as curvas 
de fluxo-velocidade estruturadas na velocidade de projeto da via.

E, somente na terceira edição, publicada em 1985, as curvas fluxo-velocidade passam a ser baseadas na velocidade de fluxo livre da via, em vez da velocidade de projeto. Com essa modificação, a edição de 1985 introduziu o conceito de trechos rodoviários homogêneos, os quais são definidos como segmentos de rodovias com características, físicas e de tráfego, uniformes. Desde então, o método do HCM, já em sua sexta edição, utiliza as curvas fluxo-velocidade e avalia as rodovias, por meio da análise individual de trechos homogêneos.

\subsubsection{Classificação de rodovias}

O HCM divide rodovias de fluxo não interrompido em três classes, autoestradas (freeways), rodovias de pista dupla (multlilanes highways) e rodovias de pista simples (two-lanes highways) (TRB, 2010).

- Autoestradas são rodovias de alto padrão, com duas ou mais faixas de rolamento em cada direção, divisão central obrigatória e controle total de acesso;

- Rodovias de pista dupla são definidas como rodovias com duas ou mais faixas de rolamento em cada direção e que não apresentam controle total de acessos. Esse tipo de via pode apresentar cruzamentos em nível, semáforos ou rotatórias, desde que espaçados, em média, $3 \mathrm{~km}$ de distância um do outro; e

- Rodovias de pista simples são rodovias com uma única faixa de rolamento em cada direção, com semáforos ou rotatórias, desde que espaçados, em média, $3 \mathrm{~km}$ de distância um do outro.

\subsubsection{Tipos de trechos}

O HCM divide os trechos de autoestradas e rodovias de pista dupla, conforme as características físicas dos segmentos da via. Os tipos de trechos são definidos segundo condições físicas e operacionais, como existência de divisória central física, controle total de acessos e cruzamento em nível (TRB, 2010; TRB, 2016). Os tipos de trechos definidos são: segmentos básicos (basic segments), dispositivos de acesso (ramps) e entrelaçamentos (weaving).

Os dispositivos de acesso são denominados dispositivos de entrada (on-ramps), quando duas ou mais correntes de fluxo de tráfego se unem, e dispositivos de saída (off-ramps), quando uma corrente de tráfego é dividida em outras.

Já os entrelaçamentos (weaving) são segmentos em que duas ou mais correntes de fluxo de tráfego, com mesmo sentido, cruzam-se durante um determinado comprimento de rodovia. Os entrelaçamentos são constituídos quando um dispositivo de saída é precedido por um dispositivo de entrada, em um curto comprimento de rodovia, até $750 \mathrm{~m}$ de distância. Os segmentos 
que não são dispositivos de acesso ou entrelaçamentos são classificados como segmentos básicos.

\subsubsection{Condições padrão de operação}

O método desenvolvido pelo HCM para análise de trechos de rodovias com fluxo não interrompido calibrou a relação fluxo-velocidade, sob condições padrão de operação (base conditions). As condições padrão refletem a operação e a infraestrutura em que os modelos do manual foram calibrados, nos quais a capacidade máxima da via é atingida. Nos trechos em que as condições padrão não existem, a capacidade, a velocidade e, consequentemente, a qualidade de serviço tendem a ser afetadas (TRB, 2010).

As condições padrão para autoestradas e rodovias de pista dupla incluem: tempo bom; boa visibilidade; pavimento em bom estado de conservação; largura de faixas com pelo menos 3,6m; largura livre lateral externa mínima de 1,8m para autoestradas; motoristas acostumados com a via; e inexistência de veículos pesados, como caminhões, ônibus e veículos recreacionais na corrente de tráfego (TRB, 2010).

Junto às condições padrão, a calibração leva em consideração as características físicas da via que podem afetar a velocidade média da corrente e o fluxo de tráfego . Tais características incluem geometria vertical e horizontal. Em situações em que a condição padrão não existe, o manual apresenta ajustamentos a serem efetuados para aplicação do método.

\subsubsection{Modelo}

As versões do HCM 2010 e 2016 utilizam a mesma modelagem matemática do HCM 2000, para descrever a relação fluxo-velocidade da corrente de tráfego para autoestradas e rodovias de pista dupla. A diferença entre as versões do modelo do HCM 2010 e 2016 são representadas por coeficientes de ajustes para a velocidade de fluxo livre e capacidade existentes na versão de 2016. O modelo consiste em cinco parâmetros, $u_{f}, q_{c}, k_{c}, b p$ e $\alpha$, que representam uma curva com dois segmentos que variam conforme o fluxo na corrente de tráfego, expresso por:

$$
\begin{cases}q<b_{p} & , \quad u=u_{f} \\ b_{p}<q<q_{c} & , \quad u=u_{f}-\left(u_{f}-\frac{q_{c}}{k_{c}}\right) \cdot\left(\frac{q-b_{p}}{q_{c}-b_{p}}\right)^{\alpha}\end{cases}
$$

Em que:

- $q$ : Volume de tráfego;

- $u$ : Velocidade média da corrente;

- $u_{f}$ : Velocidade de fluxo livre;

- $q_{c}$ : Volume na capacidade; 
- $k_{c}$ : Densidade na capacidade;

- $b p$ : Ponto de transição; e

- $\alpha$ : Coeficiente de calibração.

A relação fluxo-velocidade da corrente de tráfego para autoestradas e rodovias de pista dupla do HCM é apresentada somente para a região de fluxo-livre da corrente de tráfego, diferentemente de outros modelos da literatura, como Greenshields e Van Aerde, que apresentam equações únicas para os regimes de fluxo livre e congestionado.

\subsubsection{Limitações do método}

Os métodos desenvolvidos pelo HCM, para análise de autoestradas e rodovias de pista dupla, apresentam algumas limitações de configurações, dentre elas (TRB, 2010):

- Faixas especiais destinadas para um tipo de veículo específico, como faixa de alta ocupação de passageiros;

- Restrição de manobras entre faixas;

- Segmentos extensos de ponte ou túnel;

- Formação de filas à jusante de dispositivos viários;

- Bloqueios temporários resultantes de acidentes e obras na via;

- Segmentos próximos à praça de pedágio; e

- Presença de pontos de ônibus.

\subsection{Inferência bayesiana}

Neste item são apresentados, brevemente, os principais conceitos relacionados à Inferência Bayesiana. Para tanto, são discutidas questões teóricas sobre tipos de inferência estatística, teoria bayesiana e principais formas de cálculo.

\subsubsection{Contexto}

Na ciência, toda informação disponível a respeito de um fenômeno natural é sempre incompleta e o conhecimento que se tem a respeito da natureza é, necessariamente, probabilístico. Sendo assim, a inferência estatística se baseia em uma teoria de probabilidade (GREGORY, 2005).

Ao longo do tempo, duas vertentes de inferência estatística foram desenvolvidas baseadas em diferentes definições de probabilidade: a clássica, também denominada de frequentista 
(frequentism) e a bayesiana. Na estatística clássica, o conceito de probabilidade de um evento é definido como a frequência relativa de ocorrência deste evento após sucessivas repetições, enquanto, na estatística bayesiana, a probabilidade de um evento consiste no grau de conhecimento a seu respeito (VANDERPLAS, 2014).

De forma ampla, as diferentes concepções a respeito de probabilidade estão relacionadas às considerações com relação aos parâmetros de modelos e aos dados. Enquanto a inferência clássica considera os parâmetros de um modelo como fixos e os dados como aleatórios, a inferência bayesiana consiste no oposto, os parâmetros do modelo são considerados aleatórios e os dados, fixos.

Consequentemente, os intervalos de confiança e de credibilidade, respectivamente, referentes às estatísticas clássica e bayesiana, consistem em conceitos distintos. Enquanto a abordagem bayesiana fixa um conjunto de dados e garante que, por exemplo, 95\% dos possíveis valores de um parâmetro estarão dentro deste, na abordagem frequentista, o valor do parâmetro é fixo, e garante-se que, por exemplo, $95 \%$ dos conjuntos de dados conterão o parâmetro. A Figura 2.3 ilustra os conceitos descritos.

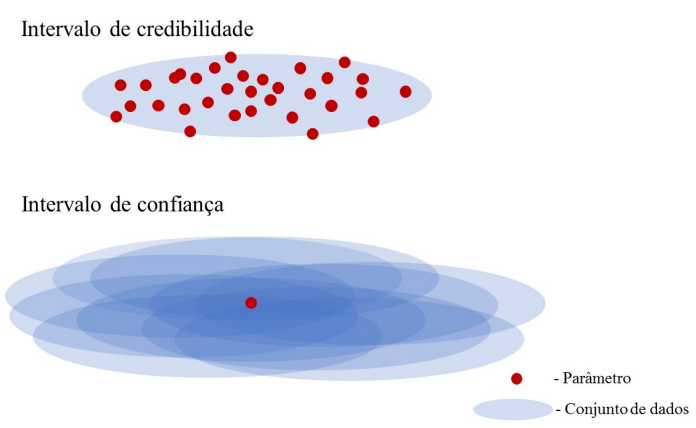

Figura 2.3 - Intervalo de credibilidade e confiança

Este item não tem como objetivo detalhar as diferentes visões de inferência estatística e suas implicações, mas apresentar os principais conceitos relacionados à Inferência Bayesiana, abordagem utilizada no desenvolvimento do presente trabalho. Para tanto, são abordados a seguir o teorema de Bayes e técnicas de cálculo de distribuições posteriores, mais especificamente, os métodos computacionais baseados em Monte Carlo via cadeias de Markov (MCMC).

\subsubsection{Teorema de Bayes}

A Inferência Bayesiana é um método estatístico probabilístico, baseado no teorema de Bayes. Tal método disponibiliza uma forma de calcular as probabilidades condicional e posterior de uma hipótese ser verdadeira, segundo provas dadas (KLEIN, 2012). O teorema de Bayes é definido como:

$$
p(A \mid B)=\frac{p(A) p(B \mid A)}{p(B)}
$$


Em que:

- $p(A)$ : é a probabilidade de ocorrência do evento $\mathrm{A}$, independentemente do evento $\mathrm{B}$;

- $p(B)$ : é a probabilidade de ocorrência do evento $\mathrm{B}$, independentemente do evento A;

- $p(B \mid A)$ : é a probabilidade de ocorrência do evento $\mathrm{B}$, dado que o evento A é verdadeiro; $\mathrm{e}$

- $p(A \mid B)$ : é a probabilidade de ocorrência do evento $\mathrm{A}$, dado que o evento B é verdadeiro.

Outra forma de interpretar o teorema de Bayes é por meio da interpretação diacrônica, que consiste na probabilidade de uma hipótese variar no tempo, conforme mais informações houver a respeito dela forem adicionadas (DOWNEY, 2013).

Sendo assim, o teorema pode ser escrito como:

$$
p(H \mid D)=\frac{p(H) p(D \mid H)}{p(D)}
$$

- $p(H)$ : é a probabilidade da hipótese antes da observação dos dados; denominada de probabilidade a priori;

- $p(D)$ : é a probabilidade do dado sob qualquer hipótese; denominada de constante de normalização;

- $p(D \mid H)$ : é a probabilidade do dado sob a hipótese em questão; denominada de função de verossimilhança; e

- $p(H \mid D)$ : é a probabilidade a ser calculada depois de novos dados serem observados; denominada probabilidade posterior.

Em resumo, a análise bayesiana é um método estatístico que realiza inferência sobre grandezas desconhecidas, como parâmetros de modelos, por meio da união de conhecimentos prévios sobre o assunto em questão, com evidências existentes, representadas por um conjunto de dados. Dessa forma, um modelo bayesiano pode ser interpretado em duas partes: função de verossimilhança, a qual descreve a distribuição dos dados sobre o assunto em questão e distribuição a priori, que reflete o conhecimento prévio a respeito do assunto, independentemente da observação dos dados. A partir da função de verossimilhança, da distribuição a priori e da observação dos dados, o conhecimento prévio é atualizado pelo teorema de Bayes resultando na estimação da distribuição a posteriori (CHEN, 2009).

Em teoria, as distribuições posteriores contêm todas as informações necessárias para realizar inferências a respeito do assunto que representam. Porém, na prática, as distribuições 
posteriores são difíceis de serem estimadas, especialmente de forma analítica e para problemas complexos, uma vez que envolvem o cálculo de integrais múltiplas. Dessa forma, para se obter estimativas das distribuições posteriores, a maioria das análises bayesianas se estruturam em sofisticados métodos computacionais, como, por exemplo, os métodos de simulação baseados em Monte Carlo via cadeias de Markov.

\subsubsection{Monte Carlo via cadeias de Markov}

A partir da década de 1990 os métodos baseados em Monte Carlo via cadeias de Markov (MCMC) emergiram como ferramentas extremamente populares no campo da ciência na análise de complexos modelos estatísticos, especialmente no campo da Inferência Bayesiana. Essa ascensão no campo da Inferência Bayesiana se relaciona com a necessidade de calcular e avaliar integrais, usualmente, complexas e de múltiplas dimensões, necessárias para se obter distribuições posteriores (COWLES; CARLIN, 1996).

Os métodos de MCMC correspondem a métodos de simulação que, quando corretamente definidos e implementados, possibilitam realizar amostragens sucessivas de distribuições posteriores. A etapa de Monte Carlo dos métodos de MCMC consiste na estimação de propriedades de distribuições, por meio da análise de amostras aleatórias dessas distribuições, enquanto as cadeias de Markov do MCMC se baseiam no conceito que amostras aleatórias são geradas por meio de processos sequenciais específicos, nos quais a geração de uma nova amostra depende da amostra anterior.

De forma geral, o método MCMC é extremamente útil à Inferência Bayesiana, pois permite estimar distribuições posteriores, o que é extremamente difícil de se obter por meio de métodos analíticos. Contudo, a utilização dos métodos de MCMC apresentam elevado custo computacional e dificuldades em determinar a convergência.

A convergência dos métodos MCMC consiste em definir em que momento as amostras da distribuição posterior podem ser caracterizadas como representativas, ou seja, em que momento a distribuição posterior se encontra estacionária, estabilizada. Dentro desse contexto, diversos esforços vêm sendo realizados para determinar a convergência dos métodos de MCMC, contudo, nenhum método existente garante a convergência do processo.

Assim, apesar de não ser possível garantir a convergência dos métodos MCMC, diversas abordagens sobre o problema, tanto teórica como por meio de testes estatísticos, são propostas na literatura. A Tabela 2.1 apresenta alguns dos principais métodos utilizados na literatura para análise da convergência do MCMC. Nela são apresentados: métodos; medida de análise, gráfica ou quantitativa; quantidade de cadeias de Markov necessárias; base teórica; e forma de análise das distribuições, individual ou em conjunto.

Ressalta-se aqui, o teste estatístico de Gelman e Rubin, um dos mais populares na literatura (COWLES; CARLIN, 1996). O teste de Gelman e Rubin avalia a convergência do MCMC por meio 
Tabela 2.1 - Métodos de análise de convergência MCMC

\begin{tabular}{lllll}
\hline \multicolumn{1}{c}{ Método } & \multicolumn{1}{c}{ Tipo de medida } & Tipo de cadeias & \multicolumn{1}{c}{ Base teórica } & Forma de análise da distribuição \\
\hline Gelman e Rubin (1992) & Quantitativa & Múltipla & Teoria normal de grande amostras & Unidimensional \\
Raftery e Lewis (1991) & Quantitativa & Única & Teoria de cadeia de Markov & Unidimensional \\
Geweke (1991) & Quantitativa & Unica & Análise espectral & Unidimensional \\
Roberts (1992) & Gráfica & Múltipla & Teoria de probabilidade & Multidimensional \\
Ritter e Tanner (1992) & Gráfica & Múltipla e Única & Ponderação de importância & Multidimensional \\
Zellner e Min (1995) & Quantitativa & Única & Probabilidade condicional & Multidimensional \\
Liu, Liu e Rubin (1992) & Quantitativa e Gráfica & Múltipla & Teoria de probabilidade & Multidimensional \\
Johnson (1996) & Quantitativa & Múltipla & Teoremas de ponto fixo & Multidimensional \\
\hline
\end{tabular}

da análise de múltiplas cadeias de Markov. Para tanto, o teste baseia no princípio de que se múltiplas cadeias convergem, então, elas devem ser similares umas às outras; e se não forem, as cadeias não convergem.

Para verificar a similaridade, o teste realiza uma análise de variância, na qual compara a variância dos parâmetros estimados do modelo entre uma mesma cadeia de Markov e entre as múltiplas cadeias. Uma grande diferença entre as variâncias indica a não convergência do método MCMC (BROOKS; GELMAN, 1998).

A estatística do teste se baseia em um parâmetro interno, $\hat{R}$, que representa o nível de associação entre as variâncias de uma cadeia e de múltiplas cadeias. Os autores do teste sugerem que se pode, confiantemente, considerar que o MCMC alcançou a convergência, quando todos os parâmetros do modelo apresentam um $\hat{R}<1,1$.

\subsection{Considerações finais}

Este capítulo apresenta uma introdução sobre a teoria de fluxo de tráfego. Para tanto, abordamse alguns dos principais conceitos da área, como tipos de dados de tráfego e modelos que descrevem o comportamento da corrente de tráfego, em especial, o desenvolvido pelo HCM. Também, apresentam-se conceitos gerais sobre Inferência Bayesiana, que corresponde ao método estatístico de inferência utilizado ao longo do trabalho. A partir desses conceitos base, desenvolve-se o restante do trabalho. 


\section{Capítulo}

\section{Banco de dados}

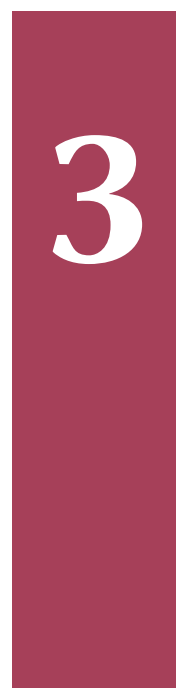

Este capítulo apresenta o banco de dados e o método de tratamento utilizado no desenvolvimento do trabalho que tem por objetivo fornecer informações que permitam investigar as relações fundamentais de tráfego e a calibração da relação fluxo-velocidade do modelo do HCM, em rodovias paulistas de pista dupla e autoestradas. Nos itens a seguir, o banco de dados é descrito conforme suas características e fontes de obtenção. Em seguida, é apresentado o método de tratamento desenvolvido. Por fim, são exibidos os resultados alcançados.

\subsection{Considerações iniciais}

A obtenção de um conjunto de dados é uma etapa primordial em todo processo de estimação de parâmetros de modelos. Para a calibração de modelos de tráfego que descrevam a relação fluxo-velocidade e a capacidade de um segmento, é necessário um conjunto significativo de dados (ROESS; PRASSAS; MCSHANE, 2010), de forma a representar adequadamente as características da via e dos motoristas. Dessa forma, esta pesquisa utilizou um conjunto de 3.373.056 dados de tráfego, em intervalos de cinco e seis minutos, de sensores localizados em rodovias concessionadas do estado de São Paulo, e dados geométricos, que correspondem aos trechos rodoviários nos quais os sensores de tráfego estão localizados. Os dados geométricos foram provenientes de Andrade e Setti (2011).

\subsubsection{Dados de Tráfego}

Os dados de tráfego foram obtidos por sensores de laços indutivos, em quatro rodovias do estado de São Paulo, SP-348 (Rodovia dos Bandeirantes), SP-280 (Rodovia Presidente Castelo Branco), SP-270 (Rodovia Raposo Tavares) e SP-021 (Rodoanel Mário Covas Oeste). O banco 
de dados foi fornecido pelas concessionárias responsáveis pelas rodovias, CCR Via Oeste, CCR Rodoanel e CCR AutoBan, e contém informações de fluxo e de velocidade média da corrente de tráfego, com veículos classificados como automóveis e veículos pesados, durante o período de setembro de 2011 a agosto de 2012. Tais dados são desagregados por faixa e disponibilizados em intervalos de cinco minutos para a SP-280, SP-270 e SP-021, e de seis minutos para a SP348. A localização das rodovias e dos sensores utilizados no desenvolvimento da pesquisa são apresentados na Figura 3.1, e as principais características de cada rodovia são descritas a seguir.

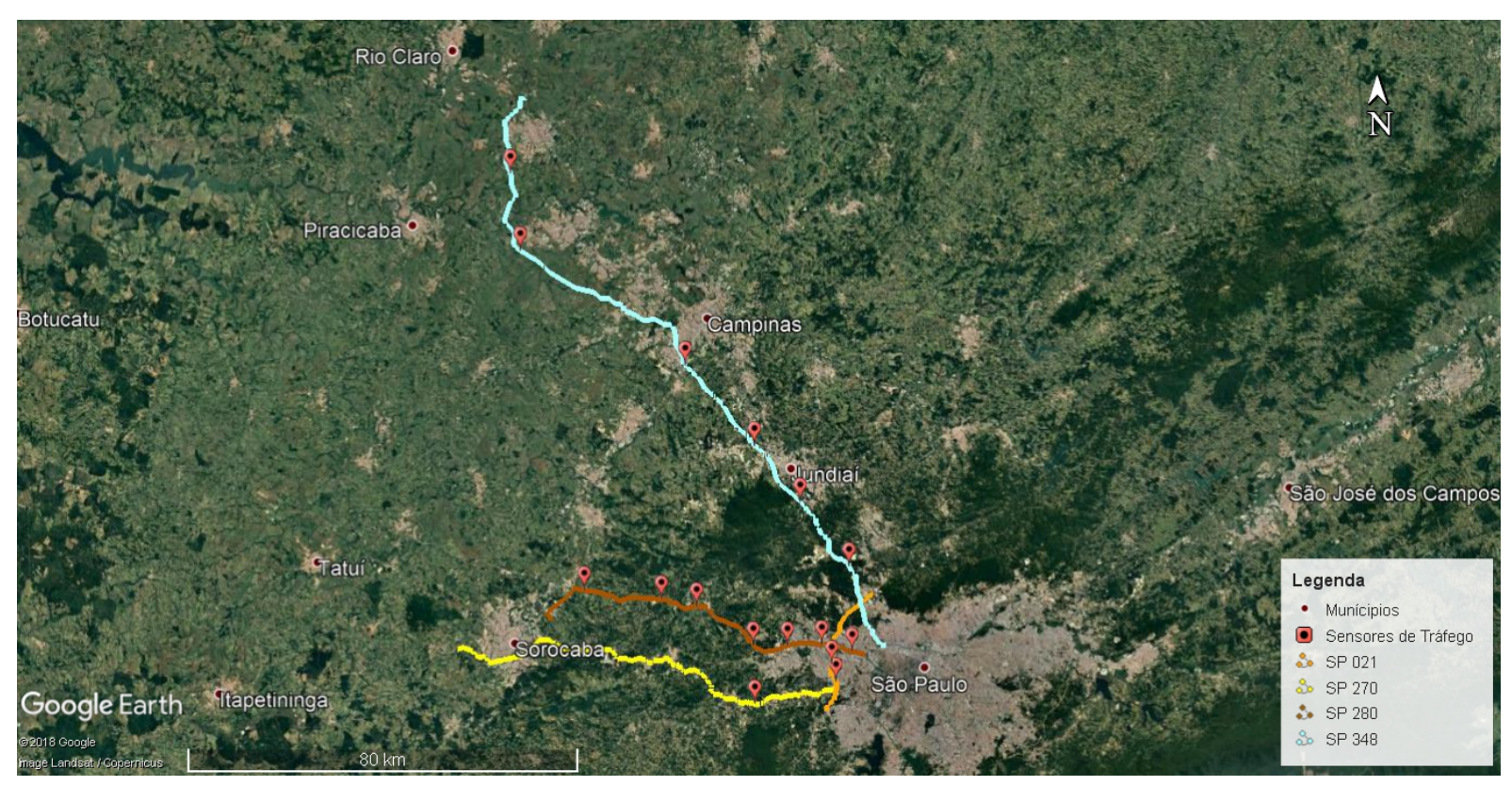

Figura 3.1 - Localização dos sensores de tráfego e das rodovias

- SP-348 (Rodovia dos Bandeirantes): consiste em uma rodovia de alto padrão, com características de tráfego rodoviário de longas distâncias, que interliga as regiões centro e noroeste do estado de São Paulo;

- SP-280 (Rodovia Presidente Castelo Branco): rodovia subdividida em dois segmentos, com o primeiro servindo de conexão entre cidades ao redor da metrópole de São Paulo, como Osasco e Barueri, e o segundo que realiza a conexão dessas regiões ao centro-oeste do estado;

- SP-270 (Rodovia Raposo Tavares): rodovia de trechos com diversas configurações que interligam a cidade de São Paulo ao município de Sorocaba; e

- SP-021 (Rodoanel Mário Covas Oeste): rodovia que se localiza no entorno da região metropolitana da capital e tem como objetivo interligar as principais vias que chegam a São Paulo, a exemplo das três rodovias descritas anteriormente. 
Os dados dos sensores foram obtidos por intermédio da ARTESP, em um total de 34 sensores de tráfego, divididos em 12 na SP-348, 18 na SP-280, 2 na SP-270 e 2 na SP-021. As informações disponíveis em cada sensor consistem em: data e hora de início de intervalo, número de automóveis, número de veículos pesados, velocidade média de automóveis, velocidade média de veículos pesados e ocupância. A princípio, a determinação se algum trecho atinge a capacidade foi realizada por meio de inspeção visual da relação fluxo-velocidade para cada sensor. A Tabela 3.1 apresenta as principais características por sensor, segundo o TRB (2010) e TRB (2016).

Tabela 3.1 - Características dos sensores

\begin{tabular}{|c|c|c|c|c|c|c|}
\hline $\mathrm{km}$ & Sentido & Tipo de via & Tipo de trecho & Limitações referente ao $\mathrm{HCM}$ & $\begin{array}{l}\text { Ocupação } \\
\text { lindeira }\end{array}$ & $\begin{array}{l}\text { Atinge } \\
\text { capacidade }\end{array}$ \\
\hline \multicolumn{7}{|c|}{ SP-280 (Rodovia Castelo Branco) } \\
\hline 16,0 & Leste - Expresssa & Rodovia de pista dupla & entrelaçamento (weaving) & & Urbana & Sim \\
\hline 16,0 & Oeste - Expressa & Rodovia de pista dupla & segmento básico & & Urbana & Não \\
\hline 16,0 & Leste - Marginal & Rodovia de pista dupla & & & Urbana & Não \\
\hline 16,0 & Oeste - Marginal & Rodovia de pista dupla & & & Urbana & Não \\
\hline 22,4 & Leste - Expresssa & Autoestrada & segmento básico & & Urbana & Não \\
\hline 22,4 & Oeste - Expressa & Autoestrada & segmento básico & & Urbana & Sim \\
\hline 22,4 & Leste - Marginal & Autoestrada & segmento básico & & Urbana & Não \\
\hline 22,4 & Oeste - Marginal & Autoestrada & segmento básico & & Urbana & Sim \\
\hline 29,5 & Leste & Autoestrada & segmento básico & & Urbana & Sim \\
\hline 29,5 & Oeste & Autoestrada & dispositivo de acesso (ramp) & & Urbana & Sim \\
\hline 37,0 & Leste & Rodovia de pista dupla & segmento básico & & Rural & Sim \\
\hline 37,0 & Oeste & Rodovia de pista dupla & segmento básico & \multirow[t]{2}{*}{ Estrangulamento a jusante } & Rural & Não \\
\hline 51,9 & Leste & Rodovia de pista dupla & segmento básico & & Rural & Sim \\
\hline 51,9 & Oeste & Rodovia de pista dupla & segmento básico & \multirow[t]{2}{*}{ Radar } & Rural & Não \\
\hline 59,6 & Leste & Rodovia de pista dupla & segmento básico & & Rural & Sim \\
\hline 59,6 & Oeste & Rodovia de pista dupla & segmento básico & \multirow{3}{*}{$\begin{array}{l}\text { Radar } \\
\text { Praça de pedágio }\end{array}$} & Rural & Não \\
\hline 75,9 & Leste & Rodovia de pista dupla & segmento básico & & Rural & Sim \\
\hline 75,9 & Oeste & Rodovia de pista dupla & segmento básico & & Rural & Não \\
\hline \multicolumn{7}{|c|}{ SP-348 (Rodovia dos Bandeirantes) } \\
\hline 32,0 & Norte & Autoestrada & segmento básico & \multirow{12}{*}{ Radar } & Rural & Sim \\
\hline 32,0 & Sul & Autoestrada & segmento básico & & Rural & Sim \\
\hline 50,0 & Norte & Autoestrada & segmento básico & & Rural & Sim \\
\hline 50,0 & Sul & Autoestrada & segmento básico & & Rural & Sim \\
\hline 65,0 & Norte & Autoestrada & segmento básico & & Rural & Não \\
\hline 65,0 & Sul & Autoestrada & segmento básico & & Rural & Sim \\
\hline 87,0 & Norte & Autoestrada & segmento básico & & Rural & Sim \\
\hline 87,0 & Sul & Autoestrada & segmento básico & & Rural & Sim \\
\hline 131,7 & Norte & Autoestrada & segmento básico & & Rural & Não \\
\hline 131,7 & Sul & Autoestrada & segmento básico & & Rural & Não \\
\hline 149,6 & Norte & Autoestrada & segmento básico & & Rural & Não \\
\hline 149,6 & Sul & Autoestrada & segmento básico & & Rural & Não \\
\hline \multicolumn{7}{|c|}{ SP-021 (Rodoanel) } \\
\hline 18,3 & Norte & Rodovia de pista dupla & segmento básico & & Urbana & Sim \\
\hline 22,3 & Sul & Rodovia de pista dupla & segmento básico & & Urbana & Sim \\
\hline \multicolumn{7}{|c|}{ SP-270 (Raposo Tavares) } \\
\hline 39,9 & Leste & Rodovia de pista dupla & segmento básico & & Urbana & Não \\
\hline 39,9 & Oeste & Rodovia de pista dupla & dispositivo de acesso (ramp) & & Urbana & Não \\
\hline
\end{tabular}

\subsubsection{Dados geométricos}

Os dados geométricos foram obtidos de Andrade e Setti (2011) e correspondem a características físicas e geométricas dos locais nos quais se encontram os sensores de tráfego. O levantamento desse banco de dados foi realizado entre o período de 2009 e 2012 e os principais parâmetros coletados, referentes à localização de cada sensor, são apresentados na Tabela 3.2.

A Tabela 3.2 apresenta para cada ponto de coleta, o local, o sentido do tráfego, o tipo do trecho, a ocupação lindeira, o número de faixas, a velocidade máxima permitida do trecho por classe de veículo, e alguns parâmetros geométricos dos trechos, como Rise and Fall, curvatura 
Tabela 3.2 - Características físicas dos trechos observados

\begin{tabular}{|c|c|c|c|c|c|c|c|c|c|}
\hline \multirow[t]{2}{*}{$\mathrm{km}$} & \multirow[t]{2}{*}{ Sentido } & \multirow[t]{2}{*}{ Tipo de via } & \multirow{2}{*}{$\begin{array}{l}\text { Ocupação lin- } \\
\text { deira }\end{array}$} & \multirow{2}{*}{$\begin{array}{l}\text { Número } \\
\text { faixas }\end{array}$} & \multicolumn{2}{|c|}{ Velocidade máxima (km/h) } & \multirow{2}{*}{$\begin{array}{l}\text { Rise and Fall } \\
(\mathrm{m} / \mathrm{km})\end{array}$} & \multirow{2}{*}{$\begin{array}{l}\text { Curvatura } \\
(\% / \mathrm{km})\end{array}$} & \multirow{2}{*}{$\begin{array}{l}\text { Greide } \\
(\%)\end{array}$} \\
\hline & & & & & Veículos leves & Veículos pesados & & & \\
\hline \multicolumn{10}{|c|}{ SP-280 (Rodovia Castelo Branco) } \\
\hline 16,0 & Leste - Expresssa & Rodovia de pista dupla & Urbana & 3 & 100 & 90 & 20,0 & 35,4 & 2,0 \\
\hline 16,0 & Oeste - Expressa & Rodovia de pista dupla & Urbana & 3 & 100 & 90 & 20,0 & 35,4 & 2,0 \\
\hline 16,0 & Leste - Marginal & Rodovia de pista dupla & Urbana & & & & & & \\
\hline 16,0 & Oeste - Marginal & Rodovia de pista dupla & Urbana & & & & & & \\
\hline 22,4 & Leste - Expresssa & Autoestrada & Urbana & 3 & 100 & 90 & 22,0 & 61,2 & $-1,0$ \\
\hline 22,4 & Oeste - Expressa & Autoestrada & Urbana & 3 & 100 & 90 & 22,0 & 61,2 & 1,0 \\
\hline 22,4 & Leste - Marginal & Autoestrada & Urbana & & & & & & \\
\hline 22,4 & Oeste - Marginal & Autoestrada & Urbana & & & & & & \\
\hline 29,5 & Leste & Autoestrada & Urbana & 3 & 120 & 90 & 43,6 & 52,1 & 2,0 \\
\hline 29,5 & Oeste & Autoestrada & Urbana & 3 & 120 & 90 & 43,6 & 52,1 & $-2,0$ \\
\hline 37,0 & Leste & Rodovia de pista dupla & Rural & 3 & 120 & 90 & 47,4 & 16,3 & 5,0 \\
\hline 37,0 & Oeste & Rodovia de pista dupla & Rural & 3 & 120 & 90 & 47,4 & 16,3 & $-5,0$ \\
\hline 51,9 & Leste & Rodovia de pista dupla & Rural & 3 & 120 & 90 & 33,5 & 20,1 & 4,5 \\
\hline 51,9 & Oeste & Rodovia de pista dupla & Rural & 3 & 120 & 90 & 33,5 & 20,1 & $-4,5$ \\
\hline 59,6 & Leste & Rodovia de pista dupla & Rural & 3 & 120 & 90 & 42,7 & 13,6 & $-2,0$ \\
\hline 59,6 & Oeste & Rodovia de pista dupla & Rural & 3 & 120 & 90 & 42,7 & 13,6 & $-5,0$ \\
\hline 75,9 & Leste & Rodovia de pista dupla & Rural & 3 & 120 & 90 & 33,0 & 16,3 & 4,0 \\
\hline 75,9 & Oeste & Rodovia de pista dupla & Rural & 3 & 120 & 90 & 33,0 & 16,3 & $-4,0$ \\
\hline \multicolumn{10}{|c|}{ SP-348 (Rodovia dos Bandeirantes) } \\
\hline 32,0 & Norte & Autoestrada & Rural & 4 & 120 & 90 & 37,2 & 42,3 & 3,5 \\
\hline 32,0 & Sul & Autoestrada & Rural & 4 & 120 & 90 & 37,2 & 42,3 & $-3,5$ \\
\hline 50,0 & Norte & Autoestrada & Rural & 3 & 120 & 90 & 41,4 & 12,6 & $-3,0$ \\
\hline 50,0 & Sul & Autoestrada & Rural & 3 & 120 & 90 & 41,4 & 12,6 & 3,0 \\
\hline 65,0 & Norte & Autoestrada & Rural & 3 & 120 & 90 & 20,9 & 21,8 & $-2,0$ \\
\hline 65,0 & Sul & Autoestrada & Rural & 3 & 120 & 90 & 20,9 & 21,8 & 2,0 \\
\hline 87,0 & Norte & Autoestrada & Rural & 3 & 120 & 90 & 25,0 & 21,6 & 2,5 \\
\hline 87,0 & Sul & Autoestrada & Rural & 3 & 120 & 90 & 25,0 & 21,6 & $-2,5$ \\
\hline 131,7 & Norte & Autoestrada & Rural & 3 & 120 & 90 & 21,0 & 15,1 & $-2,5$ \\
\hline 131,7 & Sul & Autoestrada & Rural & 3 & 120 & 90 & 21,0 & 15,1 & $-2,5$ \\
\hline 149,6 & Norte & Autoestrada & Rural & 2 & 120 & 90 & 33,4 & 10,4 & $-4,0$ \\
\hline 149,6 & Sul & Autoestrada & Rural & 2 & 120 & 90 & 33,4 & 10,4 & 4,0 \\
\hline \multicolumn{10}{|c|}{ SP-021 (Rodoanel) } \\
\hline 18,3 & Norte & Rodovia de pista dupla & Urbana & 4 & 100 & 80 & 5,4 & 18,5 & $-0,5$ \\
\hline 22,3 & Sul & Rodovia de pista dupla & Urbana & 4 & 100 & 80 & 14,4 & 26,2 & 2,5 \\
\hline \multicolumn{10}{|c|}{ SP-270 (Raposo Tavares) } \\
\hline 39,9 & Leste & Rodovia de pista dupla & Urbana & 2 & 80 & 80 & 53,2 & 78,2 & 6,5 \\
\hline 39,9 & Oeste & Rodovia de pista dupla & Urbana & 2 & 80 & 80 & 53,2 & 78,2 & 5,0 \\
\hline
\end{tabular}

e greide. O Rise and Fall e a curvatura são parâmetros que descrevem, respectivamente, a geometria vertical e horizontal da via. O primeiro pode ser entendido como a quantidade de subidas e descidas por quilômetro de via, enquanto o segundo é definido pela quantidade de curvas, em graus, por quilômetro de rodovia.

\subsection{Tratamento dos dados de tráfego}

O HCM define que a calibração do seu modelo fluxo-velocidade, para rodovias de pista dupla e autoestrada, deve ser realizada com dados de tráfego que englobam somente veículos leves, condições de operação normal e em regime de fluxo livre (TRB, 2010; TRB, 2016). Dessa forma é apresentado o método de tratamento utilizado para a filtragem dos dados seguindo as considerações propostas pelo HCM.

\subsubsection{Método de tratamento}

O método de tratamento proposto é baseado na aplicação de três critérios, que apresentam como objetivo remover observações consideradas inadequadas. A partir de então, é gerado 
um conjunto de dados, com configurações apropriadas, para realizar a calibração do modelo em estudo. Tais critérios são apresentados a seguir.

\subsubsection{Veículos leves}

A fim de se obter uma corrente de fluxo de tráfego, composta somente por veículos leves, optou-se por utilizar a faixa de rolamento da esquerda dos locais onde os dados foram coletados, bem como remover observações em que foram detectadas a presença de qualquer porcentagem de veículos pesados nesta faixa de tráfego. A escolha dos dados da faixa da esquerda se justifica por esta faixa apresentar a menor parcela de veículos pesados perante as demais faixas.

Já a opção pela remoção das observações com veículos pesados foi realizada considerando que a faixa da esquerda apresenta pequena porcentagem de veículos pesados e sua retirada não afeta significativamente a quantidade de observações por sensor. Dessa forma, a corrente de tráfego era composta apenas com veículos leves, evitando o emprego do equivalente veicular para veículos pesados, visto que esses veículos causam grande impacto na corrente (CUNHA; SETTI, 2009).

A Figura 3.2 apresenta a relação fluxo-velocidade, por meio de um conjunto de observações sem tratamento, e a porcentagem média de veículos pesados para cada faixa de rolamento do sensor localizado no $\mathrm{km} \mathrm{51,9} \mathrm{da} \mathrm{SP-280,} \mathrm{sentido} \mathrm{leste.} \mathrm{O} \mathrm{fluxo} \mathrm{é} \mathrm{dado} \mathrm{em} \mathrm{veic/(h.faixa),} \mathrm{e} \mathrm{a}$ velocidade média da corrente $\mathrm{em} \mathrm{km} / \mathrm{h}$.

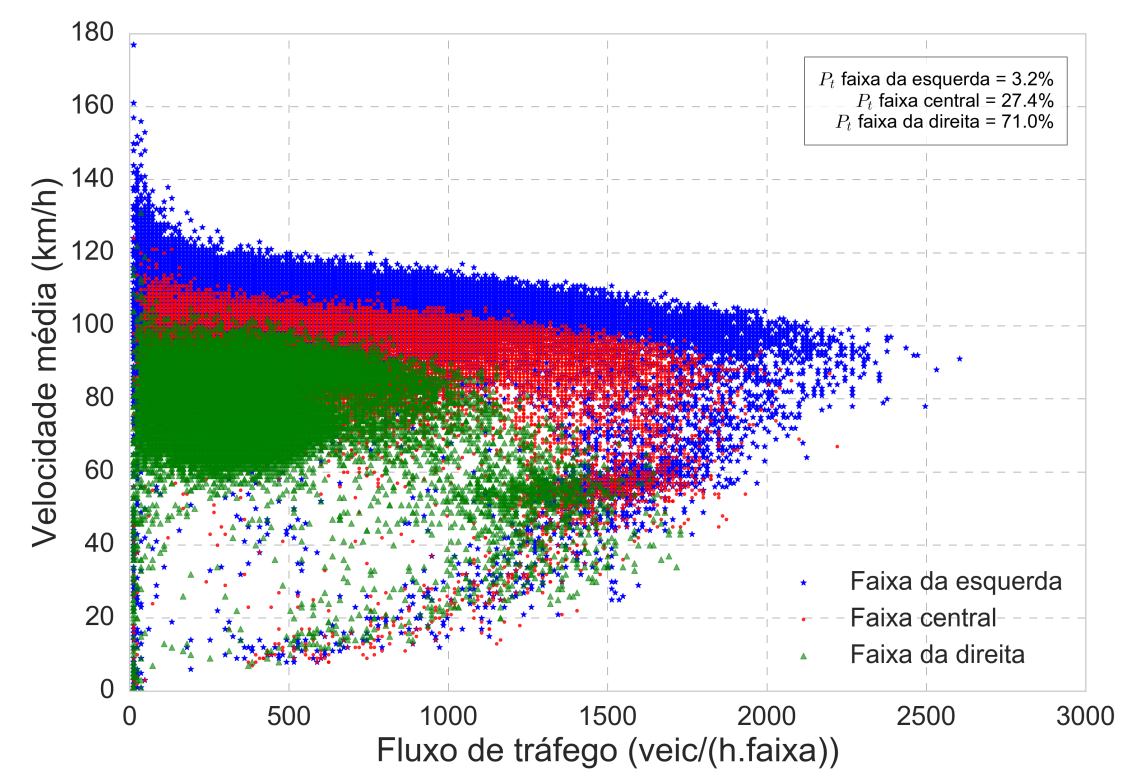

Figura 3.2 - Observações da velocidade média dos veículos em função da taxa de fluxo de tráfego (veic/(h.faixa)), para cada uma das três faixas de tráfego - SP-280, km 51,9 leste

Como pode ser observado, a faixa da esquerda apresenta a menor porcentagem de veículos pesados entre todas as faixas, com 3,2\% de veículo pesados e altos valores de fluxo e de velocidade média. Em seguida, aparece a faixa central e da direita com, respectivamente, maiores 
porcentagens de veículos pesados, $27,4 \%$ e 71,0\%, e menores valores de fluxo e de velocidade média. Esse comportamento das faixas mais próximas à lateral esquerda da rodovia apresentarem menor porcentagem de veículos pesados em relação às demais, aliado a maiores valores de fluxo e velocidade média, é observado em todos os outros pontos de coleta. As Figuras 3.3, 3.4 e 3.5 apresentam os histogramas das porcentagens de veículos pesados nas faixas de tráfego, referentes ao $\mathrm{km} \mathrm{51,9} \mathrm{da} \mathrm{rodovia} \mathrm{SP-280,} \mathrm{sentido} \mathrm{leste.}$

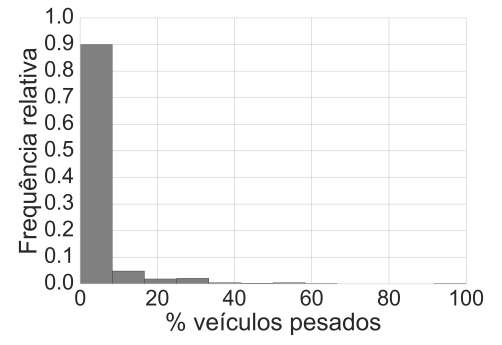

Figura 3.3 - Porcentagem de veículos pesados na faixa da esquerda - SP-280, km 51,9 leste

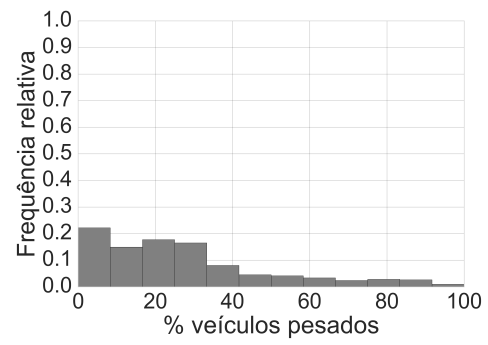

Figura 3.4 - Porcentagem de veículos pesados na faixa central SP-280, km 51,9 leste

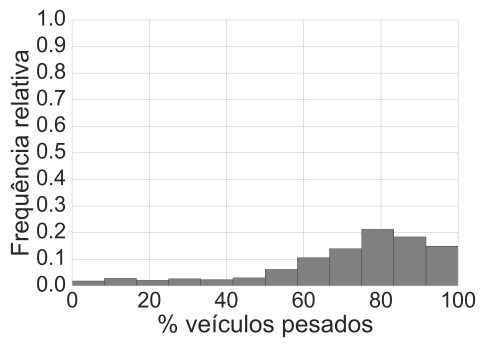

Figura 3.5 - Porcentagem de veículos pesados na faixa da direita SP-280, km 51,9 leste

\subsubsection{Condições de operação normal}

Os dados de tráfego utilizados neste trabalho foram coletados por meio de sensores do tipo laço indutivo, que funcionam por meio da detecção da alteração do campo magnético em seu entorno, após a passagem de um veículo no local em que estão instalados. Como qualquer forma de coleta de dados é sujeita a falhas, inclusive a realizada por meio de dispositivos eletrônicos, optou-se por remover observações com erros aparentes. Devido a essa razão, foram removidas observações que apresentavam: (a) contagem igual a zero e velocidades diferentes de zero; (b) dados faltantes; e (c) valores negativos de contagem, de velocidade ou de ocupância. Em seguida, foram eliminados dados considerados como outliers. Para isso, foram consideradas observações com velocidade média superior a $180 \mathrm{~km} / \mathrm{h}$, fluxo maior que $2.800 \mathrm{veic} /(\mathrm{h}$.faixa) e densidade da corrente maior que 160 veic/(h.faixa), (WASHBURN et al., 2010).

\subsubsection{Regime de fluxo livre}

Apenas os dados de tráfego que se encontram no regime não congestionado interessam para a calibração do modelo em estudo. Contudo, o limite que divide o regime de fluxo livre e congestionado não é evidente, assim como qual variável da relação fundamental de tráfego - fluxo, velocidade e densidade - deve ser utilizada como parâmetro de divisão. Em diversos estudos (ANDRADE, 2012; BESSA-JÚNIOR, 2009; SUN; ZHOU, 2005; ANDRADE; SETTI, 2014), o limite que divide os regimes de fluxo de tráfego foi determinado por meio da velocidade e a abordagem utilizada para tanto se baseia na aplicação da análise de cluster. 
Neste trabalho, para os pontos de coleta em que a capacidade é atingida, a divisão dos regimes foi realizada por meio da densidade da corrente de tráfego. Para tanto, foi proposto um método baseado na detecção de pontos de transição de sistemas, por meio da análise das funções de densidade de probabilidade das variáveis da relação fundamental de tráfego. O método proposto é detalhado no Capítulo 4

\subsection{Resultados}

Ao final do tratamento de dados, o sensor localizado no $\mathrm{km} 16,0$ da SP-280, sentido leste faixa

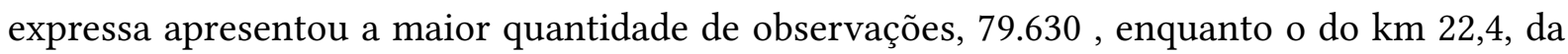
SP-280, sentido leste da faixa marginal obteve a menor quantidade, 26.390 observações, em um total de 1.730 .216 observações para todos os 34 pontos de coleta utilizados no estudo. A Tabela 3.3 apresenta para cada ponto de coleta local, sentido, ocupação lindeira, número de observações após tratamento e densidade na capacidade, para os trechos em que a capacidade é atingida. As densidades de transição estimadas pelo método proposto variam entre 38,2 e $18,2 \mathrm{cpe} /(\mathrm{km}$. faixa $)$.

Tabela 3.3 - Características do fluxo nos trechos observados

\begin{tabular}{|c|c|c|c|c|c|c|c|}
\hline $\mathrm{km}$ & Sentido & Tipo de via & $\begin{array}{l}\text { Ocupação lin- } \\
\text { deira }\end{array}$ & $\begin{array}{l}\text { Observações após } \\
\text { tratamento }\end{array}$ & Atinge capacidade & $\begin{array}{l}\text { Densidade } \\
\text { capacidade } \\
\text { cpe/(km.faixa) }\end{array}$ & na \\
\hline \multicolumn{8}{|c|}{ SP-280 (Rodovia Castelo Branco) } \\
\hline 16,0 & Leste - Expresssa & Rodovia de pista dupla & Urbana & 67.459 & Sim & 38,2 & \\
\hline 16,0 & Oeste - Expressa & Rodovia de pista dupla & Urbana & 79.630 & Não & & \\
\hline 16,0 & Leste - Marginal & Rodovia de pista dupla & Urbana & 56.228 & Não & & \\
\hline 16,0 & Oeste - Marginal & Rodovia de pista dupla & Urbana & 61.006 & Não & & \\
\hline 22,4 & Leste - Expresssa & Autoestrada & Urbana & 53.520 & Não & & \\
\hline 22,4 & Oeste - Expressa & Autoestrada & Urbana & 52.588 & Sim & 24,5 & \\
\hline 22,4 & Leste - Marginal & Autoestrada & Urbana & 26.390 & Não & & \\
\hline 22,4 & Oeste - Marginal & Autoestrada & Urbana & 45.421 & Sim & 27,3 & \\
\hline 29,5 & Leste & Autoestrada & Urbana & 37.525 & Sim & 23,9 & \\
\hline 29,5 & Oeste & Autoestrada & Urbana & 38.367 & Sim & 22,9 & \\
\hline 37,0 & Leste & Rodovia de pista dupla & Rural & 43.256 & Sim & 18,2 & \\
\hline 37,0 & Oeste & Rodovia de pista dupla & Rural & 49.286 & Não & & \\
\hline 51,9 & Leste & Rodovia de pista dupla & Rural & 58.322 & Sim & 21,2 & \\
\hline 51,9 & Oeste & Rodovia de pista dupla & Rural & 63.336 & Não & & \\
\hline 59,6 & Leste & Rodovia de pista dupla & Rural & 54.479 & Sim & 23,2 & \\
\hline 59,6 & Oeste & Rodovia de pista dupla & Rural & 47.583 & Não & & \\
\hline 75,9 & Leste & Rodovia de pista dupla & Rural & 40.120 & Sim & 25,8 & \\
\hline 75,9 & Oeste & Rodovia de pista dupla & Rural & 56.857 & Não & & \\
\hline \multicolumn{8}{|c|}{ SP-348 (Rodovia dos Bandeirantes) } \\
\hline 32,0 & Norte & Autoestrada & Rural & 54.034 & Sim & 23,3 & \\
\hline 32,0 & Sul & Autoestrada & Rural & 56.633 & Sim & 26,3 & \\
\hline 50,0 & Norte & Autoestrada & Rural & 37.347 & Sim & 19,0 & \\
\hline 50,0 & Sul & Autoestrada & Rural & 27.561 & Sim & 19,7 & \\
\hline 65,0 & Norte & Autoestrada & Rural & 50.727 & Não & & \\
\hline 65,0 & Sul & Autoestrada & Rural & 44.691 & Sim & 22,3 & \\
\hline 87,0 & Norte & Autoestrada & Rural & 33.122 & Sim & 20,9 & \\
\hline 87,0 & Sul & Autoestrada & Rural & 56.685 & Sim & 22,6 & \\
\hline 131,7 & Norte & Autoestrada & Rural & 64.685 & Não & & \\
\hline 131,7 & Sul & Autoestrada & Rural & 69.868 & Não & & \\
\hline 149,6 & Norte & Autoestrada & Rural & 50.136 & Não & & \\
\hline 149,6 & Sul & Autoestrada & Rural & 40.708 & Não & & \\
\hline \multicolumn{8}{|c|}{ SP-021 (Rodoanel) } \\
\hline 18,3 & Norte & Rodovia de pista dupla & Urbana & 47.267 & Sim & 27,5 & \\
\hline 22,3 & Sul & Rodovia de pista dupla & Urbana & 60.778 & Sim & 28,7 & \\
\hline \multicolumn{8}{|c|}{ SP-270 (Raposo Tavares) } \\
\hline 39,9 & Leste & Rodovia de pista dupla & Urbana & 54.957 & Não & & \\
\hline 39,9 & Oeste & Rodovia de pista dupla & Urbana & 49.644 & Não & & \\
\hline
\end{tabular}




\subsection{Considerações finais}

Nesta seção foram apresentados um banco de dados e um método de tratamento, com o objetivo de selecionar dados adequados para a calibração do modelo HCM. Para tanto, na seleção dos sensores foram considerados o número total de observações de cada sensor e a configuração dos locais em que estão localizados. O número total de observações é apresentado na Tabela 3.3 e a configuração dos locais consiste em autoestradas e de rodovias de pista dupla, com trechos classificados em entrelaçamentos (weaving), dispositivos de acessos (ramps) e segmentos básicos (basic segments) descritas em Andrade e Setti (2011).

Ao final do tratamento do banco de dados, os sensores com menor e maior número de observações apresentaram 79.630 e 26.390 entradas, respectivamente. Ao todo, reunindo as observações filtradas de todos os sensores utilizados na pesquisa, obteve-se 1.730 .216 observações, em intervalos de cinco ou seis minutos, de um total de 3.373 .056 observações brutas, o que corresponde a uma redução de aproximadamente $49 \%$ dos dados. 


\section{Capítulo}

\section{Capacidade em rodovias}

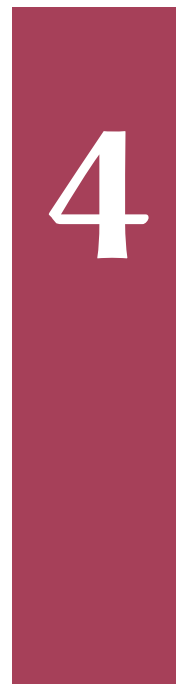

O objetivo deste capítulo é apresentar um novo método de estimação da capacidade de um segmento, de rodovia de pista dupla e autoestrada, utilizando-se do conceito de colapso da corrente de tráfego e da natureza estocástica da capacidade. A partir de uma revisão bibliográfica sobre os métodos de estimação da capacidade de um segmento de via é apresentado um método de estimação da capacidade baseado na Inferência Bayesiana. A partir de então é calculado a velocidade média na capacidade e a densidade na capacidade. O método proposto é descrito, assim como as considerações utilizadas para seu desenvolvimento.

\subsection{Considerações iniciais}

O tráfego em rodovias, especialmente em regiões urbanas e suburbanas, apresenta colapsos na corrente de tráfego, particularmente quando o volume se aproxima da capacidade. Esse fenômeno gera condições de fluxo instável, o que resulta em congestionamentos recorrentes e aleatórios (BASSAN; POLUS, 2010). O entendimento do conceito de capacidade e a sua estimação se tornam fundamentais para as atribuições da engenharia de tráfego, uma vez que a capacidade consiste em um parâmetro notável para vários modelos de fluxo de tráfego, e se relaciona diretamente com a ocorrência de congestionamentos e estimativas de tempo de viagem.

Na literatura, contudo, não existe um consenso sobre o conceito da capacidade e diversas definições foram propostas (WASHBURN et al., 2010). Tradicionalmente, a capacidade de uma rodovia é tratada pelos manuais de engenharia de tráfego como fenômeno determinístico, representado por um valor constante. Porém, diversos estudos têm demonstrado que a capacidade não consiste em valores fixos, mas em valores flutuantes, mesmo sob condições externas constantes (ELEFTERIADOU; ROESS; MCSHANE, 1995; PERSAUD; YAGAR; BROWNLEE, 1998; LORENZ; 
ELEFTERIADOU, 2000).

A maioria destes autores observou que o colapso da corrente de tráfego ocorre para diferentes fluxos sob as mesmas condições de tráfego e de operação da rodovia, o que sugere um fenômeno de natureza estocástica representado por uma variável aleatória em vez de uma variável fixa. O conceito de colapso da corrente de tráfego pode ser compreendido como a transição entre um padrão operacional adequado e condições de fluxo congestionado. Em uma rodovia, o colapso ocorre quando a demanda de fluxo é maior que a capacidade da via (GEISTEFELDT; BRILON, 2009) e pode ser observado por meio da variação abrupta da velocidade média da corrente de tráfego.

Dentro desse contexto, Brilon, Geistefeldt e Regler (2005) definem a capacidade como o volume em que a condição da corrente de tráfego passa de fluida para congestionada. Já o HCM define a capacidade como o maior fluxo de veículos que passam por uma determinada seção de via sob condições normais de tráfego e de operação (TRB, 2010; TRB, 2016), contudo não apresenta um método para estimar a capacidade a partir de dados de campo (KONDYLI et al., 2017). Na mesma direção, Washburn et al. (2010) sugerem que o conceito de processo estocástico da capacidade é mais realístico e eficiente em relação à tradicional utilização de valores únicos para sua representação.

Partindo-se do pressuposto de que qualquer valor de fluxo de tráfego superior à capacidade ocasiona o colapso da corrente, então, a função de densidade de probabilidade da capacidade representa a probabilidade de ocorrência de colapso da corrente de tráfego em função do fluxo. Segundo Geistefeldt e Brilon (2009), duas abordagens se destacam para a estimação empírica das funções de densidade de probabilidade da capacidade, por meio de dados coletados em campo. Ambos os métodos baseiam-se na definição da capacidade como fenômeno estocástico e recomendam que os dados de tráfego sejam agregados em intervalos de tempo curto, de 5 ou 6 minutos (BRILON; GEISTEFELDT; REGLER, 2005).

\subsubsection{Estimação de colapso da corrente de tráfego de forma direta}

A estimação de forma direta da probabilidade de colapso consiste em dividir os dados em grupos de volume de tráfego. Para cada grupo, é determinado o número de intervalos em que ocorre o colapso da corrente de tráfego e o número total de observações. A probabilidade de colapso da corrente para cada grupo é calculada como a proporção entre o número de intervalos em que ocorre o colapso da corrente de tráfego e a quantidade de observações.

$$
F_{c}\left(q_{i}\right)=\frac{N_{i}}{n_{i}}
$$

Em que, $F_{c}\left(q_{i}\right)=$ probabilidade de colapso da corrente de tráfego; $N_{i}=$ número de ocorrências de colapso de tráfego por grupo $i ; n_{i}=$ número de intervalos por grupo; e $q_{i}=$ média do fluxo em cada grupo $i$ (veic/h). 
A principal desvantagem dessa abordagem é que cada grupo de volume de tráfego é analisado separadamente e, dependendo dos dados observados e do critério de agrupamento, o método pode não apresentar uma função de distribuição de probabilidade da capacidade estritamente crescente. A abordagem descrita foi aplicada nos trabalhos de Persaud, Yagar e Brownlee (1998), Lorenz e Elefteriadou (2001).

\subsubsection{Estimação de colapso da corrente de tráfego por meio de modelos estatísticos}

A estimação da função de densidade de probabilidade por meio de modelos estatísticos foi abordada inicialmente por Minderhoud, Botma e Bovy (1997). A proposta da abordagem consiste em dividir os dados de tráfego em dois grupos, denominados de rotulados e não rotulados, para intervalos de tempo ordenados.

Os dados são considerados não rotulados se apresentarem observações que atingem a capacidade. Para tanto, é considerado que uma observação atinge a capacidade se o volume de tráfego $\left(q_{i}\right)$ proporciona o colapso da corrente (BRILON; ZURLINDEN, 2003; BRILON; GEISTEFELDT; REGLER, 2005), por meio da redução da velocidade média da corrente abaixo de um limiar (treshhold) no intervalo subsequente, $i+1$. O volume então é considerado como a capacidade momentânea. Já, se a corrente de tráfego não apresenta colapso no intervalo de tempo $i$ e no intervalo subsequente, $i+1$, a observação é classificada como rotulada, o que significa que o volume observado $\left(q_{i}\right)$ no intervalo $i$ é menor que a capacidade do intervalo.

A estimação das funções de distribuição que incluem dados rotulados pode ser realizada por métodos paramétricos e não paramétricos (LAWLESS, 2011), baseados em análises de ciclo de vida e de confiabilidade. O método mais consagrado nesse contexto é o método não paramétrico Product Limit Method (PLM), desenvolvido por Kaplan e Meier (1958). A função de densidade de probabilidade do $\operatorname{PLM}, F_{c}\left(q_{i}\right)$, pode ser estimada por:

$$
F_{c}(q)=1-\prod_{i: q_{i} \leq q} \frac{k_{i}-d_{i}}{k_{i}}, i \in\{B\}
$$

Em que, $F_{c}(q)=$ probabilidade de colapso da corrente de tráfego; $q=$ fluxo de tráfego veic $/ \mathrm{h}$; $q_{i}=$ fluxo de tráfego no intervalo $i$ veic/h; $k_{i}=$ número de intervalos com fluxo de tráfego $q<q_{i} ; d_{i}=$ número de colapsos com fluxo $q_{i}$; e $\{B\}=$ conjunto de intervalos com colapso da corrente de tráfego.

Para a utilização de um método paramétrico na estimação da função de densidade de probabilidade, é necessário pré-determinar um tipo de distribuição da função de densidade de probabilidade. Conforme estudos de Brilon e Zurlinden (2003) e Brilon, Geistefeldt e Zurlinden (2007), a capacidade possui distribuição de Weibull. Dessa forma, a função de densidade de probabilidade da capacidade é representada na Equação 4.3, e pode ser estimada por meio 
da técnica de máxima verossimilhança.

$$
F_{c}(q)=1-e^{-\left(\frac{q}{\beta}\right)^{\alpha}}
$$

Em que, $F_{c}(q)=$ probabilidade de colapso da corrente de tráfego; $q$ = fluxo de tráfego veic/h; $\alpha=$ parâmetro da distribuição de Weibull; $\beta$ = parâmetro da distribuição de Weibull veic/h.

O parâmetro $\alpha$ determina a variância da distribuição e apresenta valores entre 10 e 22, sendo que, quanto maior o seu valor, menor a variância da distribuição. Já $\beta$ é proporcional à média $\mathrm{e}$ ao desvio padrão da distribuição e representa, principalmente, fatores que afetam a capacidade da rodovia, como número de faixas, greide, tipos de condutores (GEISTEFELDT; BRILON, 2009).

Os resultados de Geistefeldt e Brilon (2009) demonstram que as abordagens descritas acima apresentam valores representativos distintos para a capacidade, e definem que a estimação da probabilidade de colapso da corrente de tráfego, por meio de modelos estatísticos, apresenta melhores resultados.

\subsection{Método proposto}

Primeiramente, foi realizada uma busca na literatura sobre definições do conceito de capacidade e de métodos de estimação da capacidade. Conforme observado no item 4.1, as abordagens de maior destaque na estimação da capacidade partem do pressuposto de que a capacidade apresenta natureza estocástica e, a partir de então, são estimadas funções de densidade de probabilidade da capacidade.

O método proposto neste capítulo consiste em um método empírico de estimar a capacidade de uma rodovia, levando-se em consideração a natureza estocástica do colapso da corrente de tráfego e da capacidade. Para tanto, o método estima a capacidade, por meio da relação entre a variação da velocidade média da corrente de tráfego e o volume de tráfego, a partir da Inferência Bayesiana.

O método parte do pressuposto de que para um determinado valor de fluxo de tráfego, a relação entre a variação da velocidade média da corrente e o volume de tráfego muda de comportamento de forma abrupta. O momento em que ocorre a mudança de comportamento é considerado como ponto de transição do sistema, o qual é associado à capacidade. O ponto de transição consiste em uma distribuição de probabilidades de volume de tráfego.

A partir da distribuição de probabilidades do ponto de transição, é determinado um valor representativo por meio de um atributo, o qual, neste caso, foi adotado a média da distribuição. Em seguida, é calculada a velocidade na capacidade por meio da média das velocidades médias associadas ao fluxo na capacidade, e por fim, via a relação fundamental de tráfego, é calculada a densidade na capacidade. 
Dessa forma, o método consiste das seguintes etapas: definição das distribuições a priori dos parâmetros do modelo; determinação da função de verossimilhança e das cadeias de Markov de Monte Carlo; estimação da distribuição posterior do ponto de transição e definição de um valor representativo da distribuição posterior.

Os códigos foram escritos em linguagem Python 2.7, com auxílio das bibliotecas Numpy 1.11.0, Pandas 0.19.1, Scikit-learn 0.17.1, Pymc 2.3.6 e Matplotlib 1.5.1. O computador utilizado para processamento foi um Core i7, $2.0 \mathrm{GHz}$ com $8 \mathrm{~Gb}$ de memória RAM.

\subsubsection{Descrição do modelo}

O modelo proposto consiste em determinar o momento em que ocorre uma mudança significativa na variação do modulo da velocidade média da corrente de tráfego em função fluxo, dado em veic/h, para intervalos de tempo subsequentes, $(i$ e $i+1)$. Para tanto, parte do pressuposto de que a relação entre a variação do módulo da velocidade média da corrente de tráfego e o volume de tráfego, em intervalos de tempo subsequentes, é derivada de um processo de Poisson com parâmetro interno $\lambda$, conforme evidencia no item 4.2.4.

A partir de então, assume-se que ocorre uma mudança no comportamento da distribuição de Poisson, a qual é derivada da variação do modulo da velocidade média da corrente de tráfego em função do fluxo. A mudança de comportamento da distribuição de Poisson é controlada internamente por $\lambda$, que pode ser interpretado como a intensidade da distribuição de Poisson, já que, conforme maior o valor de $\lambda$, maior a probabilidade de ocorrência de grandes valores e, conforme menor o valor de $\lambda$, maior a probabilidade da ocorrência de pequenos valores.

Em seguida, define-se a existência de dois $\lambda$ distintos, $\lambda_{1}$ e $\lambda_{2}$, cujos valores são associados a probabilidades de ocorrência, por meio de uma distribuição exponencial. Para o momento em que ocorre a mudança no valor de $\lambda$, denominado de $\tau$, atribui-se uma distribuição uniforme. A concepção do modelo é apresentada pelo modelo a seguir.

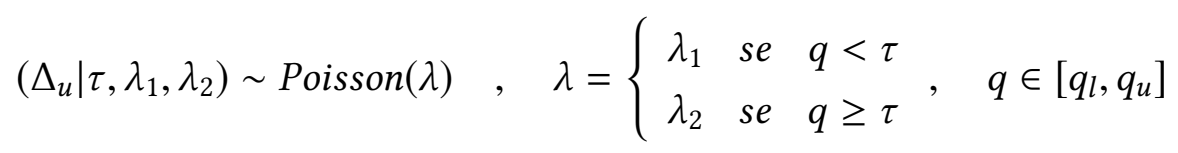

Sendo:

$$
\begin{gathered}
\tau \sim \text { Uniforme }\left(q_{l}, q_{u}\right) \\
\alpha=\frac{1}{\mu_{\Delta_{u}}} \\
\lambda_{1} \sim \text { Exponencial }(\alpha) \\
\lambda_{2} \sim \text { Exponencial }(\alpha)
\end{gathered}
$$

- $\Delta_{u}$ : Variação do modulo da velocidade média;

- $\lambda$ : Parâmetro da distribuição de Poisson em relação ao fluxo $q$; 
- $\tau$ : Volume em que ocorre mudança no valor do parâmetro $\lambda$, denominado ponto de transição do modelo;

- $\alpha$ : Parâmetro da distribuição Exponencial;

- $\lambda_{1}$ : Parâmetro da distribuição de Poisson antes do ponto de transição;

- $\lambda_{2}$ : Parâmetro da distribuição de Poisson depois do ponto de transição; e

- $q_{l}$ e $q_{u}$ : limite inferior e superior do volume $q$.

A Figura 4.1 apresenta o grafo acíclico que representa a ideia do modelo proposto. Nela, os círculos sem preenchimento correspondem às variáveis estocásticas não observadas: ponto de transição, $\lambda_{1}$ e $\lambda_{2}$. Já o círculo preenchido representa a variável estocástica observada, variação do modulo da velocidade média, enquanto o triângulo representa a variável determinística oriunda das variáveis estocásticas não observadas. A relação entre as variáveis é determinada pelo sentido das flechas, enquanto a passagem de parâmetros é representada pelas letras ao redor das flechas.

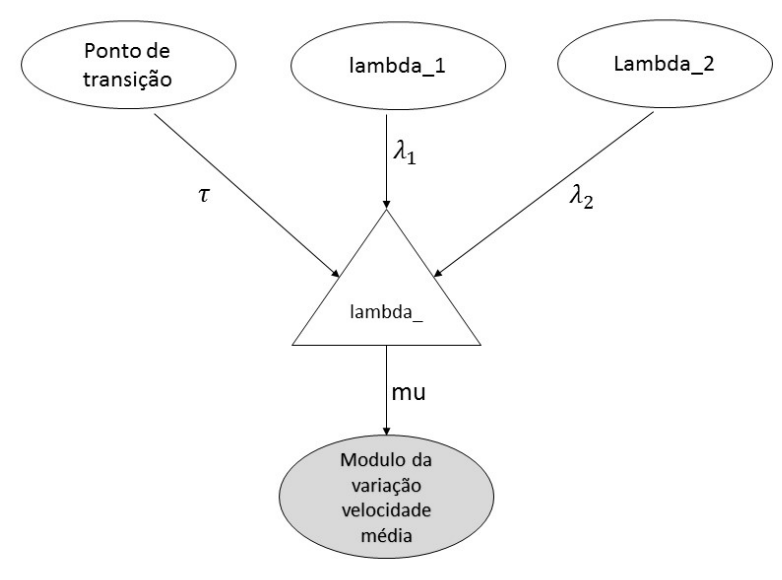

Figura 4.1 - Grafo acíclico do modelo do proposto

Ressalta-se que o objetivo final do modelo consiste em determinar a distribuição posterior de $\tau$. A partir de então, a capacidade da rodovia é determinada por meio de um valor representativo da distribuição posterior. A escolha de um valor representativo para uma distribuição posterior na Inferência Bayesiana consiste na escolha de um parâmetro que represente a distribuição por meio de um valor único (point estimate).

Algumas métricas tradicionais como a média e a mediana relacionam-se com funções de otimização conhecidas, sendo que a média minimiza o erro quadrático, $\left|\left(\theta-\theta^{\prime}\right)^{2}\right|$, enquanto a mediana minimiza o erro absoluto, $\left|\left(\theta-\theta^{\prime}\right)\right|$, em que, $\theta$ e $\theta^{\prime}$ correspondem, respectivamente, 
ao valor observado e ao valor estimado. Nesse estudo, o valor representativo consiste na média da distribuição. A seguir, as etapas para desenvolvimento do modelo são apresentadas detalhadamente.

\subsubsection{Banco de dados}

Os dados de tráfego utilizados nesta etapa foram obtidos por sensores de laços indutivos, localizados em rodovias de pista dupla e autoestradas do Estado de São Paulo, conforme descrito no Capítulo 3 deste trabalho. Ao todo, o banco de dados compreende quatro rodovias do estado de São Paulo, SP-348, SP-280, SP-270 e SP-021, em um total de 34 sensores de tráfego.

As informações disponíveis contém fluxo e velocidade média da corrente tráfego. As Figuras 4.2 e 4.3 mostram, respectivamente, as observações de velocidade e taxa de fluxo dos dados brutos e após o tratamento do $\mathrm{km} \mathrm{51,9} \mathrm{da} \mathrm{SP-280,} \mathrm{sentido} \mathrm{leste.} \mathrm{O} \mathrm{tratamento} \mathrm{do} \mathrm{banco} \mathrm{de} \mathrm{da-}$ dos foi realizado aplicando-se os critérios de veículos leves e condições de operação normal, descritos no Capítulo 3.

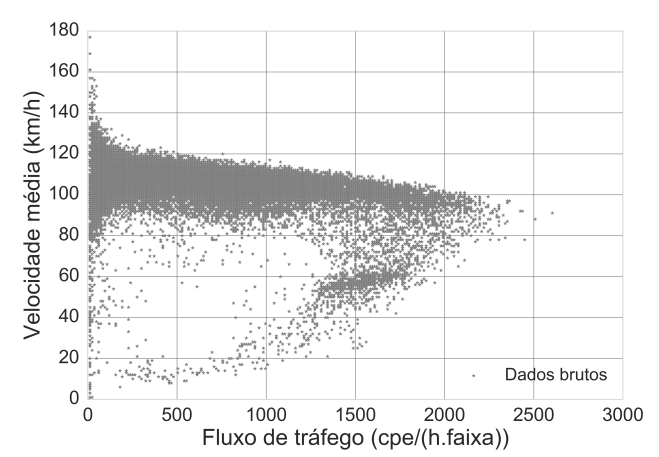

Figura 4.2 - Observações de velocidade e taxa de fluxo dos dados brutos - SP-280, km 51,9 leste

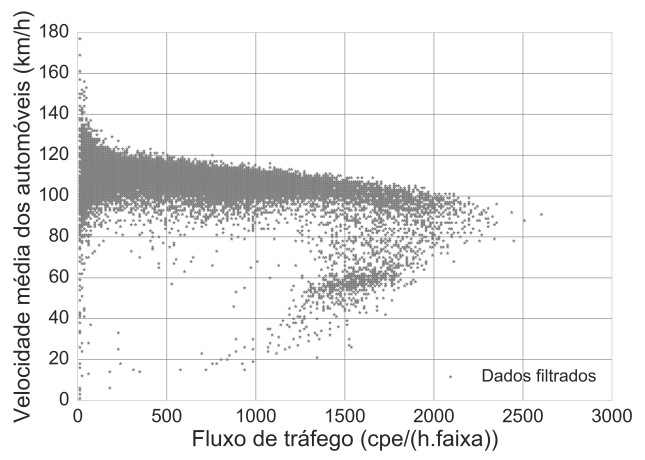

Figura 4.3 - Observações de velocidade e taxa de fluxo após tratamento - SP-280, km 51,9 leste

\subsubsection{Distribuição a priori}

As distribuições dos parâmetros $\lambda_{1}$ e $\lambda_{2}$ do modelo proposto foram determinadas como exponenciais. O parâmetro interno, $\alpha$, das distribuições foi considerado como o inverso da média da variação do modulo da velocidade média da corrente de tráfego. A opção por utilizar uma distribuição exponencial para representar $\lambda_{1}$ e $\lambda_{2}$ consiste no fato de que, usualmente, para um processo derivado de Poisson a distribuição do parâmetro interno $(\lambda)$ segue uma distribuição exponencial, cujo comportamento é controlado por $\alpha$.

Já para o parâmetro $\tau$ foi associada uma distribuição uniforme com limites inferior de 1.400 veic/h e superior de $2.800 \mathrm{veic} / \mathrm{h}$. A justificativa para isso é que a distribuição uniforme apresenta probabilidades iguais de ocorrência para todos os valores situados entre os limites inferior e 
superior. Sendo assim, qualquer valor de fluxo de tráfego situado entre os limites apresenta a mesma possibilidade de ocorrência.

\subsubsection{Função de verossimilhança}

A função de verossimilhança foi determinada como uma distribuição de Poisson por meio da análise da variação do modulo da velocidade média da corrente de tráfego em função do volume de tráfego. As Figuras 4.4 e 4.5 apresentam, respectivamente, a variação do modulo da velocidade média em função do volume de tráfego e a função de densidade de probabilidade da variação do modulo da velocidade média para o sensor do km 51,9 da SP-280, sentido leste.

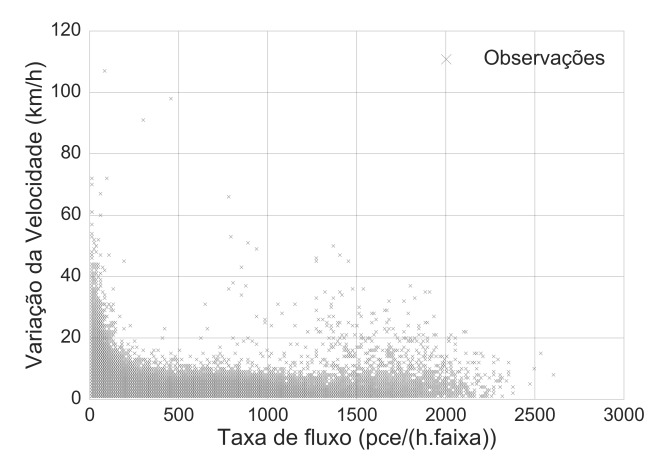

Figura 4.4 - Variação do modulo da velocidade média em função volume de tráfego SP-280, km 51,9 leste

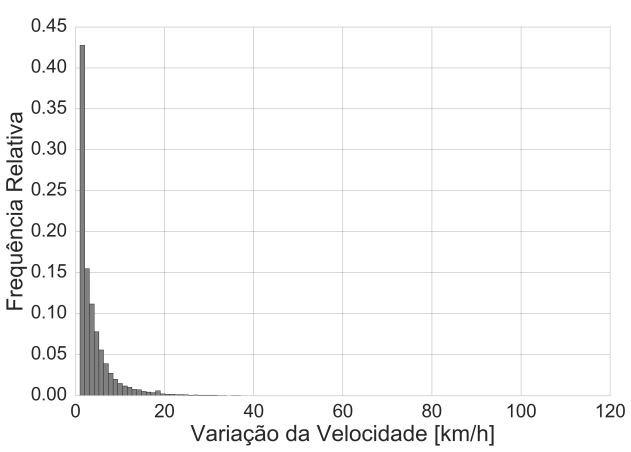

Figura 4.5 - Função de densidade de probabilidade da variação do modulo da velocidade média - SP-280, km 51,9 leste

Assumiu-se uma distribuição de Poisson, uma vez que a relação entre o volume de tráfego e a variação do modulo da velocidade média é derivada de um processo de contagem. Na literatura (ROSS, 1996), uma das definições para um processo ser considerado como Poisson, $\operatorname{com} \lambda(t) \cdot t, \lambda>0$, deve satisfazer as seguintes condições:

1. número de eventos para tempo, $t=0$, deve ser igual a zero;

2. processo possui incrementos independentes; e

3. número de eventos em qualquer intervalo de tempo $t$ possui distribuição de Poisson com média $\lambda(t) \cdot t$, para $t>0$.

A primeira condição é satisfeita, uma vez que, para o fluxo igual a zero, o número de eventos que corresponde a variação da velocidade média, é zero. Já para a segunda condição, assumese que a variação do módulo da velocidade média da corrente de tráfego possui incrementos independentes, ou seja, os eventos são independentes para observações subsequentes. Por fim, a terceira condição é satisfeita, levando-se em consideração que a média do número de eventos em um determinado intervalo de fluxo é determinado por $\lambda(q) \cdot q$. 


\subsubsection{Monte Carlo via cadeias de Markov}

A escolha dos parâmetros do MCMC foi realizada por meio da análise da distribuição posterior, que envolveu a verificação de convergência de MCMC e o tempo de processamento dos dados. Para tanto, foram utilizadas 3 cadeias de MCMC com o mesmo número de iterações, porém, com valores iniciais distintos. Escolheu-se utilizar cadeias MCMC distintas para utilizar o teste estatístico de Gelman e Rubin, que tem por objetivo investigar a convergência do processo MCMC.

O teste de Gelman e Rubin consiste em analisar a variância e a média de cadeias de Markov, e verificar a similaridade para diferentes constituições de MCMC. O tempo de processamento e as configurações do MCMC são apresentadas nos resultados a seguir.

\subsection{Resultados}

\subsubsection{Distribuição posterior}

O método proposto foi aplicado nos 18 pontos de coleta nos quais se verifica que a capacidade é atingida, sendo 11 em rodovias classificadas como rurais e 7 em urbanas. As Figuras 4.6, 4.7 e 4.8 apresentam as distribuições posteriores de $\tau, \lambda_{1}$ e $\lambda_{2}$, referentes ao $\mathrm{km} 51,9$ da rodovia SP-280, sentido leste.

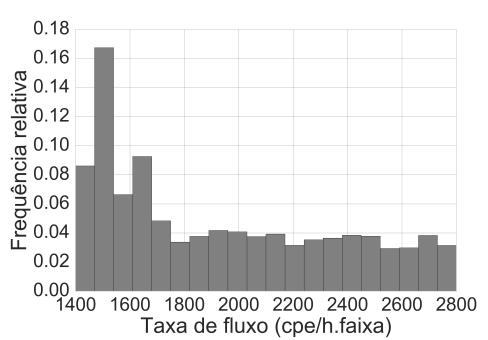

Figura 4.6 - Distribuição posterior de $\tau$

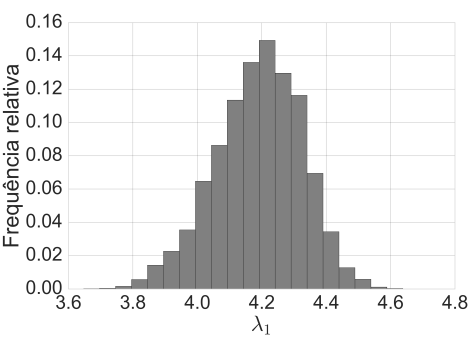

Figura 4.7 - Distribuição posterior de $\lambda_{1}$

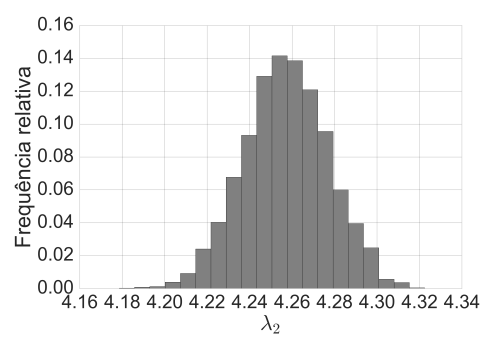

Figura 4.8 - Distribuição posterior de $\lambda_{2}$

Como valor representativo das distribuições posteriores, utilizou-se a média da distribuição, o que nesse caso, para $\tau$ corresponde a um fluxo de $1.923 \mathrm{cpe} /\left(\right.$ h.faixa), $\lambda_{1}$ a 4,18 e $\lambda_{2}$ a 4,26 . A partir de então, determinou-se a velocidade média da corrente de tráfego para essa condição em $90,7 \mathrm{~km} / \mathrm{h}$, como sendo a média das velocidades das observações no intervalo de fluxo maior que 1.920 e menor que $1.932 \mathrm{cpe} /($ h.faixa). Por meio da relação fundamental de tráfego, foi calculada a densidade na capacidade como $21,2 \mathrm{cpe} /(\mathrm{km}$.faixa). A Tabela 4.1 apresenta os valores encontrados para capacidade, velocidade na capacidade e densidade na capacidade, para cada trecho abordado. 
Tabela 4.1 - Capacidade, velocidade na capacidade e densidade na capacidade por trecho

\begin{tabular}{|c|c|c|c|c|c|c|c|}
\hline $\mathrm{km}$ & Sentido & Tipo de via & $\begin{array}{l}\text { Ocupação } \\
\text { lindeira }\end{array}$ & $u_{f}(\mathrm{~km} / \mathrm{h})$ & $q_{c}($ cpe/(h.faixa) $)$ & $\mu_{c}(\mathrm{~km} / \mathrm{h})$ & $k_{c}$ (cpe/(km.faixa) \\
\hline \multicolumn{8}{|c|}{ SP-280 (Rodovia Castelo Branco) } \\
\hline 16,0 & Leste - Expresssa & Rodovia de pista dupla & Urbana & 72,1 & 2.128 & 55,7 & 38,2 \\
\hline 22,4 & Oeste - Expressa & Autoestrada & Urbana & 105,2 & 2.152 & 87,7 & 24,5 \\
\hline 22,4 & Oeste - Marginal & Autoestrada & Urbana & 110,8 & 2.021 & 74,1 & 27,3 \\
\hline 29,5 & Leste & Autoestrada & Urbana & 100,8 & 1.947 & 81,4 & 23,9 \\
\hline 29,5 & Oeste & Autoestrada & Urbana & 114,6 & 2.101 & 91,8 & 22,9 \\
\hline 37,0 & Leste & Rodovia de pista dupla & Rural & 115,1 & 1.916 & 105,4 & 18,2 \\
\hline 51,9 & Leste & Rodovia de pista dupla & Rural & 109,6 & 1.923 & 90,7 & 21,2 \\
\hline 59,6 & Leste & Rodovia de pista dupla & Rural & 119,9 & 2.352 & 101,3 & 23,2 \\
\hline 75,9 & Leste & Rodovia de pista dupla & Rural & 103,1 & 2.038 & 79,1 & 25,8 \\
\hline \multicolumn{8}{|c|}{ SP-348 (Rodovia dos Bandeirantes) } \\
\hline 32,0 & Norte & Autoestrada & Rural & 115,7 & 2.248 & 96,7 & 23,3 \\
\hline 32,0 & Sul & Autoestrada & Rural & 115,5 & 2.488 & 94,5 & 26,3 \\
\hline 50,0 & Norte & Autoestrada & Rural & 122,9 & 2.040 & 107,5 & 19,0 \\
\hline 50,0 & Sul & Autoestrada & Rural & 119,6 & 2.073 & 105,2 & 19,7 \\
\hline 65,0 & Sul & Autoestrada & Rural & 116,2 & 2.270 & 102,0 & 22,3 \\
\hline 87,0 & Norte & Autoestrada & Rural & 119,3 & 2.166 & 103,6 & 20,9 \\
\hline 87,0 & Sul & Autoestrada & Rural & 111,8 & 2.277 & 100,8 & 22,6 \\
\hline \multicolumn{8}{|c|}{ SP-021 (Rodoanel) } \\
\hline 18,3 & Norte & Rodovia de pista dupla & Urbana & 101,9 & 2.189 & 79,6 & 27,5 \\
\hline 22,3 & Sul & Rodovia de pista dupla & Urbana & 98,7 & 2.407 & 83,9 & 28,7 \\
\hline
\end{tabular}

\subsubsection{MCMC}

A análise de MCMC teve como base a verificação da convergência de MCMC e o tempo de processamento dos dados. Para a análise de convergência, foi verificada a autocorrelação e a variação dos valores das amostras por meio de uma análise gráfica, aliada ao teste estatístico de Gelman e Rubin. A Tabela 4.2 apresenta as configurações utilizadas no processo, no qual o Burn in consiste no descarte de iterações iniciais enquanto o Thin corresponde ao descarte de iterações em intervalos sucessivos.

Tabela 4.2 - Configuração de Monte Carlo via cadeias de Markov

\begin{tabular}{lccc}
\hline \multicolumn{4}{c}{ MCMC } \\
\hline Configuração & Iterações & Burn in & Thin \\
\hline 1 & 20.000 & 0 & 0 \\
2 & 30.000 & 10.000 & 0 \\
3 & 50.000 & 30.000 & 0 \\
\hline
\end{tabular}

As Figuras 4.9, 4.10 e 4.11 apresentam a variação dos valores das amostras geradas pelas configurações de MCMC utilizadas e a autocorrelação, respectivamente, para $\tau, \lambda_{1}$ e $\lambda_{2}$, referentes ao $\mathrm{km} \mathrm{51,9} \mathrm{da} \mathrm{rodovia} \mathrm{SP-280,} \mathrm{sentido} \mathrm{leste.}$

As Figuras 4.9, 4.10 e 4.11 mostram, para todas as configurações de MCMC utilizadas, que conforme o aumento do número de iterações, a autocorrelação diminui, indicando uma convergência do processo. Com a diminuição da autocorrelação e o aumento do número de iterações, a flutuação dos valores dos parâmetros, especialmente para $\lambda_{1}$ e $\lambda_{2}$, variam em torno de uma região bem delimitada, apontando para uma convergência de MCMC. 

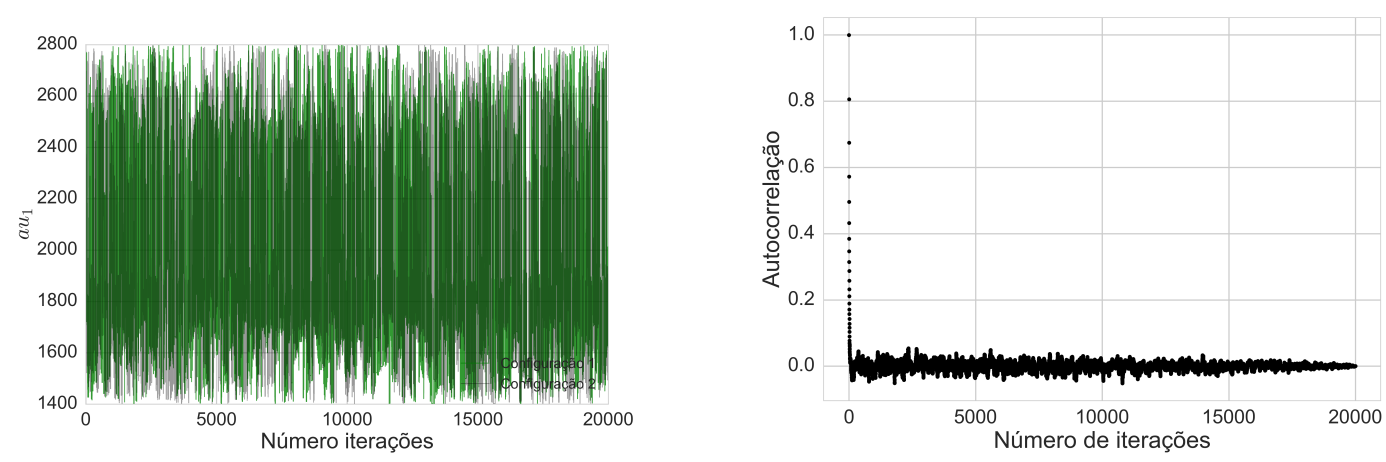

Figura 4.9 - Amostras e Autocorrelação de $\tau$
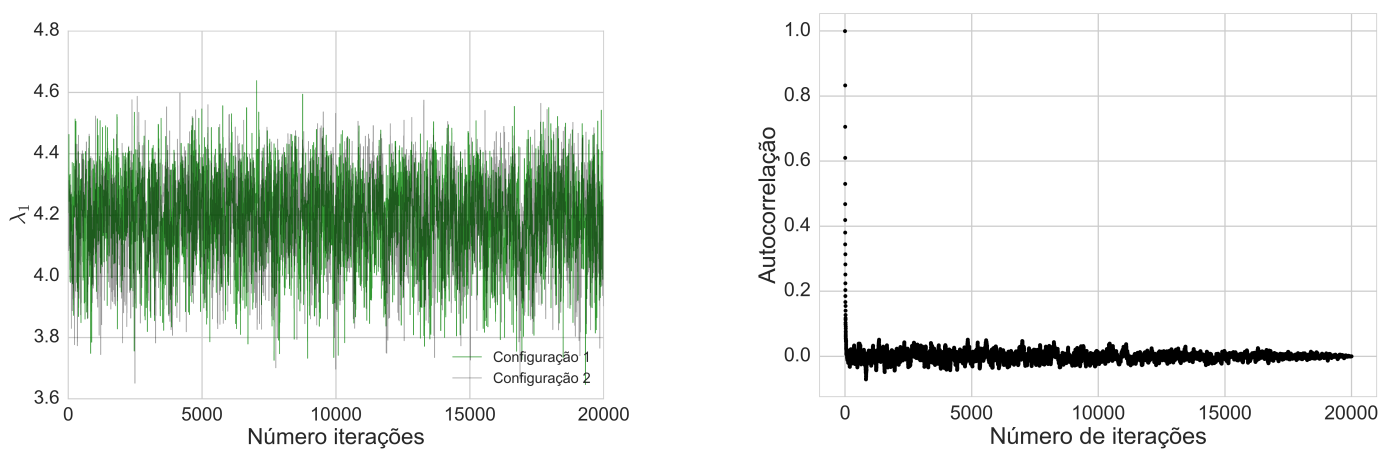

Figura 4.10 - Amostras e Autocorrelação de $\lambda_{1}$
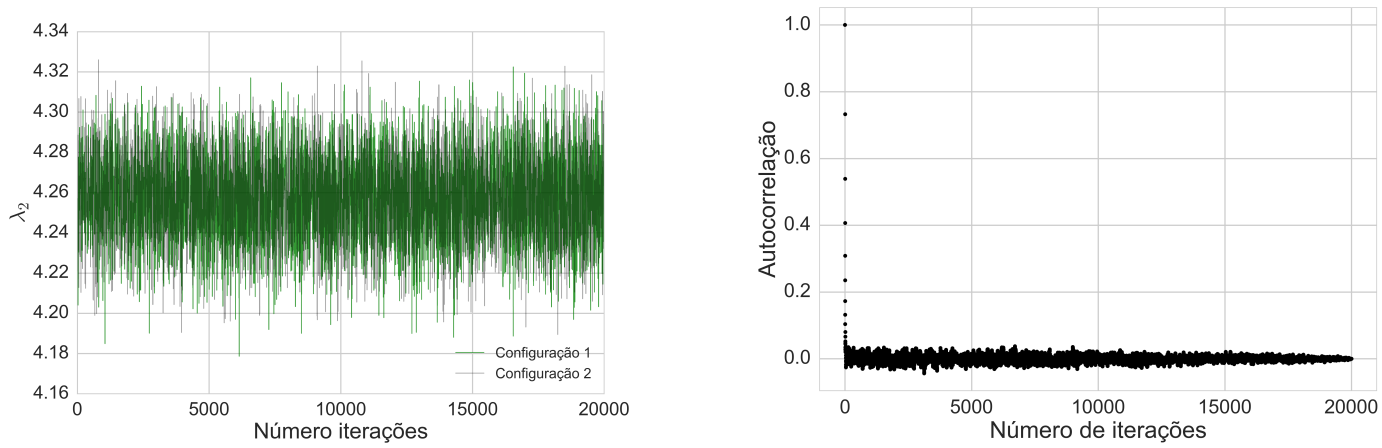

Figura 4.11 - Amostras e Autocorrelação de $\lambda_{2}$

Além da análise gráfica, foi aplicado o teste de Gelman e Rubin, o qual fornece indícios da convergência do processo MCMC por meio de um método estatístico que se baseia na análise da variância entre a mesma cadeia e entre diferentes cadeias de MCMC. A Tabela B.1 apresenta os valores do teste para cada parâmetro estimado do modelo, o qual tem por base que um $\hat{\mathrm{R}}$ menor que 1.1, corrobora com a convergência do processo MCMC.

A partir da análise descrita anteriormente, conclui-se que todos os parâmetros estimados apresentaram convergência. A Tabela B.1 lista o tipo da distribuição posterior para cada parâmetro, $\tau, \lambda_{1}$ e $\lambda_{2}$, bem como o tempo de processamento para cada ponto de coleta utilizado na pesquisa. 


\subsection{Considerações Finais}

Na engenharia de tráfego, a capacidade de uma via consiste em um parâmetro essencial para diversos modelos de fluxo de tráfego, e se relaciona diretamente com a ocorrência de congestionamentos e estimativa de tempo de viagem. Assim, nesta etapa, após a investigação das definições de capacidade existentes na literatura e das abordagens comumente utilizadas para sua estimação, apresentou-se um método para estimar a capacidade de uma rodovia, levandose em consideração a natureza estocástica do colapso da corrente de tráfego.

O método proposto consiste em um modelo estatístico probabilístico, baseado na inferência bayesiana, que apresenta como objetivo identificar a mudança de comportamento da variação da velocidade média da corrente de tráfego em função do fluxo de tráfego, para intervalos de tempo subsequentes. Para tanto, parte-se do pressuposto de que a relação entre a variação da velocidade média e o fluxo de tráfego muda de comportamento em determinado momento, o qual corresponde à variação abrupta da velocidade média da corrente em função de valores de fluxo tráfego.

A partir de então, assume-se que a relação entre a variação do módulo da velocidade média da corrente e o fluxo de trafego é derivada de um processo de Poisson, controlado internamente por um parâmetro $\lambda$. A mudança no comportamento do sistema é identificada pela alteração no valor de $\lambda$, e corresponde a uma função de densidade de probabilidade. A função de densidade de probabilidade de fluxo de tráfego em que ocorre a mudança no comportamento da relação entre a variação do modulo da velocidade em função do fluxo é associada à distribuição de probabilidade da capacidade. Por fim, utiliza-se a média da distribuição como valor representativo para a capacidade.

Com a capacidade definida, estima-se a velocidade na capacidade como a média das velocidades associados ao fluxo correspondente, e pela relação fundamental de tráfego é calculada a densidade na capacidade. O método foi aplicado para cada ponto de coleta em que a capacidade é atingida, sendo os resultados avaliados em seguida.

Como resultados, foram estabelecidos os parâmetros fundamentais de tráfego associados à capacidade, sendo a densidade na capacidade utilizada no modelo de fluxo-velocidade a ser calibrado no capítulo a seguir. 


\section{Capítulo}

\section{Calibração da curva fluxo-velocidade}

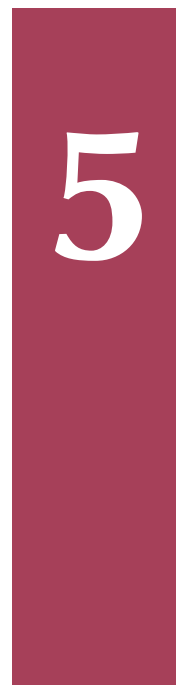

Este capítulo descreve o desenvolvimento de um método de calibração da relação fluxo-velocidade do modelo do HCM para autoestradas e rodovias de pista dupla, um dos objetivos desta pesquisa de mestrado. Para tanto, este capítulo detalha a relação fluxo-velocidade do modelo do HCM. O método proposto é descrito, assim como as considerações utilizadas para seu desenvolvimento.

\subsection{Considerações iniciais}

Importantes decisões de investimentos em rodovias são influenciadas, significativamente, pelos resultados de análises de um ou mais segmentos, existentes ou em planejamento, que formam uma rodovia. As análises estão diretamente associadas às teorias de fluxo de tráfego, que possibilitam descrever o fenômeno relacionado ao tráfego veicular. Dessa forma, as teorias de fluxo de tráfego tornam-se indispensáveis na implementação de modelos e ferramentas para o planejamento e gestão de infraestruturas de transportes e rodovias (POMPIGNA; RUPI, 2015)

As teorias de fluxo de tráfego procuram descrever a interação entre os veículos, os condutores e a infraestrutura viária (KLEIN et al., 2006). Entre as principais características, destaca-se a presença de elementos com variabilidade comportamental, espacial e temporal, decorrente, respectivamente, dos usuários do sistema, do local em análise e do período de estudo. A interação entre os parâmetros macroscópicos, comumente utilizados para descrever o comportamento da corrente de tráfego, fluxo, velocidade média e densidade, é expressa pela relação fundamental de tráfego, $q=k \cdot u$. A partir de então, diversos modelos vêm sendo propostos para representar a relação entre os parâmetros fundamentais de tráfego $q=f(u), q=f(k)$ ou $u=f(k)$. 
Dentro desse contexto destaca-se o modelo do Highway Capacity Manual, principal referência mundial sobre avaliação operacional de dispositivos viários. A relação fluxo-velocidade da corrente de tráfego para autoestradas e rodovias de pista dupla do HCM é representada por um modelo desenvolvido somente para a região de fluxo-livre da corrente de tráfego, diferentemente de outros modelos da literatura, como Greenshields e Van Aerde, que apresentam equações únicas para os regimes de fluxo livre e congestionado.

As versões do HCM 2010 e 2016 utilizam a mesma modelagem matemática do HCM 2000, para descrever a relação fluxo-velocidade da corrente de tráfego para autoestradas e rodovias de pista dupla. O modelo consiste em cinco parâmetros, $u_{f}, q_{c}, k_{c}, b p$ e $\alpha$, que representam uma curva com dois segmentos que variam conforme o fluxo na corrente de tráfego, expresso por:

$$
\begin{cases}q<b_{p} & , \quad u=u_{f} \\ b_{p}<q<q_{c} & , \quad u=u_{f}-\left(u_{f}-\frac{q_{c}}{k_{c}}\right) \cdot\left(\frac{q-b_{p}}{q_{c}-b_{p}}\right)^{\alpha}\end{cases}
$$

Em que:

- $q$ : Volume de tráfego;

- $u$ : Velocidade média da corrente;

- $u_{f}$ : Velocidade de fluxo livre;

- $q_{c}$ : Volume na capacidade;

- $k_{c}$ : Densidade na capacidade;

- $b p$ : Ponto de transição; e

- $\alpha$ : Coeficiente de calibração.

O primeiro segmento parte do pressuposto de que existe um patamar de velocidade, caracterizado pela velocidade de fluxo livre $\left(u_{f}\right)$, no qual a velocidade se mantém constante em função do aumento do fluxo até um ponto de transição $(b p)$. O segundo consiste em uma curva convexa ancorada em $b p$ e na densidade na capacidade $\left(k_{c}\right)$ da via, (Roess, 2011), e é caracterizado pela queda da velocidade média da corrente em função do aumento do fluxo.

O manual do HCM 2010 apresenta um conjunto de curvas calibradas, com velocidade de fluxo livre variando de 90 a $120 \mathrm{~km} / \mathrm{h}$ para autoestradas, e de 70 a $100 \mathrm{~km} / \mathrm{h}$ para rodovias de pista dupla. A Figura 5.1 mostra as curvas do manual de 2010 para os dois tipos de via.

Para rodovias de pista dupla, a essência do equacionamento é a mesma apresentada para autoestradas. Contudo, o $b p$ é considerando constante, enquanto $k_{c}$ varia para diferentes valores de $u_{f}$, conforme ilustrado na Figura 5.1 b. 

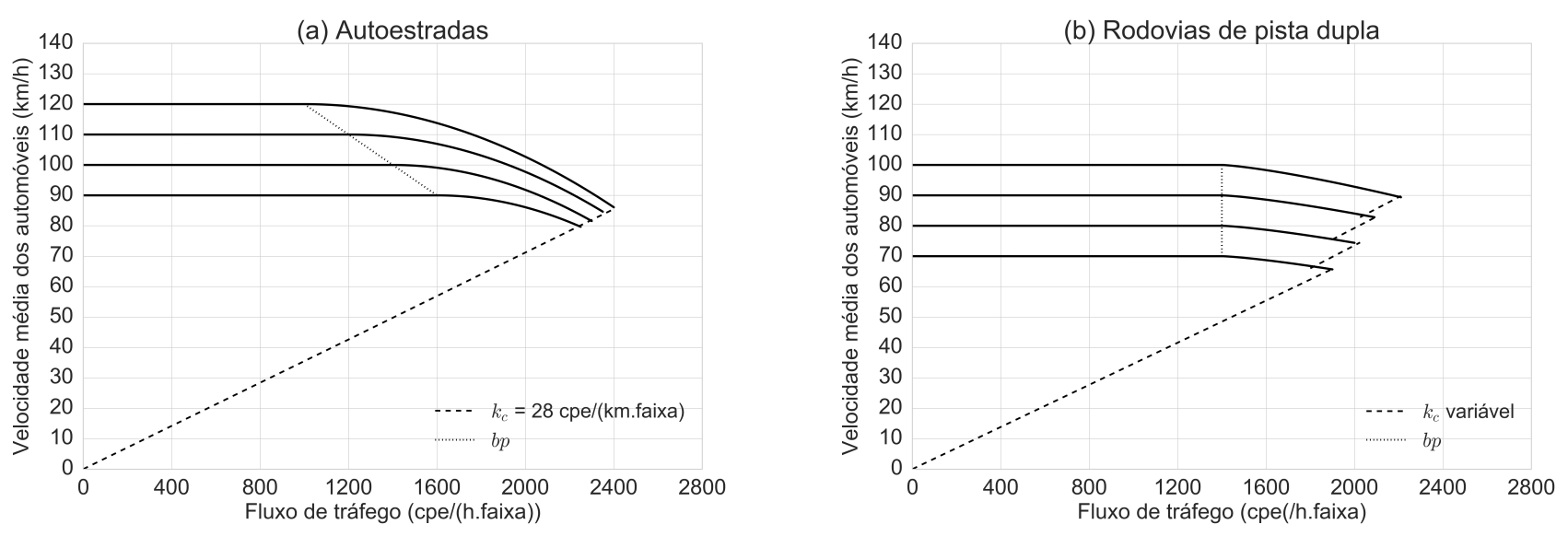

Figura 5.1 - Curvas fluxo-velocidade do HCM 2010 para: (a) autoestradas; (b) rodovias de pista dupla

Embora o manual apresente um conjunto de curvas simplificadas em função de $u_{f}$ e $q$, conforme ilustrado na Figura 5.1, o equacionamento do modelo consiste em curvas ancoradas no ponto de transição $(b p)$ e na densidade na capacidade $\left(k_{c}\right)$, que está relacionado à capacidade $\left(q_{c}\right)$ e à velocidade na capacidade $\left(u_{c}\right)$, por meio da relação fundamental de tráfego. Dessa forma, para se obter o conjunto de curvas fluxo-velocidade, deve-se, inicialmente, determinar $b p$ e $k_{c}$.

Na elaboração do HCM 2010 (ROESS, 2011), a determinação do ponto de transição ( $b p$ ) foi realizada testando valores crescentes de $b p$ e verificando a variação do desvio padrão, em intervalos de fluxo, das observações de velocidade. A partir do momento em que ocorreu um aumento brusco nos desvios padrões, determinou-se o ponto de transição. Já a velocidade de fluxo livre foi estimada diretamente a partir dos dados obtidos em campo (ROESS, 2009), embora os autores não explicitem o método para tal. O conjunto de curvas fluxo-velocidade do modelo do HCM 2010 foi obtido a partir do agrupamento de curvas com velocidades de fluxo livre próximas entre si. As curvas utilizadas para agrupamento foram calibradas individualmente por meio de uma análise de regressão em função de $q_{c}, b p, u_{f}$. O coeficiente de calibração $(\alpha)$ foi determinado otimizando-se o erro quadrático médio da velocidade.

Contudo, o próprio HCM recomenda a necessidade de adaptação para as condições locais de cada região, pois os seus procedimentos foram concebidos a partir de características das rodovias norte-americanas (TRB, 2010; TRB, 2016). A utilização de seus métodos sem a adaptação às condições locais, ou sem embasamento técnico cientifico adequado, pode levar a resultados incoerentes (SETTI, 2009).

Neste contexto, diversos estudos no Brasil têm se dedicado à calibração dos procedimentos do HCM. A calibração dos parâmetros para rodovias de pista simples e dupla vem sendo realizada no Departamento de Engenharia de Transportes da Universidade de São Paulo. Dentre esses trabalhos, Demarchi (2000), Cunha (2007), Andrade (2012) calibraram métodos e parâmetros para condições observadas em autoestradas e rodovias de pista dupla paulistas. Andrade 
(2012) verificou que a classificação do HCM em autoestradas e rodovias de pista dupla não é adequada e, então, sugeriu uma divisão em rodovias rurais e urbanas.

Além disso, Andrade (2012) propôs uma calibração dos parâmetros da relação fluxo-velocidade baseada em uma composição de métodos: $b p$ foi estimado pelo mesmo método do HCM 2010; $u_{f}$ foi determinada pela média das velocidades observadas em determinados intervalos de fluxo; $k_{c}$ foi determinada por meio da relação fundamental de tráfego após a estimação de $q_{c}$ pelo método não paramétrico Product Limit Method (PLM), descrito no Capítulo 4, e de $u_{c}$, o qual foi determinado por meio da média das velocidades correspondentes a capacidade encontrada pelo método PLM. Em seguida, Andrade (2012) determinou uma equação linear de $q_{c}$ em função da velocidade de fluxo livre e, também, o coeficiente de calibração $(\alpha)$, sendo ambos obtidos por meio de uma calibração que utiliza todos os sensores simultaneamente. A otimização é realizada minimizando o erro quadrático médio da velocidade.

\subsection{Método proposto}

O método proposto neste capítulo consiste na calibração da relação fluxo-velocidade do modelo do HCM para autoestradas e rodovias de pista dupla, por meio da Inferência Bayesiana. Primeiramente, foi realizada uma busca na literatura sobre modelos de fluxo de tráfego macroscópicos e os métodos de calibração comumente associados. Conforme observado na literatura, diversos modelos foram propostos e continuam a ser desenvolvidos para representar a relação de fluxo na corrente de tráfego.

Devido à grande quantidade de modelos existentes conforme descrito no Capítulo 3, optouse por trabalhar com o modelo do HCM, uma vez que este consiste no manual de referência mundial na avaliação operacional de dispositivos viários, inclusive no Brasil. Sendo assim, este trabalho apresenta um novo método para calibrar os parâmetros do modelo de fluxo-velocidade do HCM.

O método proposto consiste nas seguintes etapas: coleta de dados e tratamento do banco de dados; classificação do trecho e definição da densidade na capacidade da via; definição das distribuições a priori dos parâmetros do modelo; determinação da função de verossimilhança e do método de Monte Carlos via cadeias de Markov; estimação da distribuição posterior dos parâmetros do modelo e definição de um valor representativo da distribuição posterior.

Os códigos foram escritos em linguagem Python 2.7, com auxílio das bibliotecas Numpy 1.11.0, Pandas 0.19.1, Scikit-learn 0.17.1, Pymc 2.3.6 e Matplotlib 1.5.1. O computador utilizado para processamento foi um Core i7, $2.0 \mathrm{GHz}$ com $8 \mathrm{~Gb}$ de memória RAM.

\subsubsection{Banco de dados}

Assim como no Capítulo 4, os dados de tráfego utilizados nesta etapa foram obtidos por sensores de laços indutivos, localizados em autoestradas e rodovias de pista dupla do Estado de São 
Paulo, conforme descrito no Capítulo 3 deste trabalho. Ao todo, o banco de dados compreende quatro rodovias do Estado de São Paulo, SP-348, SP-280, SP-270 e SP-021, em um total de 34 sensores de tráfego.

As informações disponíveis contém fluxo e velocidade média da corrente tráfego. As Figuras 5.2 e 5.3 mostram, respectivamente, as observações de velocidade e taxa de fluxo dos dados brutos e após o tratamento do km 51,9 da SP-280, sentido leste. O tratamento do banco de dados foi realizado aplicando-se os critérios de veículos leves, condições de operação normal e regime de fluxo livre, descritos no Capítulo 3.

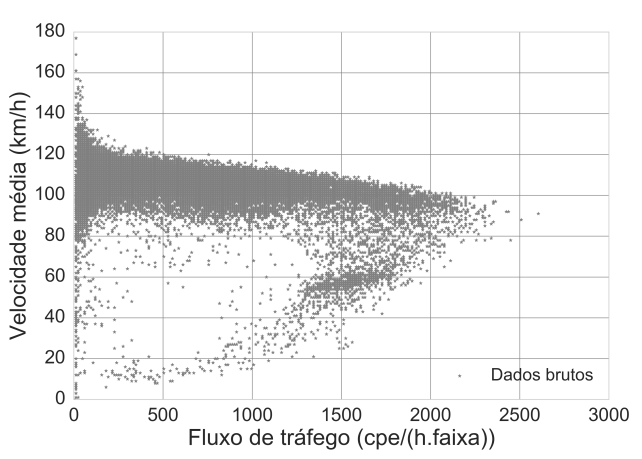

Figura 5.2 - Observações de velocidade e taxa de fluxo dos dados brutos - SP-280, km 51,9 leste

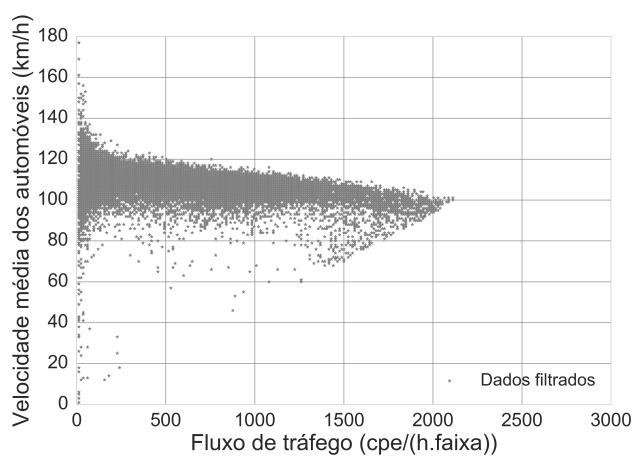

Figura 5.3 - Observações de velocidade e taxa de fluxo após tratamento - SP-280, km 51,9 leste

\subsubsection{Classificação dos trechos}

A classificação de trechos de rodovias do HCM consiste na divisão em autoestradas e rodovias de pista dupla, com valores distintos de $b p$ e $k_{c}$, conforme descrito no item 5.1.3. Dessa forma, após o tratamento do banco de dados, a primeira etapa na calibração do modelo de fluxovelocidade do HCM consiste na forma de classificação dos trechos de uma rodovia.

Neste trabalho, optou-se por classificar os trechos, segundo o tipo de ocupação lindeira da rodovia, em urbano e rural, conforme proposto em Andrade (2012), o qual evidencia que faz pouco sentido dividir as rodovias do estado de São Paulo em autoestradas e rodovias de pista dupla, conforme preconiza o HCM. Para tanto, propõe uma divisão entre rodovias rurais e urbanas, uma vez que as principais diferenças entre autoestradas e rodovias de pista dupla convencionais do estado de São Paulo se referem ao controle de acessos e à densidade de acessos não controlados da via, diferentemente das autoestradas e rodovias de pista dupla norte-americanas, que possuem características físicas distintas, como cruzamento em nível e semáforos ocasionais.

Tais características pertinentes às rodovias do Estado de São Paulo, controle de acesso da rodovia e densidade de acessos não controlados, consistem em atributos típicos associados à ocupação lindeira da rodovia. Assim, para trechos em que a capacidade da via é atingida, 
utilizou-se a densidade calculada no local pelo método desenvolvido no Capítulo 4 desta dissertação. Já para trechos em que a capacidade não fora atingida, utilizou-se a média da densidade na capacidade para o conjunto de trechos classificados em rodovias urbanas e rurais. No cálculo da densidade média para rodovias urbanas, optou-se por desconsiderar o sensor do $\mathrm{km} \mathrm{16,0}$ sentido leste da pista expressa da SP-280 por ser um trecho de entrelaçamento (weaving) e apresentar valor muito distinto em relação aos demais, 38,3 cpe/(km.faixa).

A densidade na capacidade, para trechos em que a capacidade não fora atingida foi estimada em 26 cpe/(km.faixa) para vias urbanas e $22 \mathrm{cpe} /(\mathrm{km}$.faixa) para vias rurais. No HCM 2010, os valores de $k_{c}$ para rodovias de pista dupla variam de 25 e $28 \mathrm{cpe} /(\mathrm{km}$.faixa), enquanto que para autoestradas $k_{c}$ é fixo e corresponde a $28 \mathrm{cpe} /\left(\mathrm{km}\right.$.faixa). No HCM 2016, $k_{c}$ é fixo em $28 \mathrm{cpe} /(\mathrm{km}$. faixa) tanto para autoestradas e rodovias de pista dupla. Já em Andrade (2012), o valor encontrado para rodovias urbanas e rurais foi de $27 \mathrm{cpe} /(\mathrm{km} . \mathrm{faixa})$.

Dessa forma, o valor da densidade na capacidade para rodovias urbanas se aproxima do encontrado para autoestradas do HCM e para rodovias urbanas em Andrade (2012). No entanto, para rodovias rurais, $k_{c}$ é significantemente menor do que o encontrado para rodovias de pista dupla do HCM e também para rodovias rurais de Andrade (2012).

\subsubsection{Distribuições a priori}

As distribuições dos parâmetros, $u_{f}, q_{c}, b p, \alpha$, da relação fluxo-velocidade do modelo do HCM 2010 foram determinadas como uniformes. O intervalo inferior e superior de cada parâmetro é apresentado na Tabela 5.1 .

Tabela 5.1 - Distribuição a priori dos parâmetros

\begin{tabular}{llll}
\hline Parâmetro & Tipo de Distribuição & Limite Inferior & Limite Superior \\
\hline$u_{f}$ & Uniforme & $0 \mathrm{~km} / \mathrm{h}$ & $160 \mathrm{~km} / \mathrm{h}$ \\
$q_{c}$ & Uniforme & $0 \mathrm{veic} / \mathrm{h}$ & $2.800 \mathrm{veic} / \mathrm{h}$ \\
$b p$ & Uniforme & $0 \mathrm{veic} / \mathrm{h}$ & $2.000 \mathrm{veic} / \mathrm{h}$ \\
$\alpha$ & Uniforme & 1 & 3 \\
\hline
\end{tabular}

A opção por utilizar uma distribuição uniforme para representar os parâmetros do modelo tem por objetivo escolher uma distribuição a priori mais objetiva possível, ou seja, assume-se que não se conhece o comportamento dos parâmetros previamente. A distribuição uniforme apresenta essa característica, uma vez que todos os valores no intervalo de cada parâmetro apresentam a mesma probabilidade de ocorrência.

\subsubsection{Função de verossimilhança}

A função de verossimilhança foi determinada como uma distribuição Normal. Para tanto, analisou-se a função densidade de probabilidade (PDF) da variável velocidade média da corrente de tráfego. Os parâmetros da distribuição, média e desvio padrão, foram obtidos a partir 
dos dados tratados. A Figura 5.5 apresenta a função de densidade de probabilidade da velocidade média da corrente de tráfego, para o sensor do km 51,9 da SP-280, sentido Leste, a partir dos dados filtrados.

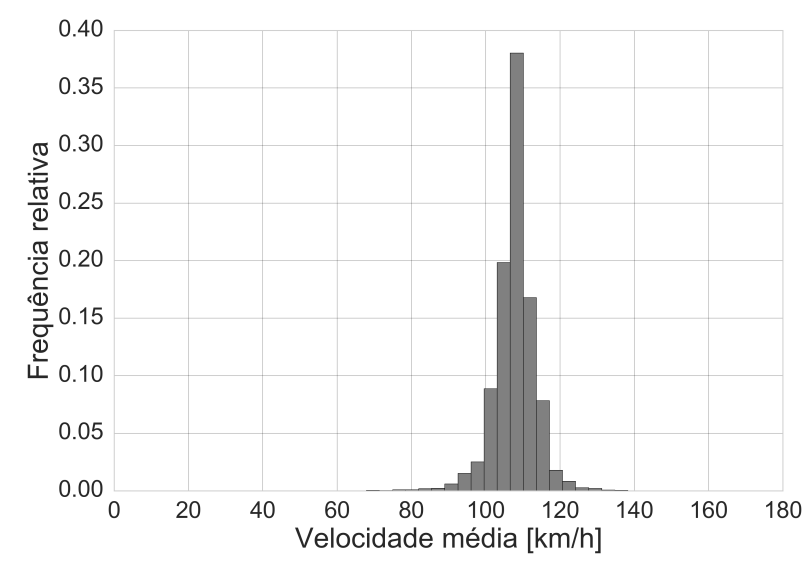

Figura 5.4 - Função densidade de probabilidade da velocidade média - SP-280, km 51,9 leste

\subsubsection{Monte Carlo via cadeias de Markov}

Assim como no Capítulo 4, a escolha dos parâmetros do MCMC foi realizada por meio da análise da distribuição posterior, que envolveu a verificação de convergência de MCMC e o tempo de processamento dos dados. Para tanto, foram utilizadas 3 cadeias de MCMC com o mesmo número de iterações, porém, com valores iniciais distintos. Escolheu-se utilizar cadeias MCMC distintas para utilizar o teste estatístico de Gelman e Rubin, que tem por objetivo investigar a convergência do processo MCMC.

\subsection{Resultados}

A estimação dos parâmetros da relação fluxo-velocidade do modelo do HCM foi realizada nos 34 pontos de coleta, sendo que 18 atingem a capacidade da via. Ao todo 20 trechos foram classificados como rodovias rurais e 14 em rodovias urbanas. Nos resultados foram avaliados: distribuições posteriores dos parâmetros do modelo; convergência do processo MCMC; comparação entre os valores dos parâmetros obtidos do modelo pelo método proposto e pelo HCM 2010 e Andrade (2012), e análise de erro.

\subsubsection{Distribuição posterior}

A Figura 5.5 apresenta as distribuições posteriores de $u_{f}, q_{c}, b p, \alpha$, referentes ao $\mathrm{km} \mathrm{51,9} \mathrm{da}$ rodovia SP-280, sentido leste.

Utilizou-se, como valor representativo das distribuições posteriores, a média da distribuição, o que nesse caso, para $u_{f}$ corresponde a uma velocidade de fluxo livre de 109,6 km/h, $q_{c}$ a um 

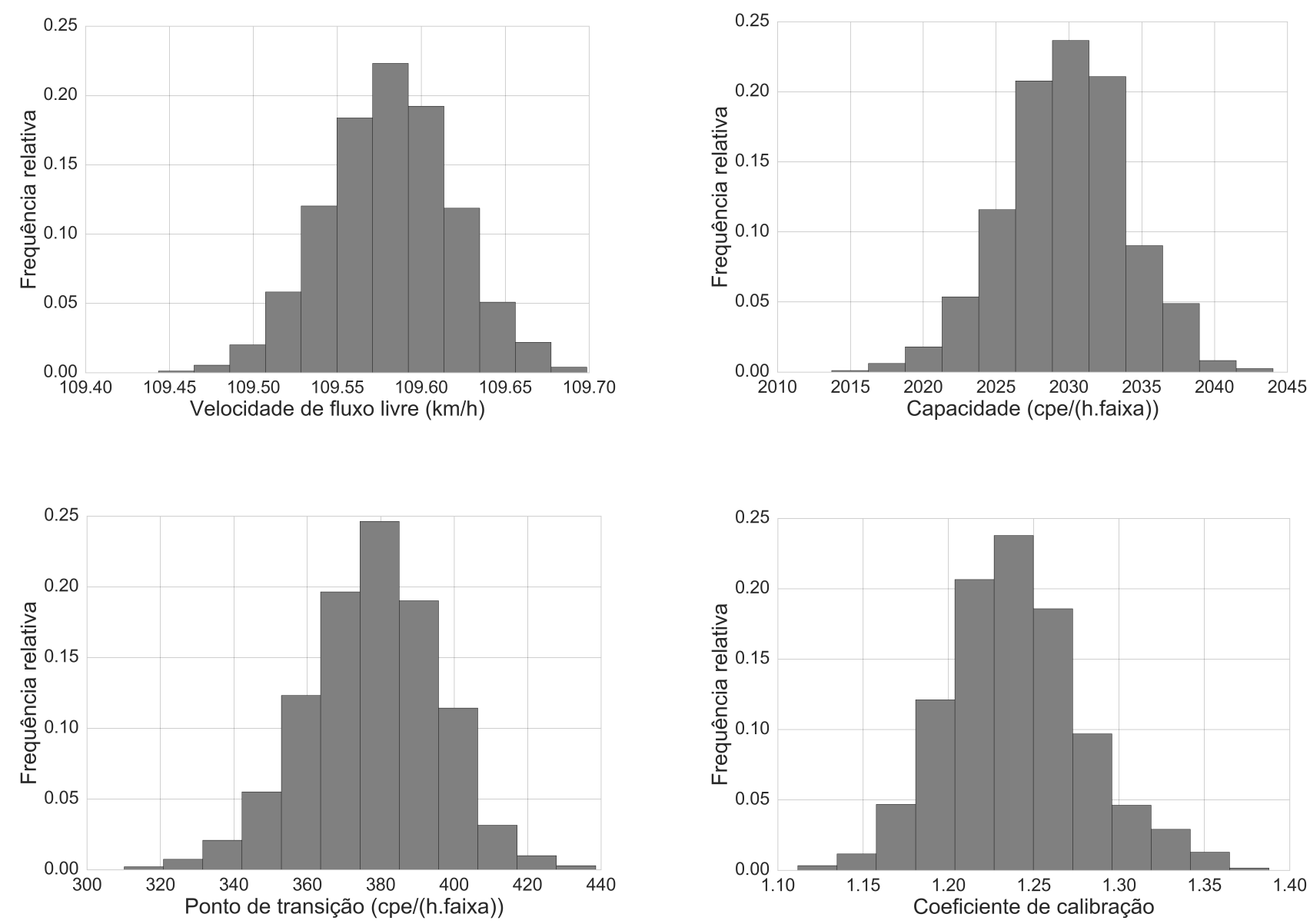

Figura 5.5 - Distribuição posterior para (a) velocidade de fluxo livre; (b) capacidade; (c) ponto de transição; e (d) coeficiente de calibração, para - SP-280, km 51,9 leste

fluxo de $2.030 \mathrm{cpe} /($ h.faixa), $b p$ a um fluxo de $377 \mathrm{cpe} /($ h.faixa) e $\alpha$ a 1,24. A Tabela 5.2 apresenta, para cada trecho abordado, os valores estimados dos parâmetros.

\subsubsection{MCMC}

Da mesma forma que no capítulo anterior, a análise de MCMC teve como base a verificação da convergência de MCMC e o tempo de processamento dos dados. Para a análise de convergência foi verificada a autocorrelação e a variação dos valores das amostras, por meio de uma análise gráfica e do teste estatístico de Gelman e Rubin. A Tabela 5.3 apresenta as configurações utilizadas no processo, no qual o Burn in consiste no descarte de iterações iniciais enquanto o Thin corresponde ao descarte de iterações em intervalos sucessivos.

As Figuras 5.6, 5.7, 5.8 e 5.9 apresentam a variação dos valores das amostras geradas pelas configurações de MCMC utilizadas e a autocorrelação, respectivamente, para $u_{f}, q_{c}, b p$ e $\alpha$, referentes ao $\mathrm{km} \mathrm{51,9} \mathrm{da} \mathrm{rodovia} \mathrm{SP-280,} \mathrm{sentido} \mathrm{leste.}$

As Figuras 5.6, 5.7, 5.8 e 5.9 mostram que, para todas as configurações de MCMC utilizadas, conforme o aumento do número de iterações, a autocorrelação diminui, indicando uma 
Tabela 5.2 - Parâmetros estimados pelo método proposto para cada trecho

\begin{tabular}{|c|c|c|c|c|c|c|c|c|}
\hline $\mathrm{km}$ & Sentido & Tipo de via & Ocupação lindeira & $u_{f}$ & $q_{c}$ & $b p$ & $\alpha$ & $u_{c}$ \\
\hline \multicolumn{9}{|c|}{ SP-280 (Rodovia Castelo Branco) } \\
\hline 16,0 & Leste - Expresssa & Rodovia de pista dupla & Urbana & 72,1 & 2.261 & 513 & 1,20 & 59,2 \\
\hline 16.0 & Oeste - Expressa & Rodovia de pista dupla & Urbana & 79,3 & 1.810 & 8 & 1,00 & 69,6 \\
\hline 16,0 & Leste - Marginal & Rodovia de pista dupla & Urbana & 93,7 & 1.904 & 599 & 1,09 & 73,2 \\
\hline 16,0 & Oeste - Marginal & Rodovia de pista dupla & Urbana & 102,9 & 2.178 & 124 & 1,03 & 83,8 \\
\hline 22,4 & Leste - Expresssa & Autoestrada & Urbana & 105,9 & 2.104 & 48 & 1,56 & 80,9 \\
\hline 22,4 & Oeste - Expressa & Autoestrada & Urbana & 105,2 & 2.196 & 42 & 1,01 & 89,6 \\
\hline 22,4 & Leste - Marginal & Autoestrada & Urbana & 100,7 & 2.062 & 62 & 1,26 & 79,3 \\
\hline 22,4 & Oeste - Marginal & Autoestrada & Urbana & 110,8 & 2.112 & 8 & 1,45 & 77,0 \\
\hline 29,5 & Leste & Autoestrada & Urbana & 100,8 & 2.061 & 244 & 1,38 & 85,8 \\
\hline 29,5 & Oeste & Autoestrada & Urbana & 114,6 & 2.191 & 67 & 1,28 & 95,9 \\
\hline 37,0 & Leste & Rodovia de pista dupla & Rural & 115,1 & 1.914 & 873 & 1,05 & 105,0 \\
\hline 37,0 & Oeste & Rodovia de pista dupla & Rural & 111,7 & 2.050 & 479 & 1,51 & 93,2 \\
\hline 51,9 & Leste & Rodovia de pista dupla & Rural & 109,6 & 2.030 & 377 & 1,24 & 95,7 \\
\hline 51,9 & Oeste & Rodovia de pista dupla & Rural & 110,1 & 2.134 & 260 & 2,16 & 97,0 \\
\hline 59,6 & Leste & Rodovia de pista dupla & Rural & 119,9 & 2.282 & 594 & 1,30 & 100,3 \\
\hline 59,6 & Oeste & Rodovia de pista dupla & Rural & 116,4 & 2.193 & 507 & 2,12 & 99,7 \\
\hline 75,9 & Leste & Rodovia de pista dupla & Rural & 103,1 & 2.190 & 540 & 1,37 & 85,3 \\
\hline 75,9 & Oeste & Rodovia de pista dupla & Rural & 116,5 & 2.273 & 43 & 1,59 & 103,3 \\
\hline \multicolumn{9}{|c|}{ SP-348 (Rodovia dos Bandeirantes) } \\
\hline 32,0 & Norte & Autoestrada & Rural & 115,7 & 2.350 & 122 & 1,54 & 99,9 \\
\hline 32,0 & Sul & Autoestrada & Rural & 115,5 & 2.513 & 42 & 1,89 & 95,5 \\
\hline 50,0 & Norte & Autoestrada & Rural & 122,9 & 2.127 & 521 & 1,16 & 111,7 \\
\hline 50,0 & Sul & Autoestrada & Rural & 119,6 & 2.057 & 527 & 1,22 & 104,7 \\
\hline 65,0 & Norte & Autoestrada & Rural & 126,4 & 2.423 & 367 & 1,07 & 110,1 \\
\hline 65,0 & Sul & Autoestrada & Rural & 116,2 & 2.276 & 868 & 1,24 & 102,9 \\
\hline 87,0 & Norte & Autoestrada & Rural & 119,3 & 2.235 & 728 & 1,27 & 106,0 \\
\hline 87,0 & Sul & Autoestrada & Rural & 111,8 & 2.296 & 627 & 1,02 & 102,1 \\
\hline 131,7 & Norte & Autoestrada & Rural & 126,9 & 2.311 & 96 & 1,50 & 105,0 \\
\hline 131,7 & Sul & Autoestrada & Rural & 112,7 & 1.973 & 770 & 1,27 & 89,7 \\
\hline 149,6 & Norte & Autoestrada & Rural & 120,1 & 2.144 & 101 & 2,02 & 97,4 \\
\hline 149,6 & Sul & Autoestrada & Rural & 110,9 & 1.967 & 460 & 1,42 & 89,4 \\
\hline \multicolumn{9}{|c|}{ SP-021 (Rodoanel) } \\
\hline 18,3 & Norte (Externo) & Rodovia de pista dupla & Urbana & 101,9 & 2.216 & 223 & 1,65 & 80,5 \\
\hline 22,3 & Sul (Interna) & Rodovia de pista dupla & Urbana & 98,7 & 2.340 & 113 & 1,72 & 81,6 \\
\hline \multicolumn{9}{|c|}{ SP-270 (Raposo Tavares) } \\
\hline 39,9 & Leste & Rodovia de pista dupla & Urbana & 81,9 & 1.742 & 704 & 1,02 & 67,0 \\
\hline 39,9 & Oeste & Rodovia de pista dupla & Urbana & 85,8 & 1.659 & 43 & 1,96 & 63,8 \\
\hline
\end{tabular}

Tabela 5.3 - Configuração de Monte Carlo via cadeias de Markov

\begin{tabular}{lccc}
\hline \multicolumn{4}{c}{ MCMC } \\
\hline Configuração & Iterações & Burn in & Thin \\
\hline 1 & 20.000 & 0 & 0 \\
2 & 30.000 & 10.000 & 0 \\
3 & 50.000 & 30.000 & 0 \\
\hline
\end{tabular}



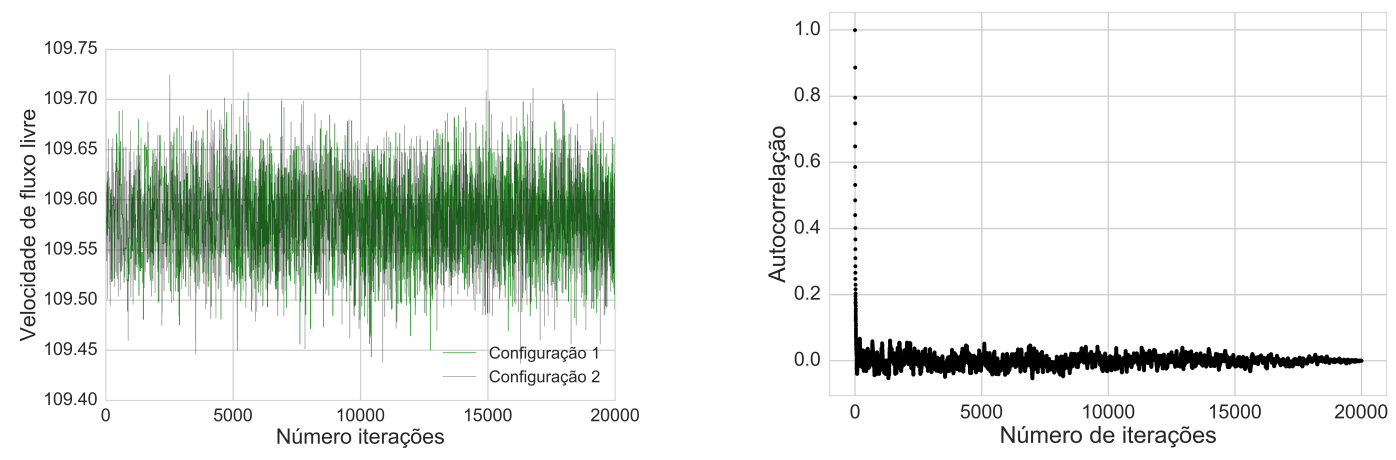

Figura 5.6 - Amostras e Autocorrelação de $u_{f}$
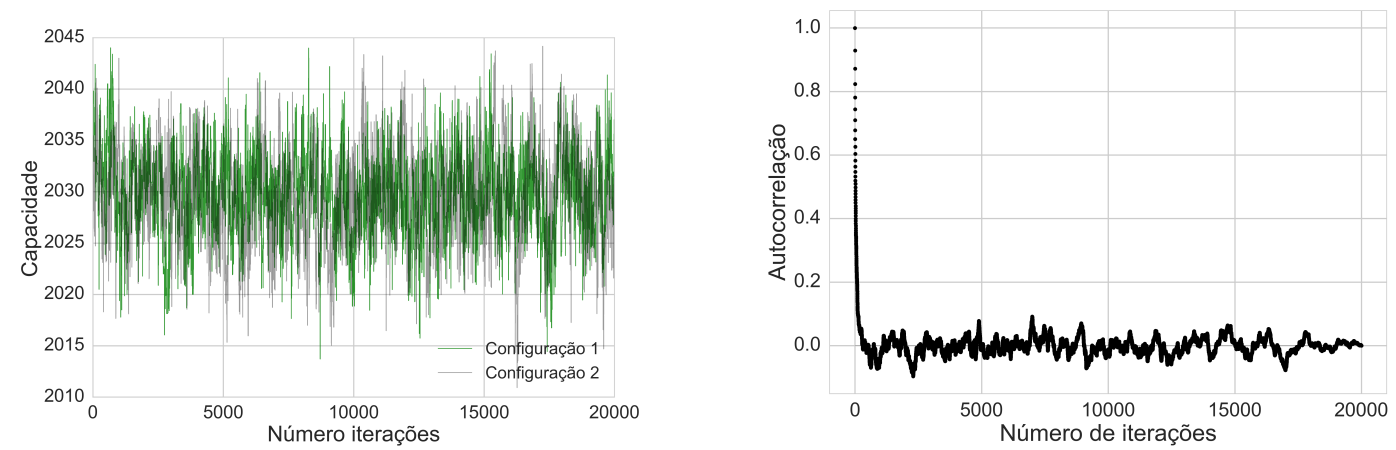

Figura 5.7 - Amostras e Autocorrelação de $q_{c}$
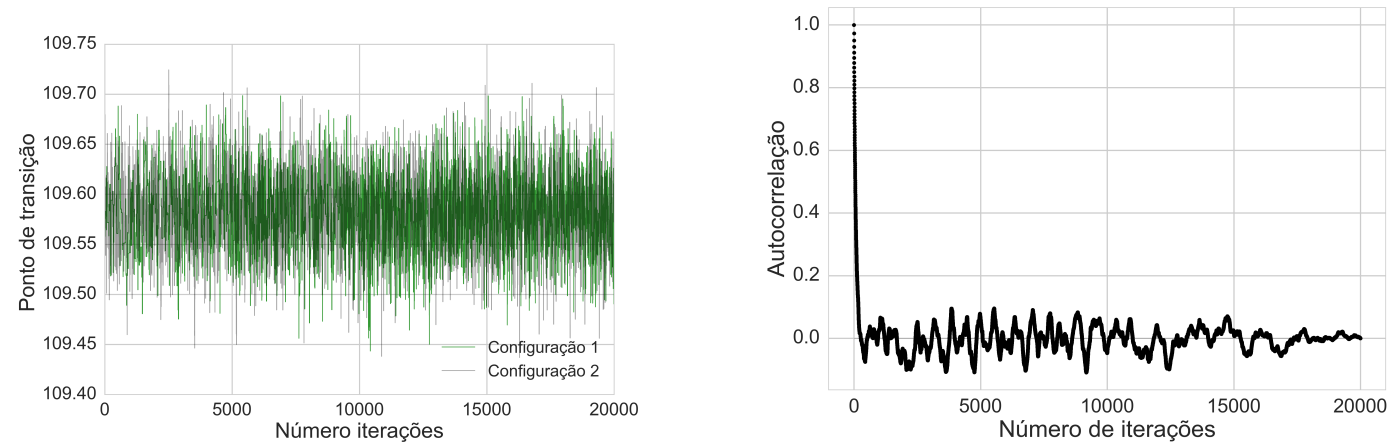

Figura 5.8 - Amostras e Autocorrelação de $b p$

convergência do processo. Com a diminuição da autocorrelação e o aumento do número de interações, a flutuação dos valores dos parâmetros varia em torno de uma região delimitada, o que aponta para uma convergência de MCMC. Ressalta-se que quanto maior a região delimitada, maior o intervalo de credibilidade do parâmetro, e quanto menor a região, menor o intervalo de credibilidade, o que graficamente é representado pela região entre os limites superior e inferior das curvas fluxo-velocidade estimadas pelo método proposto.

Além da análise gráfica, foi aplicado o teste de Gelman e Rubin, o qual fornece indícios da convergência do processo MCMC por meio de um método estatístico que se baseia na análise da variância entre a mesma cadeia e entre diferentes cadeias de MCMC. A Tabela B.1 apresenta os valores do teste para cada parâmetro estimado do modelo, o qual tem por base que um $\hat{R}$ 

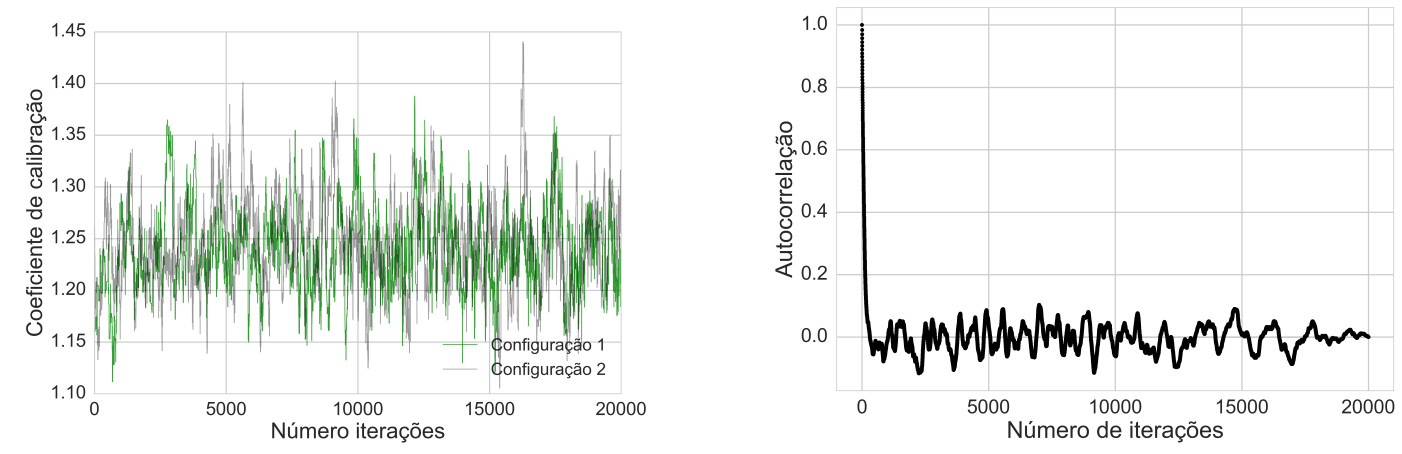

Figura 5.9 - Amostras e Autocorrelação de $\alpha$

menor que 1,1, corrobora com a convergência do processo MCMC.

A partir da análise descrita anteriormente, conclui-se que todos os parâmetros estimados apresentaram convergência. A Tabela C.2 lista o tipo da distribuição posterior para cada parâmetro do modelo, bem como o tempo de processamento para cada ponto de coleta utilizado na pesquisa.

\subsubsection{Comparação entre métodos}

A comparação entre os métodos consiste em uma análise dos valores dos parâmetros estimados pelo método proposto, HCM 2010 e Andrade (2012), juntamente com uma análise gráfica das curvas fluxo-velocidade. As Figuras 5.10 e 5.11 apresentam, respectivamente, as observações

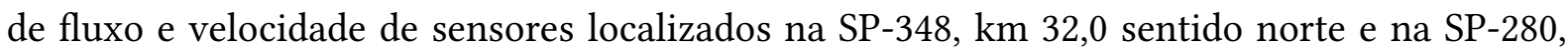
$\mathrm{km} 51,9$ sentido leste, que correspondem a trechos rurais de autoestrada e de rodovia de pista dupla.

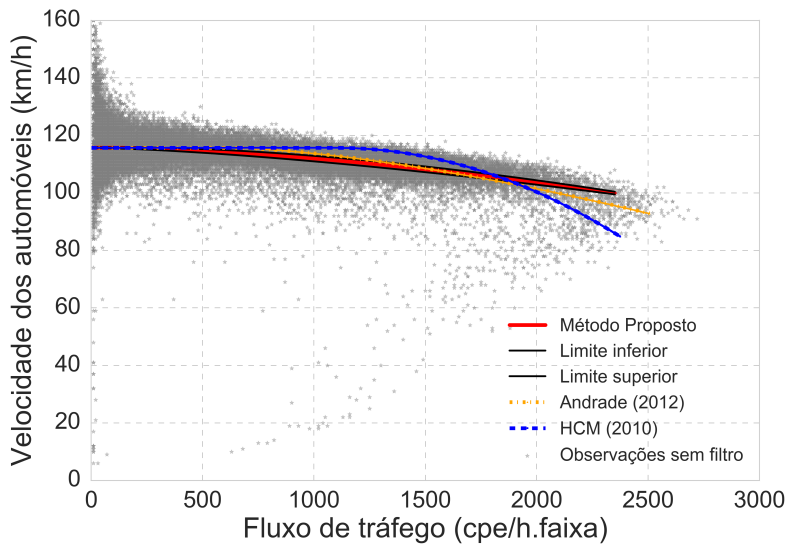

Figura 5.10 - Curva fluxo-velocidade para a SP-348, km 32,0 norte, obtidas com o modelo proposto, HCM 2010 e Andrade (2012)

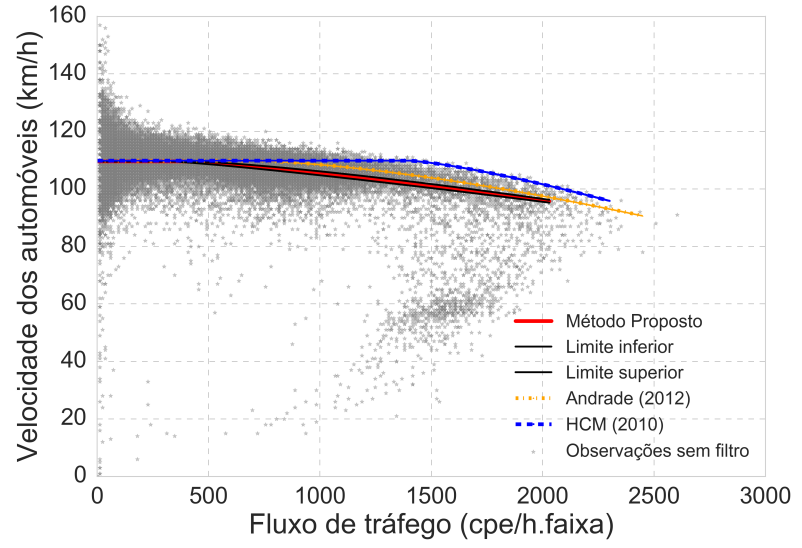

Figura 5.11 - Curva fluxo-velocidade para a SP-280, km 51,9 leste, obtidas com o modelo proposto, HCM 2010 e Andrade (2012)

Aliado às observações de fluxo e velocidade, os gráficos também apresentam as curvas fluxovelocidade obtidas, pelo método proposto, com suas respectivas regiões de credibilidade de 
95\%, e as curvas referentes ao HCM 2010 e Andrade (2012). Já as Figuras 5.12 e 5.13 apresentam as mesmas informações das figuras anteriores, contudo, para trechos urbanos de autoestrada e rodovia de pista dupla, localizados na SP-280, km 29,5 sentido leste e na SP-021, km 18,3 sentido norte, respectivamente. Além dos exemplos apresentados neste item, o Apêndice A mostra as curvas obtidas para as demais estações de coleta de dados de tráfego utilizados no trabalho.

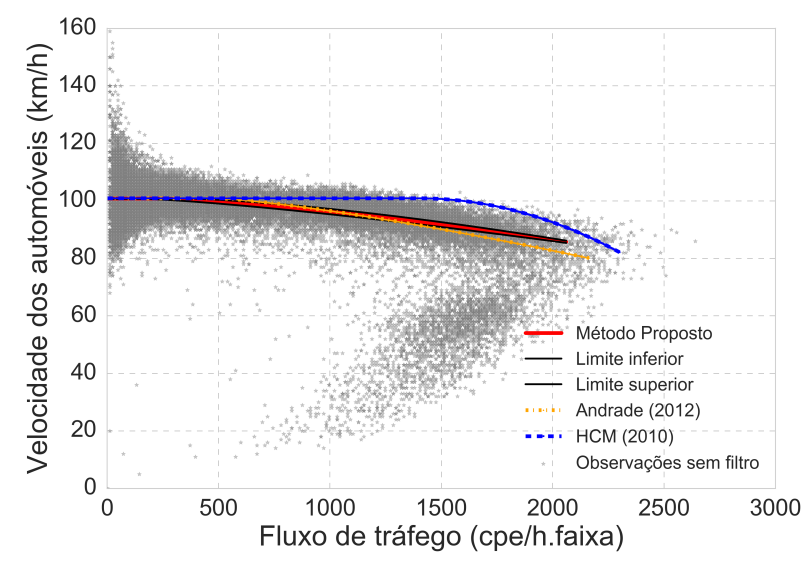

Figura 5.12 - Curva fluxo-velocidade para a SP-280, km 29,5 leste, obtidas com o modelo proposto, HCM 2010 e Andrade (2012)

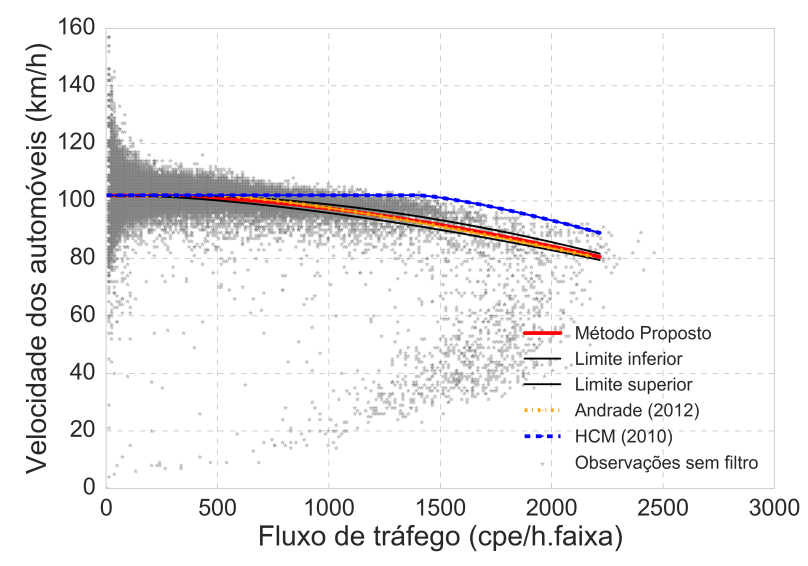

Figura 5.13 - Curva fluxo-velocidade para a SP-021, km 18,3 norte, obtidas com o modelo proposto, HCM 2010 e Andrade (2012)

No modelo de fluxo-velocidade do HCM para autoestradas e rodovias de pista dupla, as curvas são definidas em função da velocidade de fluxo livre $\left(u_{f}\right)$. Dessa forma, a estimação deste parâmetro se torna etapa fundamental para a calibração do modelo. Assim, neste trabalho, como em Andrade (2012), as curvas do HCM 2010 para cada ponto de coleta foram determinadas por meio da velocidade de fluxo livre da corrente de tráfego, a qual foi calculada por meio da média das velocidade médias observadas para intervalos de sucessivos, de 50 pce/(h.faixa) até 350 pce/(h.faixa). A Tabela 5.4 apresenta os valores dos parâmetros das curvas do HCM 2010 e Andrade (2012) para cada ponto em estudo na rodovia.

As Figuras 5.14, 5.15, 5.16, 5.17 e 5.18 apresentam os histogramas da diferença entre os valores estimados pelo método proposto e pelo HCM 2010 e Andrade (2012). Conforme se pode ver, os modelos são relativamente próximos entre si, sendo que as principais diferenças se encontram nos valores no ponto de transição, na capacidade, no coeficiente de calibração e na velocidade na capacidade. A velocidade de fluxo livre apresentou a menor diferença entre os valores estimados pelos métodos, sendo praticamente nula.

\subsubsection{Análise de erros}

A Tabela 5.5 apresenta a estatística descritiva associada ao erro quadrático médio entre a velocidade observada e a estimada para os dados utilizados na calibração. Nela, observa-se que o método proposto apresenta o menor valor médio de erro, com reduções, respectivamente, 
Tabela 5.4 - Valores estimados com HCM 2010 e Andrade (2012) para cada trecho

\begin{tabular}{|c|c|c|c|c|c|c|c|c|c|c|c|c|}
\hline \multirow[t]{2}{*}{$\mathrm{km}$} & \multirow[t]{2}{*}{ Sentido } & \multirow[t]{2}{*}{ Tipo de via } & \multirow{2}{*}{$\begin{array}{l}\text { Ocupação } \\
\text { lindeira }\end{array}$} & \multirow[t]{2}{*}{$u_{f}$} & \multicolumn{4}{|c|}{ HCM 2010} & \multicolumn{4}{|c|}{ Andrade (2012) } \\
\hline & & & & & $q_{c}$ & $b p$ & $\alpha$ & $u_{c}$ & $q_{c}$ & $b p$ & $\alpha$ & $u_{c}$ \\
\hline \multicolumn{13}{|c|}{ SP-280 (Rodovia Castelo Branco) } \\
\hline 16,0 & Leste - Expresssa & Rodovia de pista dupla & Urbana & 72,2 & 1.920 & 1.400 & 1,31 & 68,6 & 1.733 & 500 & 1,30 & 64,2 \\
\hline 16,0 & Oeste - Expressa & Rodovia de pista dupla & Urbana & 78,3 & 1.980 & 1.400 & 1,31 & 73,3 & 1.824 & 500 & 1,30 & 67,6 \\
\hline 16,0 & Leste - Marginal & Rodovia de pista dupla & Urbana & 93,4 & 2.130 & 1.400 & 1,31 & 81,0 & 2.052 & 500 & 1,30 & 76,0 \\
\hline 16,0 & Oeste - Marginal & Rodovia de pista dupla & Urbana & 102,3 & 2.220 & 1.400 & 1,31 & 88,8 & 2.185 & 500 & 1,30 & 80,9 \\
\hline 22,4 & Leste - Expresssa & Autoestrada & Urbana & 105,5 & 2.325 & 1.300 & 2,00 & 83,0 & 2.233 & 500 & 1,31 & 82,7 \\
\hline 22,4 & Oeste - Expressa & Autoestrada & Urbana & 104,1 & 2.320 & 1.320 & 2,00 & 82,9 & 2.211 & 500 & 1,31 & 81,9 \\
\hline 22,4 & Leste - Marginal & Autoestrada & Urbana & 100,0 & 2.300 & 1.400 & 2,00 & 82,1 & 2.150 & 500 & 1,31 & 79,6 \\
\hline 22,4 & Oeste - Marginal & Autoestrada & Urbana & 109,4 & 2.350 & 1.200 & 2,00 & 83,9 & 2.290 & 500 & 1,31 & 84,8 \\
\hline 29.5 & Leste & Autoestrada & Urbana & 100,9 & 2.300 & 1.400 & 2,00 & 82,1 & 2.164 & 500 & 1,31 & 80,1 \\
\hline 29,5 & Oeste & Autoestrada & Urbana & 114,1 & 2.370 & 1.120 & 2,00 & 84,6 & 2.361 & 500 & 1,31 & 87,5 \\
\hline 37,0 & Leste & Rodovia de pista dupla & Rural & 114,8 & 2.350 & 1.400 & 1,31 & 97,9 & 2.498 & 652 & 1,50 & 92,5 \\
\hline 37,0 & Oeste & Rodovia de pista dupla & Rural & 111,7 & 2.310 & 1.400 & 1,31 & 96,3 & 2.467 & 683 & 1,50 & 91,4 \\
\hline 51,9 & Leste & Rodovia de pista dupla & Rural & 109,8 & 2.300 & 1.400 & 1,31 & 95,8 & 2.448 & 702 & 1.50 & 90,7 \\
\hline 51,9 & Oeste & Rodovia de pista dupla & Rural & 110,2 & 2.300 & 1.400 & 1,31 & 95,8 & 2.452 & 698 & 1,50 & 90,8 \\
\hline 59,6 & Leste & Rodovia de pista dupla & Rural & 120,0 & 2.400 & 1.400 & 1,31 & 100,0 & 2550 & 600 & 1,50 & 94,4 \\
\hline 59,6 & Oeste & Rodovia de pista dupla & Rural & 116,3 & 2.360 & 1.400 & 1,31 & 98,3 & 2.513 & 637 & 1,50 & 93,1 \\
\hline 75,9 & Leste & Rodovia de pista dupla & Rural & 103,1 & 2.230 & 1.400 & 1,31 & 89,2 & 2.381 & 769 & 1,50 & 88,2 \\
\hline 75,9 & Oeste & Rodovia de pista dupla & Rural & 116,4 & 2.360 & 1.400 & 1,31 & 98,3 & 2.514 & 636 & 1,50 & 93,1 \\
\hline \multicolumn{13}{|c|}{ SP-348 (Rodovia dos Bandeirantes) } \\
\hline 32,0 & Norte & Autoestrada & Rural & 115,7 & 2.375 & 1.100 & 2,00 & 84,8 & 2.507 & 643 & 1,50 & 92,8 \\
\hline 32,0 & Sul & Autoestrada & Rural & 115,6 & 2.375 & 1.100 & 2,00 & 84,8 & 2.506 & 645 & 1,50 & 92,8 \\
\hline 50,0 & Norte & Autoestrada & Rural & 123.1 & 2.415 & 940 & 2,00 & 86,0 & 2.581 & 569 & 1,50 & 95,6 \\
\hline 50,0 & Sul & Autoestrada & Rural & 119.7 & 2.400 & 1.000 & 2,00 & 85,7 & 2.547 & 603 & 1,50 & 94,3 \\
\hline 65,0 & Norte & Autoestrada & Rural & 126.7 & 2.430 & 880 & 2,00 & 86,8 & 2.617 & 533 & 1,50 & 96,9 \\
\hline 65,0 & Sul & Autoestrada & Rural & 115.7 & 2.375 & 1.100 & 2,00 & 84,8 & 2.507 & 643 & 1,50 & 92,8 \\
\hline 87,0 & Norte & Autoestrada & Rural & 119.2 & 2.400 & 1.100 & 2,00 & 85,7 & 2.542 & 608 & 1,50 & 94,1 \\
\hline 87,0 & Sul & Autoestrada & Rural & 111.8 & 2.355 & 1.180 & 2,00 & 84,1 & 2.468 & 682 & 1,50 & 91,4 \\
\hline 131,7 & Norte & Autoestrada & Rural & 126.6 & 2.430 & 880 & 2,00 & 86,7 & 2.616 & 534 & 1,50 & 96,9 \\
\hline 131,7 & Sul & Autoestrada & Rural & 112.7 & 2.360 & 1.160 & 2,00 & 84,3 & 2.477 & 673 & 1,50 & 91,7 \\
\hline 149,6 & Norte & Autoestrada & Rural & 120.0 & 2.400 & 1.100 & 2,00 & 85,7 & 2.550 & 600 & 1,50 & 94,5 \\
\hline 149,6 & Sul & Autoestrada & Rural & 111.5 & 2.355 & 1.180 & 2,00 & 84,1 & 2.465 & 685 & 1,50 & 91,3 \\
\hline \multicolumn{13}{|c|}{ SP-021 (Rodoanel) } \\
\hline 18,3 & Norte & Rodovia de pista dupla & Urbana & 102,0 & 2.220 & 1.400 & 1,31 & 88,8 & 2.180 & 500 & 1,30 & 80,7 \\
\hline 22,3 & Sul & Rodovia de pista dupla & Urbana & 98.6 & 2.180 & 1.400 & 1,31 & 87,2 & 2.129 & 500 & 1,30 & 78,8 \\
\hline \multicolumn{13}{|c|}{ SP-270 (Raposo Tavares) } \\
\hline 39,9 & Leste & Rodovia de pista dupla & Urbana & 81,9 & 2.020 & 1.400 & 1,31 & 74,8 & 1.879 & 500 & 1,30 & 69,6 \\
\hline 39,9 & Oeste & Rodovia de pista dupla & Urbana & 85,6 & 2.050 & 1.400 & 1,31 & 78,8 & 1.933 & 500 & 1,30 & 71,6 \\
\hline
\end{tabular}

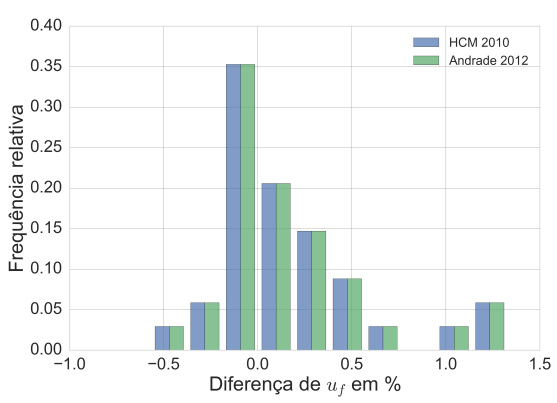

Figura 5.14 - Diferença dos valores estimados para velocidade de fluxo livre pelo método proposto e por HCM 2010 e Andrade (2012)

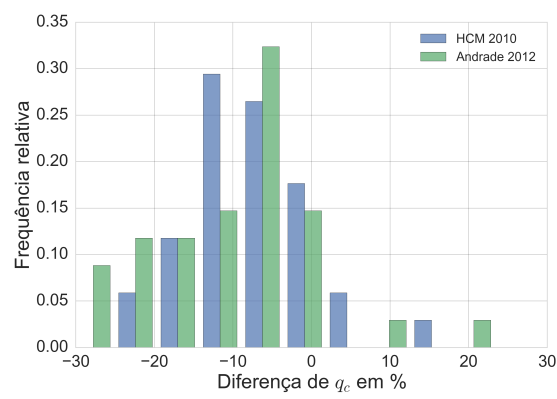

Figura 5.15 - Diferença dos valores estimados para capacidade pelo método proposto e por HCM 2010 e Andrade (2012) 


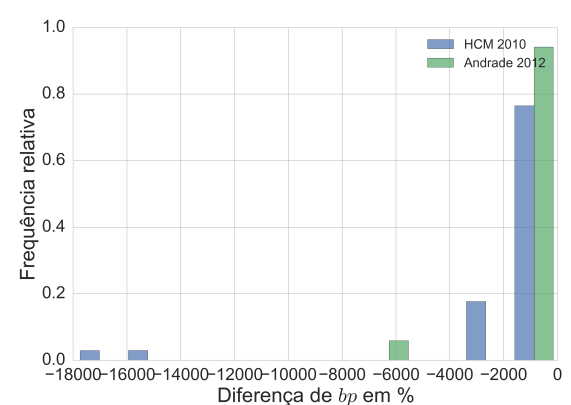

Figura 5.16 - Diferença dos valores estimados para ponto de transição pelo método proposto e por HCM 2010 e Andrade (2012)

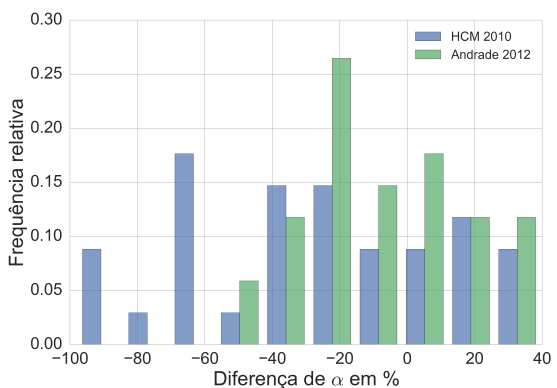

Figura 5.17 - Diferença dos valores estimados para coeficiente de calibração pelo método proposto e por HCM 2010 e Andrade (2012)

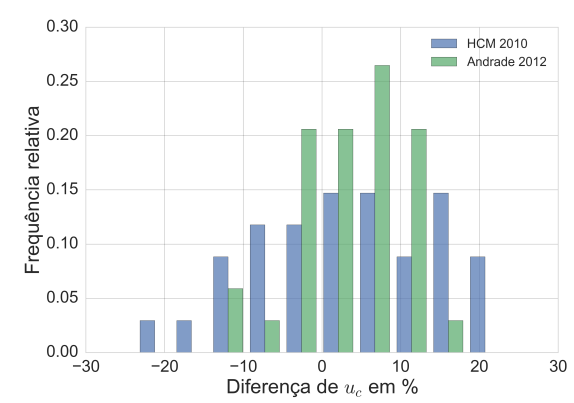

Figura 5.18 - Diferença dos valores estimados para velocidade na capacidade pelo método proposto e por HCM 2010 e Andrade (2012)

de 10,2\% e 4,6\% em relação ao HCM 2010 e Andrade (2012). Já as Figuras 5.19, 5.20 e 5.21 apresentam os histogramas do erro quadrático médio e mostram uma concentração dos erros mais próximos ao zero para o método proposto, seguido por Andrade (2012) e HCM 2010.

Tabela 5.5 - Análise descritiva do erro quadrático médio

\begin{tabular}{lccc}
\hline & Método Proposto & HCM 2010 & Andrade (2012) \\
\hline Observações & 34,00 & 34,00 & 34,00 \\
Média & 48,14 & 53,63 & 50,48 \\
Desvio Padrão & 27,34 & 29,16 & 27,88 \\
Min & 14,24 & 20,17 & 14,37 \\
$25 \%$ & 31,63 & 35,99 & 32,95 \\
$50 \%$ & 41,62 & 48,56 & 45,51 \\
$75 \%$ & 54,00 & 59,18 & 59,59 \\
Max & 141,48 & 147,02 & 141,94 \\
\hline
\end{tabular}

\subsubsection{Calibração simultânea}

Este item aborda a análise do método proposto de calibração da relação fluxo-velocidade do modelo do HCM por meio de uma calibração conjunta, ou seja, em que vários sensores são utilizados ao mesmo tempo. A justificativa por essa abordagem consiste em verificar a ade- 


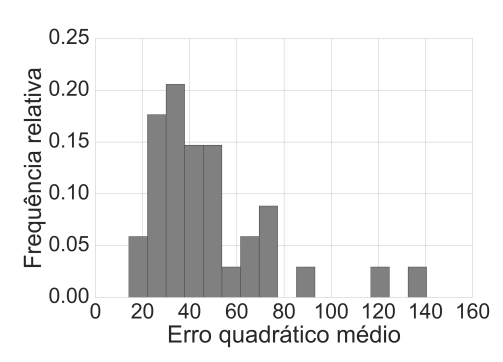

Figura 5.19 - Erro quadrático médio para método proposto

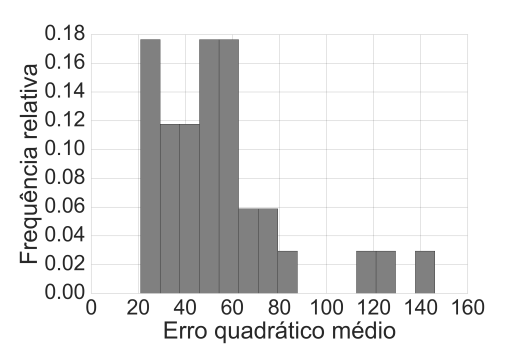

Figura 5.20 - Erro quadrático médio para HCM 2010

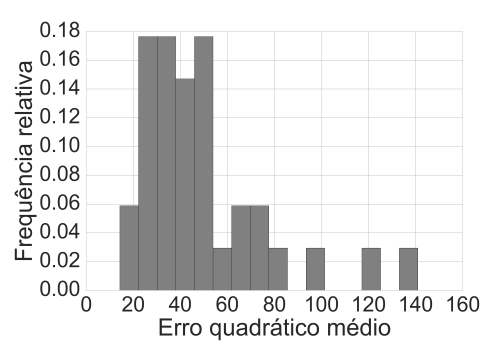

Figura 5.21 - Erro quadrático médio para Andrade (2012)

quabilidade do método proposto para um conjunto de dados distribuídos espacialmente, bem como a influência desses dados na estimação dos parâmetros.

Dessa forma, replicou-se todas as considerações descritas no desenvolvimento do trabalho. Para a calibração foram utilizados 8 sensores em conjunto da SP-280 classificados como rodovias rurais. A densidade na capacidade estimada corresponde a $28 \mathrm{cpe} /(\mathrm{km} . f a i x a)$. As Figuras 5.22 e 5.23 mostram, respectivamente, as observações de velocidade e taxa de fluxo dos dados brutos e após tratamento.

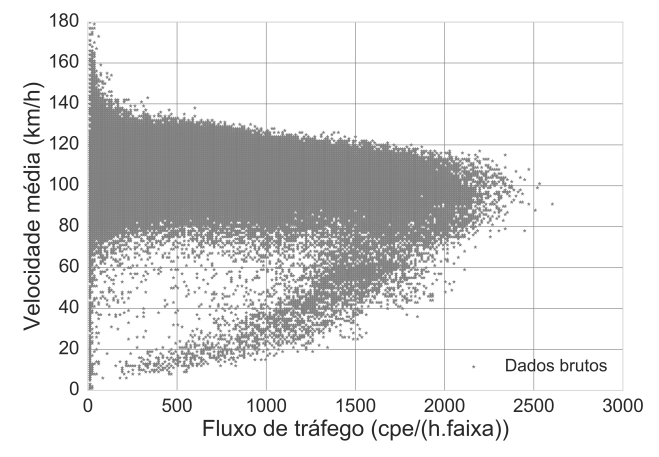

Figura 5.22 - Observações de velocidade e taxa de fluxo dos dados brutos para conjunto de sensores

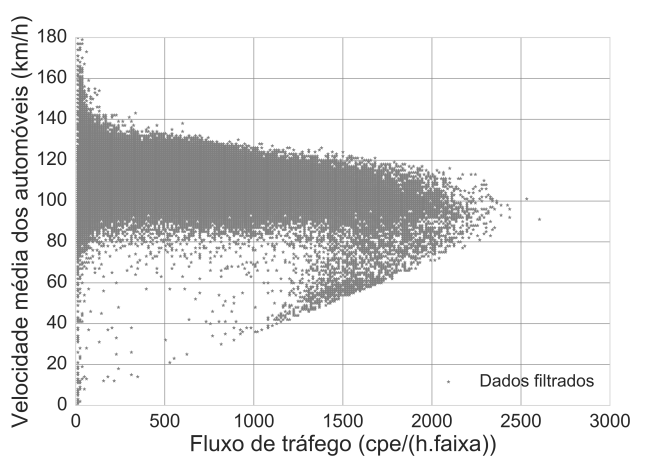

Figura 5.23 - Observações de velocidade e taxa de fluxo após tratamento para conjunto de sensores

A Figura 5.24 apresenta as observações de fluxo e velocidade bem como as curva fluxovelocidade obtidas, pelo método proposto, com sua respectiva região de credibilidade de $95 \%$, e as curvas referentes ao HCM 2010 e Andrade (2012). Assim como no item 5.3.1, verificou-se a convergência MCMC, por meio da análise da autocorrelação e da variação dos valores das amostras. Conclui-se que todos os parâmetros estimados apresentam convergência. Como pode ser observado, o método de calibração que utiliza vários sensores ao mesmo tempo apresenta uma curva coerente com o formato esperado pelo HCM.

Destaca-se a diferença entre os valores obtidos para a densidade na capacidade pela calibração em conjunto e pela média das densidades obtidas pela calibração de cada sensor individualmente. Para os 8 sensores utilizados na calibração em conjunto obteve-se 28 cpe/(km.faixa), 


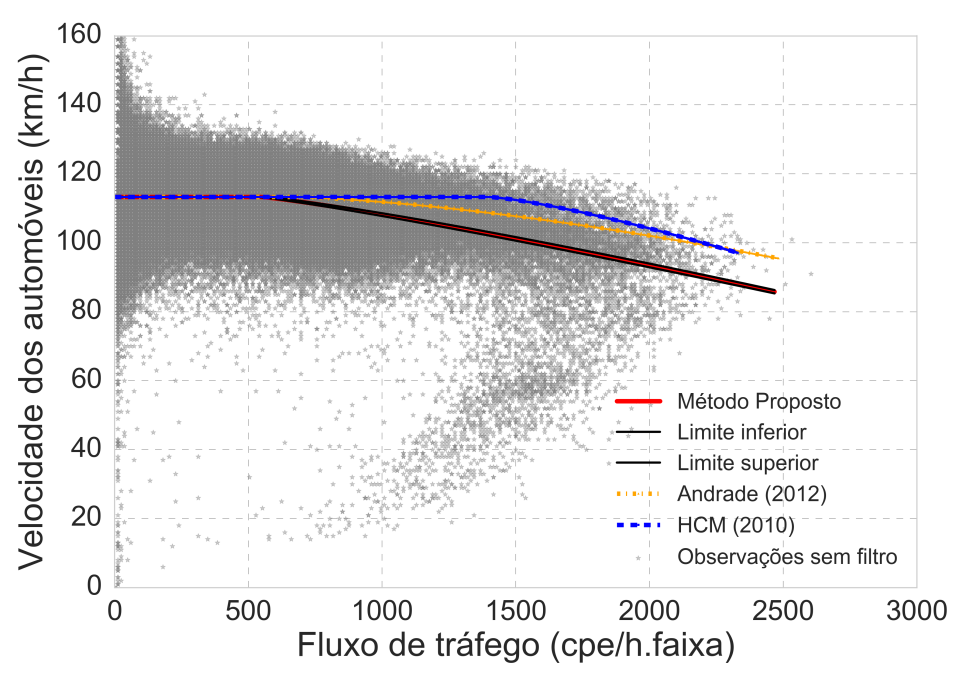

Figura 5.24 - Curva fluxo-velocidade obtidas com o modelo proposto com calibração com vários sensores ao mesmo tempo, HCM 2010 e Andrade (2012)

enquanto que pela média obteve-se $22 \mathrm{cpe} /(\mathrm{km}$.faixa). A diferença entre tais valores pode ser explicada pela quantidade de dados e sua influência na detecção na capacidade da rodovia e do sistema. Nesse caso, a capacidade estimada para a calibração em conjunto foi de 2.500 veic/h, enquanto que a capacidade individual para cada sensor, variou de $1.916 \mathrm{cpe} /(\mathrm{h}$. faixa) a $2.352 \mathrm{cpe} /($ h.faixa)

\subsection{Considerações Finais}

Este capítulo aborda a calibração das curvas fluxo-velocidade do modelo do HCM para autoestradas e rodovias pista dupla. Para tanto, o modelo fluxo-velocidade é detalhado, bem como as considerações necessárias para sua calibração.

O método proposto de calibração é estruturado na Inferência Bayesiana e consiste na definição de um conjunto de etapas. Primeiramente é definido um banco de dados de tráfego adequado, obtido por meio de um tratamento dos dados brutos que tem por objetivo remover observações inadequadas via a aplicação de três critérios, veículos leves, condições de operação normal e fluxo livre, descritos no Capítulo 3.

Em seguida, os trechos de rodovias são classificados segundo sua ocupação lindeira, em urbano e rural, diferentemente do HCM que preconiza uma divisão em autoestradas e rodovias de pista dupla, mas que conforme indicado em Andrade (2012), não se aplica as rodovias do Estado de São Paulo, uma vez que estas apresentam características físicas e operacionais distintas das rodovias norte-americanas. A partir de então, nos trechos em que a capacidade é atingida, utiliza-se a densidade calculada no local pelo método descrito no Capítulo 4. Já para os trechos em que a capacidade não é atingida, utiliza-se a média da densidade das rodovias classificadas em urbana e rural.

Em seguida, a estrutura da Inferência Bayesiana é definida. Nas distribuições a priori dos 
parâmetros do modelo utilizou-se uma distribuição uniforme, enquanto que a função de verossimilhança foi determinada como uma distribuição normal da velocidade média da corrente de tráfego. Para a estimação da distribuição posterior dos parâmetros, utilizou-se o MCMC.

Como resultados, foram obtidos os valores dos parâmetros do modelo pelo método proposto para cada trecho abordado, bem como os gráficos das curvas fluxo-velocidade. Para rodovias rurais, todos os parâmetros do modelo fluxo-velocidade tendem a ser maiores em relação a rodovias urbanas, exceto pela densidade na capacidade.

Já como análise dos resultados, foram comparados os valores dos parâmetros e dos gráficos obtidos pelo método proposto com HCM 2010 e Andrade (2012). Destaca-se o ponto de transição que apresenta valores muito abaixo em relação a literatura, sendo que em alguns casos chega a estar próximo de zero, o que sugere que a existência do patamar em que a velocidade de fluxo livre se mantém constante pode ser menor do que espera, ou até mesmo, inexistente. 


\section{Capítulo}

\section{Conclusões e sugestões}

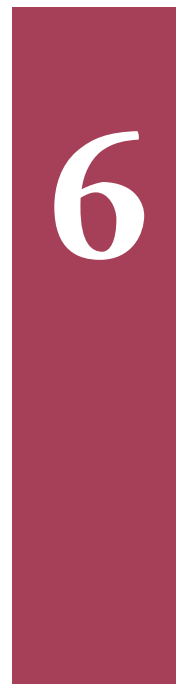

Este estudo apresentou um método de calibração da relação fluxo-velocidade do modelo do HCM para autoestradas e rodovias de pista dupla, a partir de dados empíricos. Para atingir esta meta, foram definidos os seguintes objetivos específicos:

- Obter e tratar um conjunto de dados de tráfego adequado para o estudo;

- Propor um modelo para estimação da capacidade de uma via, bem como a velocidade e a densidade na capacidade; e

- Calibrar os parâmetros do modelo de fluxo-velocidade do HCM.

A meta e os objetivos propostos para esta pesquisa foram atingidos, uma vez que os três objetivos propostos foram alcançados. A seguir são apresentadas as conclusões obtidas para cada objetivo proposto.

\subsection{Conclusões}

A revisão da literatura sobre os temas abordados no trabalho mostrou que não existe um consenso sobre a modelagem matemática ideal para descrever a relação fluxo-velocidade em autoestradas e rodovias de pista dupla, bem como a forma de calibração. No HCM, as curvas fluxovelocidade são oriundas de dados empíricos, obtidos em trechos de rodovias norte-americanas com condições previamente determinadas, denominadas de condições padrão. Neste trabalho, decidiu-se por manter uma estrutura similar à do HCM com relação aos tipos de dados e ao modelo de fluxo de tráfego. 
Quanto ao primeiro objetivo, obter e tratar um conjunto de dados de tráfego adequado para o estudo da relação fluxo-velocidade em rodovias paulistas, uma extensa análise de dados de tráfego foi realizada para verificar a adequabilidade dos dados disponíveis para a investigação do tema proposto. Para tanto, questões como nível de agregação dos dados, período de abrangência, tamanho da amostra, condições físicas e operacionais dos trechos e formas de tratamento foram abordadas.

Os dados de tráfego utilizados consistem em 1.730.216 observações, em intervalos de cinco e seis minutos, de um conjunto de 3.373.056 de dados brutos distribuídos no período de um ano, em um total 34 de sensores de tráfego disponibilizados em quatro rodovias do Estado de São Paulo. Já os dados geométricos consistem em informações referentes às características físicas e operacionais das rodovias.

O tratamento do banco de dados foi realizado por meio da aplicação de três critérios que apresentam como objetivo remover informações consideradas inadequadas, segundo o HCM. Tais critérios englobam: corrente de tráfego composta somente por veículos leves; condições de operação normal; e regime de fluxo livre. Para uma corrente de tráfego ser composta somente por veículos leves, optou-se por utilizar a faixa da esquerda, uma vez que apresenta a menor porcentagem de veículos pesados, e por remover observações que apresentavam qualquer porcentagem de veículos pesados. A remoção das observações com presença de veículos pesados se deve à baixa incidência desta categoria na faixa da esquerda, sendo que sua remoção não altera significativamente o tamanho das amostras.

Já o segundo objetivo, propor um modelo para estimação da capacidade de uma via, bem como a velocidade e a densidade na capacidade, relaciona-se com a estimação de parâmetros notáveis na Engenharia de Tráfego. A necessidade da estimação dos parâmetros relacionados a capacidade de uma via está diretamente associada com as considerações para a utilização do modelo fluxo-velocidade do HCM para autoestradas e rodovias de pista dupla, que consiste em um modelo fluxo-velocidade estruturado somente para a região de fluxo livre da corrente de tráfego. A partir de então, optou-se por utilizar a densidade na capacidade como critério de separação entre os regimes de fluxo livre e congestionado. A importância dos parâmetros notáveis relacionados a capacidade é destacada na modelagem matemática do HCM, a qual possui um segmento ancorado na densidade na capacidade, conforme observado no Capítulo 5.

Dessa forma, foi proposto um modelo para a estimação da capacidade de uma via, bem como a velocidade e a densidade na capacidade. O método de estimação parte do pressuposto de que o colapso da corrente de tráfego e a capacidade apresentam natureza estocástica, sendo a capacidade estimada por meio da relação entre a variação da velocidade média da corrente de tráfego e o volume de tráfego.

O método parte do pressuposto de que para um determinado fluxo de tráfego, a relação entre a variação da velocidade média da corrente e o volume de tráfego muda de comportamento de forma abrupta, o que corresponde ao colapso da corrente de tráfego. O momento em que 
ocorre a mudança de comportamento é associado à capacidade da rodovia. Para tanto utiliza-se dos conceitos da Inferência Bayesiana.

Após a determinação da capacidade, a velocidade na capacidade foi calculada por meio da média das velocidades associadas ao fluxo na capacidade, enquanto que a densidade na capacidade foi obtida via a relação fundamental de tráfego. Os resultados obtidos para os dezoito pontos de rodovia analisados que atingem a capacidade consistem com valores descritos na literatura, o que sugere um bom funcionamento do método proposto.

Quanto ao terceiro objetivo de calibrar os parâmetros do modelo fluxo-velocidade do HCM, diversas conclusões podem ser tecidas, tanto nas considerações adotadas para a elaboração do trabalho, quanto nos resultados obtidos. Primeiramente, a divisão das rodovias segundo a ocupação lindeira, em rural e urbana, ao invés de autoestradas e rodovias de pista dupla, para rodovias do Estado de São Paulo. Nesse caso, conforme sugerido por Andrade (2012) e evidenciado nos resultados da calibração dos parâmetros do modelo fluxo-velocidade, as rodovias paulistas sofrem maior influência da ocupação lindeira do que do tipo de rodovias, o que pode ser explicado pelo tipo de acesso as rodovias paulistas. Para rodovias rurais, a velocidade de fluxo livre, a capacidade, a velocidade na capacidade, o ponto de transição e o coeficiente de calibração tendem a ser na média maiores em relação as rodovias urbanas, conforme a Tabela 6.1 .

Tabela 6.1 - Análise descritiva por tipo de ocupação lindeira

\begin{tabular}{lccccc|cccccc}
\hline & \multicolumn{1}{c|}{ Ocupação Lindeira } \\
\cline { 2 - 12 } & \multicolumn{9}{c}{ Rural } & \multicolumn{5}{c}{ Urbana } \\
\cline { 2 - 12 } & $u_{f}$ & $q_{c}$ & $b p$ & $\alpha$ & $u_{c}$ & $u_{f}$ & $q_{c}$ & $b p$ & $\alpha$ & $u_{c}$ \\
\cline { 2 - 12 } Observações & 20 & 20 & 20 & 20 & 20 & 14 & 14 & 14 & 14 & 14 \\
Média & 116,0 & 2.187 & 445 & 1,45 & 99,7 & 96,7 & 2.060 & 200 & 1,33 & 77,7 \\
Desvio Padrão & 5,8 & 159 & 266 & 0,35 & 6,9 & 12,5 & 205 & 234 & 0,30 & 10,2 \\
Min & 103,1 & 1.914 & 42 & 1,02 & 85,3 & 72,1 & 1.659 & 8 & 1,00 & 59,2 \\
$25 \%$ & 11,8 & 2.055 & 226 & 1,24 & 95,6 & 87,8 & 1.944 & 45 & 1,05 & 70,5 \\
$50 \%$ & 116,0 & 2.192 & 493 & 1,33 & 100,1 & 100,7 & 2.108 & 90 & 1,27 & 79,9 \\
$75 \%$ & 119,7 & 2.286 & 602 & 1,55 & 104,8 & 104,6 & 2.195 & 239 & 1,54 & 83,2 \\
Max & 126.9 & 2.513 & 873 & 2,16 & 111,7 & 114,6 & 2.340 & 704 & 1,96 & 95,9 \\
\hline
\end{tabular}

Para avaliar o método de calibração proposto, os parâmetros do modelo fluxo-velocidade do HCM para autoestradas e rodovias de pista dupla foram comparados com os obtidos pelos métodos do HCM 2010 e de Andrade (2012). A velocidade de fluxo livre obtida pelo método proposto apresenta valores similares aos métodos abordados e, portanto, é considerada bem definida. Já o fluxo na capacidade apresenta em média valores menores em relação ao HCM 2010 e a Andrade (2012).

O coeficiente de calibração obtido pelo método proposto compreende uma gama de valores entre 1 e 2,16, enquanto que os métodos utilizados para comparação apresentam somente dois 
valores, que variam de acordo com o tipo de classificação da rodovia. Com relação ao ponto de transição, este apresenta valores muito abaixo dos obtidos pelo HCM 2010 e por Andrade (2012), sendo que em alguns casos chega a estar próximo de zero, o que sugere que a existência do patamar em que a velocidade de fluxo livre se mantém constante pode ser bem menor do que se espera, ou até mesmo, inexistente.

Ressalta a importância da calibração do modelo HCM para condições locais, sendo que a não realização pode acarretar em problemas sistêmicos, como a estimação errônea de nível de serviço. Tais problemas estão atrelados as significativas diferenças encontradas nos valores dos parâmetros obtidos tanto pelo método proposto, quanto por Andrade (2012), para as condições das rodovias paulistas.

Outro fato a ser destacado, consiste na forma de calibração dos métodos abordados no trabalho. Enquanto as curvas fluxo-velocidade do HCM 2010 foram obtidas a partir do agrupamento de curvas calibradas individualmente com velocidade de fluxo livre próxima entre si, Andrade (2012) utilizou uma abordagem de calibração que utiliza simultaneamente todos os dados disponíveis. Já no método proposto, a calibração é realizada individualmente para cada trecho de rodovia.

Por fim, salienta-se que a estimação de parâmetros por meio da Inferência Bayesiana gera uma distribuição posterior desses parâmetros, ou seja, uma distribuição de probabilidade de ocorrência, o que permite um compreendimento melhor do fenômeno em questão.

\subsection{Sugestões de trabalhos futuros}

A partir do desenvolvimento deste trabalho, algumas sugestões para trabalhos futuros são apresentadas. Primeiramente, sugere-se explorar o método de estimação da capacidade para outras configurações de rodovias, como túneis e pontes, bem como para outras localidades, como por exemplo, rodovias norte-americanas. Aliada a utilização do método para outras configurações, recomenda-se compará-lo com outros métodos consagrados na literatura, como o PLM. Recomenda-se investigar as implicações de se escolher outra métrica (moda, mediana, $85^{\circ}$ percentil) para o valor representativo da distribuição posterior

Quanto à calibração dos parâmetros do modelo fluxo-velocidade do HCM para autoestradas e rodovias de pista dupla, sugere-se investigar a influência das variáveis geométricas nas variáveis de tráfego. Além disso, recomenda-se estender o estudo sobre o ponto de transição do modelo do HCM, o qual, neste trabalho, indicou ser menor do que o esperado na literatura, ou até mesmo inexistente.

Propõe-se uma investigação da influência do clima na relação fluxo-velocidade, bem como na estimação da capacidade pelo método proposto. Recomenda-se também, um estudo detalhado sobre a relação fluxo-velocidade para os tipos de segmentos de uma rodovias, entrelaçamentos (weaving) e dispositivos de acesso (ramps). 
Sugere-se também estudar a quantidade de dados necessários para realizar uma calibração adequada conforme o nível de detalhamento que se deseja. Esse nível de observação do fenômeno de tráfego está associado ao tipo e quantidade de dados no domínio tempo-espaço.

Por fim, outra sugestão consiste na utilização de diferentes distribuições a priori, de forma que estas representem melhor o comportamento dos parâmetros que representam. Nesse trabalho, optou-se por utilizar a distribuição uniforme para as distribuições a priori uma vez que representa o tipo de distribuição mais objetiva possível, ou seja, assume-se que não se conhece o comportamento dos parâmetros previamente e, também, pelo fato de não ter encontrado na literatura estudos sobre o comportamento dos parâmetros envolvidos nos modelos utilizados no trabalho. 


\section{Referências}

ADAMS, W. F. Road traffic considered as a random series. Institution Civil Engineers, 1936. 1936.

AERDE, M. V.; RAKHA, H. Multivariate calibration of single regime speed-flow-density relationships. In: IEEE. VNIS/Pacific Rim Conference Proceedings. Seattle, WA, 1995. p. 334-341.

ANDRADE, G. R. Capacidade e relação fluxo-velocidade em autoestradas e rodovias de pista dupla paulistas. 154 p. Dissertação (Mestrado) - Universidade de São Paulo, São Carlos, 2012.

ANDRADE, G. R.; SETTI, J. R. Método para caracterização e classificação de trechos homogêneos rodoviários. In: ANAIS DA $7^{\circ}$ CONGRESSO BRASILEIRO DE RODOVIAS E CONCESSÕES - CBR\&C 2011. Foz do Iguaçu, PR, 2011. p. 14.

ANDRADE, G. R.; SETTI, J. R. Speed-flow relationship and capacity for expressways in brazil. Transportation Research Circular: Journal of the Transportation Research Board, 2014. E-C190, p. 10-25, 2014.

ARTESP. Procedimentos Práticos para Cálculo da Capacidade Viária e Determinação do Nível de Serviço de Operação. São Paulo, SP, 2004.

BASSAN, S.; POLUS, A. Meaning of actual capacity of freeways and its estimation. Canadian fournal of Civil Engineering, 2010. NRC Research Press, v. 37, n. 1, p. 77-87, 2010.

BESSA-JÚNIOR, J. E. Caracterização do fluxo de tráfego em rodovias de pista simples do Estado de São Paulo. 182 p. Dissertação (Mestrado) - Universidade de São Paulo, São Carlos, 2009.

BETHONICO, F. C. Calibração de simuladores microscópicos de tráfego através de medidas macroscópicas. 118 p. Dissertação (Mestrado) - Universidade de São Paulo, São Carlos, 2016.

BRILON, W.; GEISTEFELDT, J.; REGLER, M. Reliability of freeway traffic flow: a stochastic concept of capacity. In: PROCEEDINGS OF THE $16^{\circ}$ INTERNATIONAL SYMPOSIUM ON TRANSPORTATION AND TRAFFIC THEORY. College Park, MD, 2005. p. 125-144. 
BRILON, W.; GEISTEFELDT, J.; ZURLINDEN, H. Implementing the concept of reliability for highway capacity analysis. Transportation Research Record: Journal of the Transportation Research Board, 2007. Transportation Research Board of the National Academies, n. 2027, p. 1-8, 2007.

BRILON, W.; ZURLINDEN, H. Breakdown probability and traffic efficiency as design criteria for freeways. Forschung Strassenbau und Strassenverkehrstechnik, Bonn, Alemanha, 2003. v. 870, 2003.

BROOKS, S. P.; GELMAN, A. General methods for monitoring convergence of iterative simulations. Journal of computational and graphical statistics, 1998. Taylor \& Francis, v. 7, n. 4, p. 434-455, 1998.

CAREY, M.; BOWERS, M. A review of properties of flow density functions. Transport Reviews, 2012. Routledge, v. 32, n. 1, p. 49-73, 2012.

CASTILLO, J. D.; BENITEZ, F. On the functional form of the speed-density relationship: Empirical investigation. Transportation Research Part B: Methodological, 1995. Elsevier, v. 29, n. 5, p. 391-406, 1995.

CASTILLO, J. D.; BENITEZ, F. On the functional form of the speed-density relationship: General theory. Transportation Research Part B: Methodological, 1995. Elsevier, v. 29, n. 5, p. 373-389, 1995.

CHEN, F. Bayesian modeling using the mcmc procedure. In: Proceedings of the SAS Global Forum 2008 Conference. Cary, NC: SAS Institute Inc, 2009.

COWLES, M. K.; CARLIN, B. P. Markov chain monte carlo convergence diagnostics: a comparative review. Journal of the American Statistical Association, 1996. Taylor \& Francis, v. 91, n. 434, p. 883-904, 1996.

CUNHA, A. L. B. N. Avaliação do impacto da medida de desempenho no equivalente veicular de caminhões. 150 p. Dissertação (Mestrado) - Universidade de São Paulo, São Carlos, 2007.

CUNHA, A. L. B. N.; SETTI, J. R. Fatores de equivalência para caminhões em rodovias de pista dupla. In: ANAIS DA $6^{\circ}$ CONGRESSO BRASILEIRO DE RODOVIAS E CONCESSÕES CBR\&C 2009. Florianopólis, SC, 2009. p. 15.

DAIHENG, N. Traffic flow theory: Characteristics, Experimental Methods, and Numerical Techniques. 1a. ed. Oxford, UK: Elsevier, 2015.

DEMARCHI, S. H. Influência dos veículos pesados na capacidade e nível de serviço de rodovias de pista dupla. 166 p. Tese (Doutorado) - Universidade de São Paulo, São Carlos, 2000.

DNIT. Diretrizes para elaboração de estudos e projetos rodoviários - Escopo básico/instruçoes de serviço. Rio de Janeiro, RJ, 2001.

DOWNEY, A. Think Bayes: Bayesian Statistics in Python. Needham, MA: "O’Reilly Media, Inc.", 2013.

DREW, D. Deterministic aspects of freeway operations and control. Highway Research Record, 1965. v. 99, p. 48-58, 1965. 
EDIE, L. C. Car-following and steady-state theory for noncongested traffic. Operations research, 1961. INFORMS, v. 9, n. 1, p. 66-76, 1961.

ELEFTERIADOU, L.; ROESS, R. P.; MCSHANE, W. R. Probabilistic nature of breakdown at freeway merge junctions. Transportation Research Record, 1995. n. 1484, 1995.

FDOT. Quality/Level of Service Handbook. Tallahasse, FL, 2013. 152 p.

GEISTEFELDT, J.; BRILON, W. A comparative assessment of stochastic capacity estimation methods. In: Transportation and Traffic Theory 2009: Golden fubilee. Boston, MA: Springer, 2009. p. 583-602.

GELMAN, A.; RUBIN, D. B. Inference from iterative simulation using multiple sequences. Statistical Science, 1992. Institute of Mathematical Statistics, v. 7, n. 4, p. 457-472, 1992.

GERLOUGH, D.; HUBER, M. Traffic flow theory - a monograph. Transportation Research Board, Washington, D.C, EUA, 1975. Special Report, 165, 1975.

GEWEKE, J. Evaluating the accuracy of sampling-based approaches to the calculation of posterior moments. Research Department Minneapolis, MN, USA: Federal Reserve Bank of Minneapolis, 1991.

GREENBERG, H. An analysis of traffic flow. Operations research, 1959. INFORMS, v. 7, n. 1, p. 79-85, 1959.

GREENSHIELDS, B. et al. A study of traffic capacity. In: PROCEEDINGS OF HRB. Highway Research Board. Washington, D.C., 1935. v. 14, p. 448-477.

GREGORY, P. Bayesian Logical Data Analysis for the Physical Sciences: A Comparative Approach with Mathematica Support. Cambridge, UK: Cambridge University Press, 2005.

JOHNSON, V. E. Studying convergence of markov chain monte carlo algorithms using coupled sample paths. Fournal of the American Statistical Association, 1996. Taylor \& Francis, v. 91, n. 433, p. 154-166, 1996.

KAPLAN, E. L.; MEIER, P. Nonparametric estimation from incomplete observations. fournal of the American statistical association, 1958. Taylor \& Francis, v. 53, n. 282, p. 457-481, 1958.

KLEIN, L. A. Sensor technologies and data requirements for ITS. Boston, MA: Artech House, 2001.

KLEIN, L. A. et al. Traffic detector handbook. 3a. ed. Turner-Fairbank Highway Research Center, EUA, 2006. v. 1, 288 p. Disponível em: <https://www.fhwa.dot.gov/publications/research/operations/its/06139/06139.pdf $>$.

KONDYLI, A. et al. Defining, measuring, and modeling capacity for the highway capacity manual. Journal of Transportation Engineering, Part A: Systems, 2017. v. 143, n. 3, p. 04016014, 2017.

LAWLESS, J. F. Statistical models and methods for lifetime data. 2a. ed. Hoboken, New Jersey: John Wiley \& Sons, 2011.

LIU, C.; LIU, J.; RUBIN, D. B. A variational control variable for assessing the convergence of the gibbs sampler. 1992 Proceedings of Statistical Computing Section of American Statistical Association, 1992. p. 74-78, 1992. 
LORENZ, M.; ELEFTERIADOU, L. Defining freeway capacity as function of breakdown probability. Transportation Research Record: Journal of the Transportation Research Board, 2001. Transportation Research Board of the National Academies, n. 1776, p. 43-51, 2001.

LORENZ, M. R.; ELEFTERIADOU, L. A probabilistic approach to defining freeway capacity and breakdown. In: PROCEEDINGS OF THE 4TH INTERNATIONAL SYMPOSIUM ON HIGHWAY CAPACITY, TRB-CIRCULAR E-C018. TRB. Washington, D.C., 2000. p. 84-95.

MAY, A. D.; KELLER, H. E. Non-integer car-following models. Highway Research Record, 1967. v. 199, n. 1, p. 19-32, 1967.

MINDERHOUD, M.; BOTMA, H.; BOVY, P. Assessment of roadway capacity estimation methods. Transportation Research Record: Journal of the Transportation Research Board, 1997. Transportation Research Board of the National Academies, n. 1572, p. 59-67, 1997.

PERSAUD, B.; YAGAR, S.; BROWNLEE, R. Exploration of the breakdown phenomenon in freeway traffic. Transportation Research Record: Fournal of the Transportation Research Board, 1998. Transportation Research Board of the National Academies, n. 1634, p. 64-69, 1998.

PIPES, L. A. Car following models and the fundamental diagram of road traffic. Transportation Research, 1967. 1967.

PIVA, F. J. Fatores de equivalência de veícuos pesados em rodovias de pista dupla. 100 p. Dissertação (Mestrado) - Universidade de São Paulo, São Carlos, 2015.

POMPIGNA, A.; RUPI, F. Differences between hcm procedures and fundamental diagram calibration for operational los assessment on italian freeways. Transportation Research Procedia, 2015. Elsevier, v. 5, p. 103-118, 2015.

RAFTERY, A. E.; LEWIS, S. How many iterations in the Gibbs sampler? Seattles, WA, 1991.

RAKHA, H.; ARAFEH, M. Calibrating steady-state traffic stream and car-following models using loop detector data. Transportation Science, 2010. INFORMS, v. 44, n. 2, p. 151-168, 2010.

RAKHA, H.; CROWTHER, B. Comparison of greenshields, pipes, and van aerde car-following and traffic stream models. Transportation Research Record: Journal of the Transportation Research Board, 2002. Transportation Research Board of the National Academies, n. 1802, p. 248-262, 2002.

RITTER, C.; TANNER, M. A. Facilitating the gibbs sampler: The gibbs stopper and the griddy-gibbs sampler. Fournal of the American Statistical Association, 1992. American Statistical Association, v. 87, n. 419, p. 861-868, 1992.

ROBERTS, G. O. Convergence diagnostics of the gibbs sampler. Bayesian statistics, 1992. Oxford University Press Oxford, UK, v. 4, n. 4, p. 775-782, 1992.

ROESS, R. Freeway speed-flow curves. Polytechnic Institute of New York University, Brooklyn, N.Y., EUA, 2009. p. 3-92, 2009.

ROESS, R. Speed-flow curves for freeways in highway capacity manual 2010. In: 90TH ANNUAL MEETING OF TRB. Washington, D.C., EUA, 2011.

ROESS, R. P.; PRASSAS, E. S.; MCSHANE, W. R. Traffic engineering. 4a. ed. Upper Saddle River, NJ, EUA: Prentice Hall, 2010. 
ROSAS-JAIMES, O. A.; QUEZADA-TÉLLEZ, L. A.; FERNÁNDEZ-ANAYA, G. Stability analysis in greenberg's traffic model. International fournal of Modern Physics C, 2017. v. 28, n. 10, 2017. ROSS, S. M. Stochastic processes. New York, EUA: Wiley, 1996.

SEO, T. et al. Traffic state estimation on highway: A comprehensive survey. Annual Reviews in Control, 2017. Elsevier, v. 43, p. 128-151, 2017.

SETTI, J. R. Highway capacity manual ou manual de capacidade viária? In: ANAIS DA $6^{\circ}$ CONGRESSO BRASILEIRO DE RODOVIAS E CONCESSÕES - CBR\&C 2009. Florianopólis, SC, 2009. p. 11.

SUN, L.; ZHOU, J. Development of multiregime speed-density relationships by cluster analysis. Transportation Research Record: fournal of the Transportation Research Board, 2005. Transportation Research Board of the National Academies, n. 1934, p. 64-71, 2005.

TRB. Highway capacity manual 2010. Transportation Research Board, National Research Council, Washington, D.C., EUA, 2010. 2010.

TRB. Highway capacity manual 2016. Transportation Research Board, National Research Council, Washington, D.C., EUA, 2016. 2016.

UNDERWOOD, R. T. Speed, volume, and density relationships: quality and theory of traffic flow. 1961. Yale Bureau of Higway Traffic, p. 141-188, 1961.

VANDERPLAS, J. Frequentism and bayesianism: a python-driven primer. arXiv preprint arXiv:1411.5018, 2014. 2014.

WAGENINGEN-KESSELS, F. van et al. Genealogy of traffic flow models. EURO fournal on Transportation and Logistics, 2015. Springer, v. 4, n. 4, p. 445-473, 2015.

WASHBURN, S. et al. Investigation of Freeway Capacity, Part B: Freeway Capacity Estimation for Florida Freeways, Final Report. Tallahassee, FL, EUA, 2010. 119 p.

ZELLNER, A.; MIN, C.-K. Gibbs sampler convergence criteria. Fournal of the American Statistical Association, 1995. American Statistical Association, v. 90, n. 431, p. 921-927, 1995. 


\section{APÊNDICE}

\section{Gráficos fluxo-velocidade}

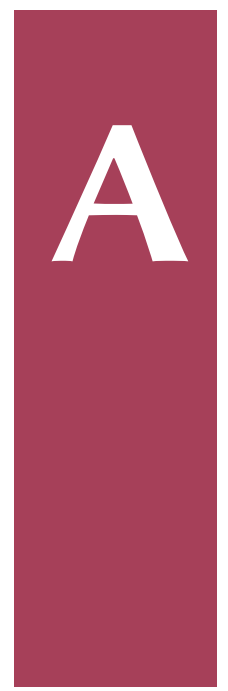

Nesta seção são apresentados os resultados obtidos para todos os trechos utilizados no trabalho, exceto aqueles já apresentado no Capítulo 5. Cada gráfico apresenta as observações de velocidade e fluxo, bem como as curvas fluxo-velocidade obtidas pelos métodos proposto, HCM 2010 e Andrade (2012). Nos locais em que a capacidade não é atingida, as curvas fluxovelocidade são apresentadas até a capacidade esperada para aquele trecho.

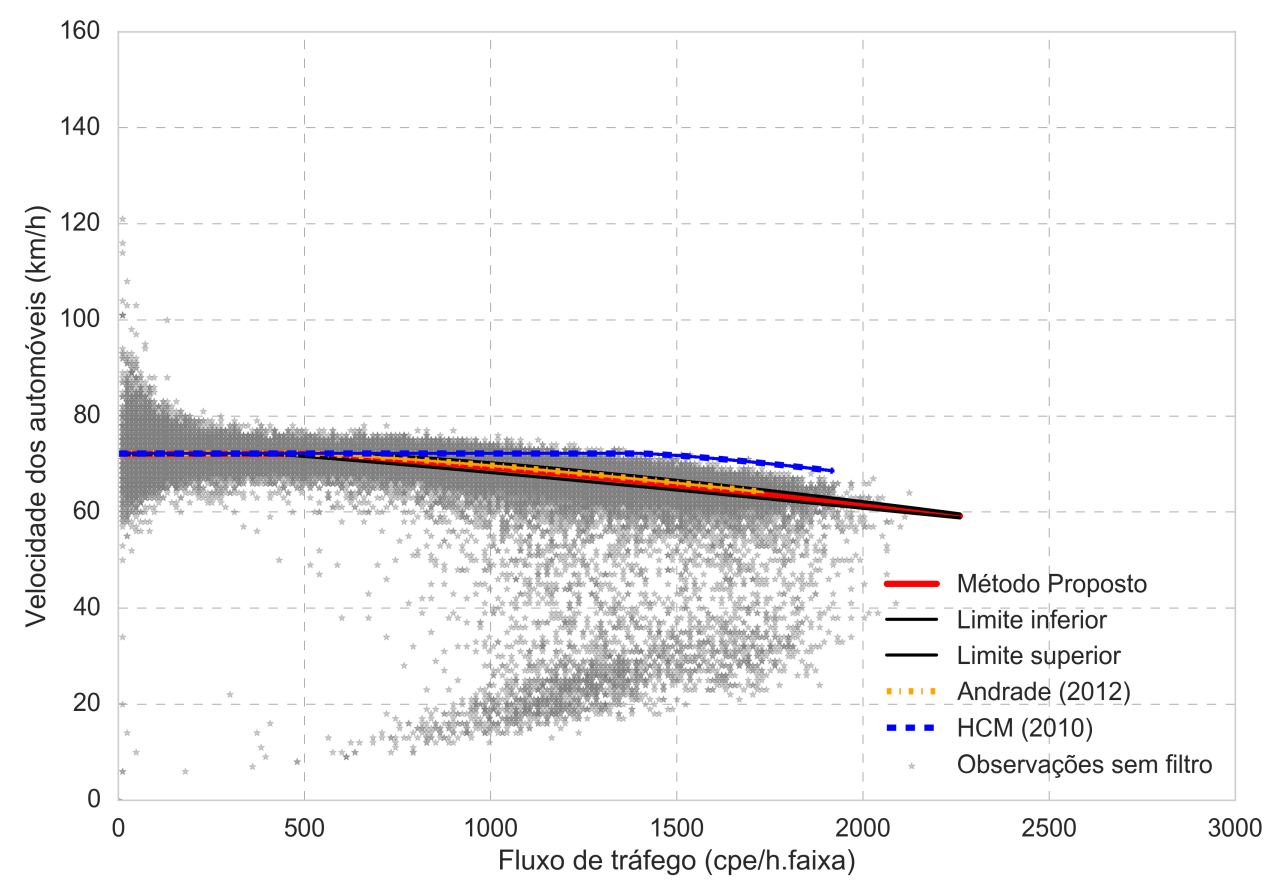

Figura A.1 - Curva fluxo-velocidade para a SP-280, km 16,0 leste, faixa expressa, obtidas com o modelo proposto, HCM 2010 e Andrade (2012) 


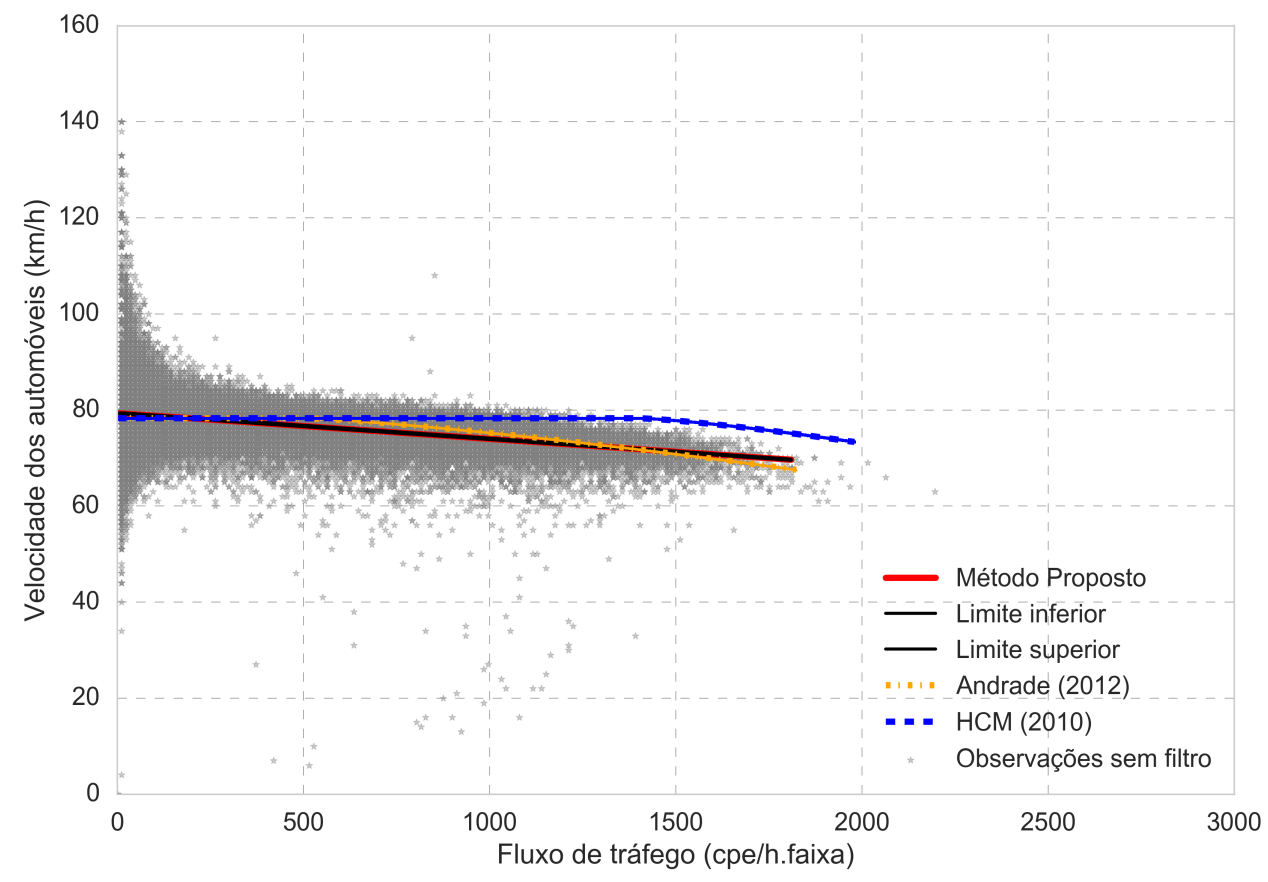

Figura A.2 - Curva fluxo-velocidade para a SP-280, km 16,0 oeste, faixa expressa, obtidas com o modelo proposto, HCM 2010 e Andrade (2012)

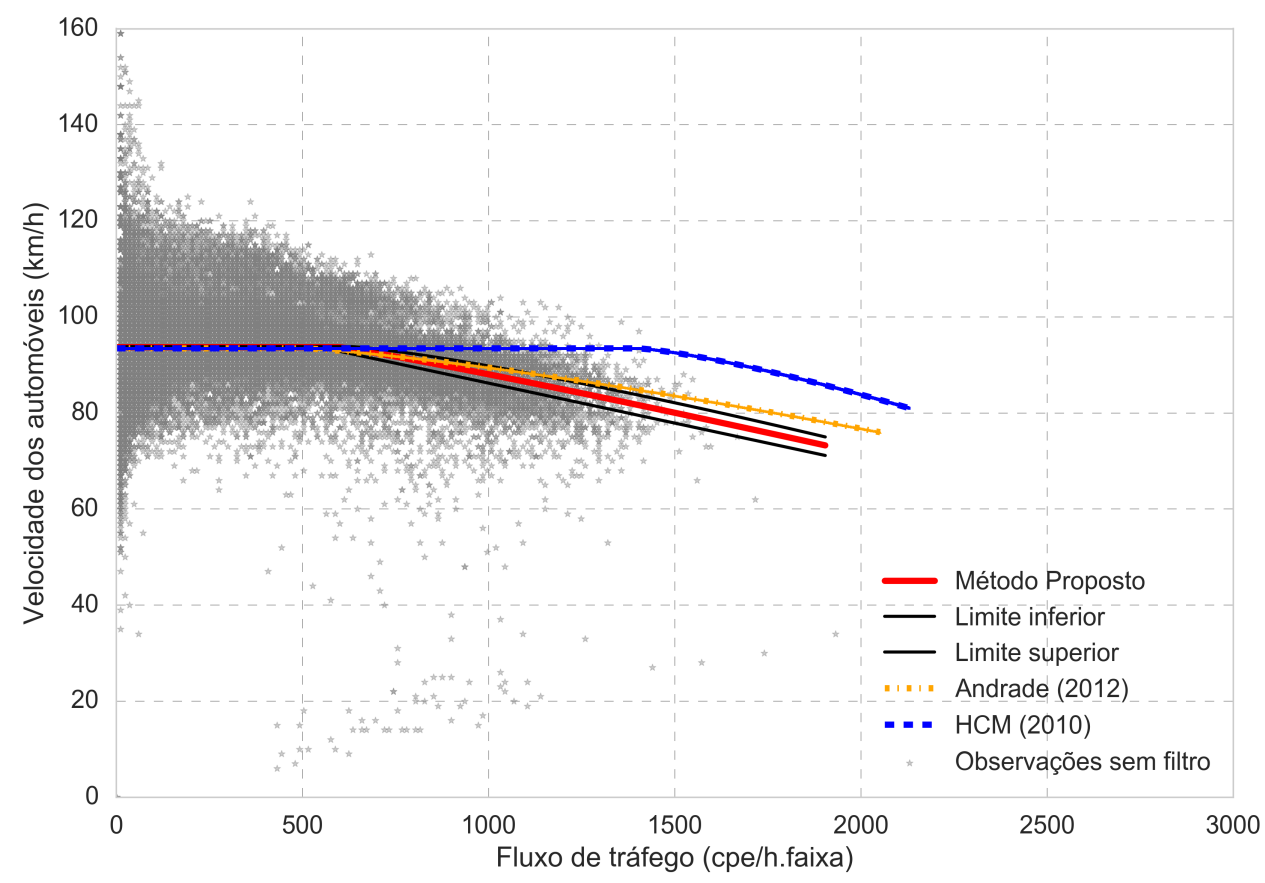

Figura A.3 - Curva fluxo-velocidade para a SP-280, km 16,0 leste, faixa marginal, obtidas com o modelo proposto, HCM 2010 e Andrade (2012) 


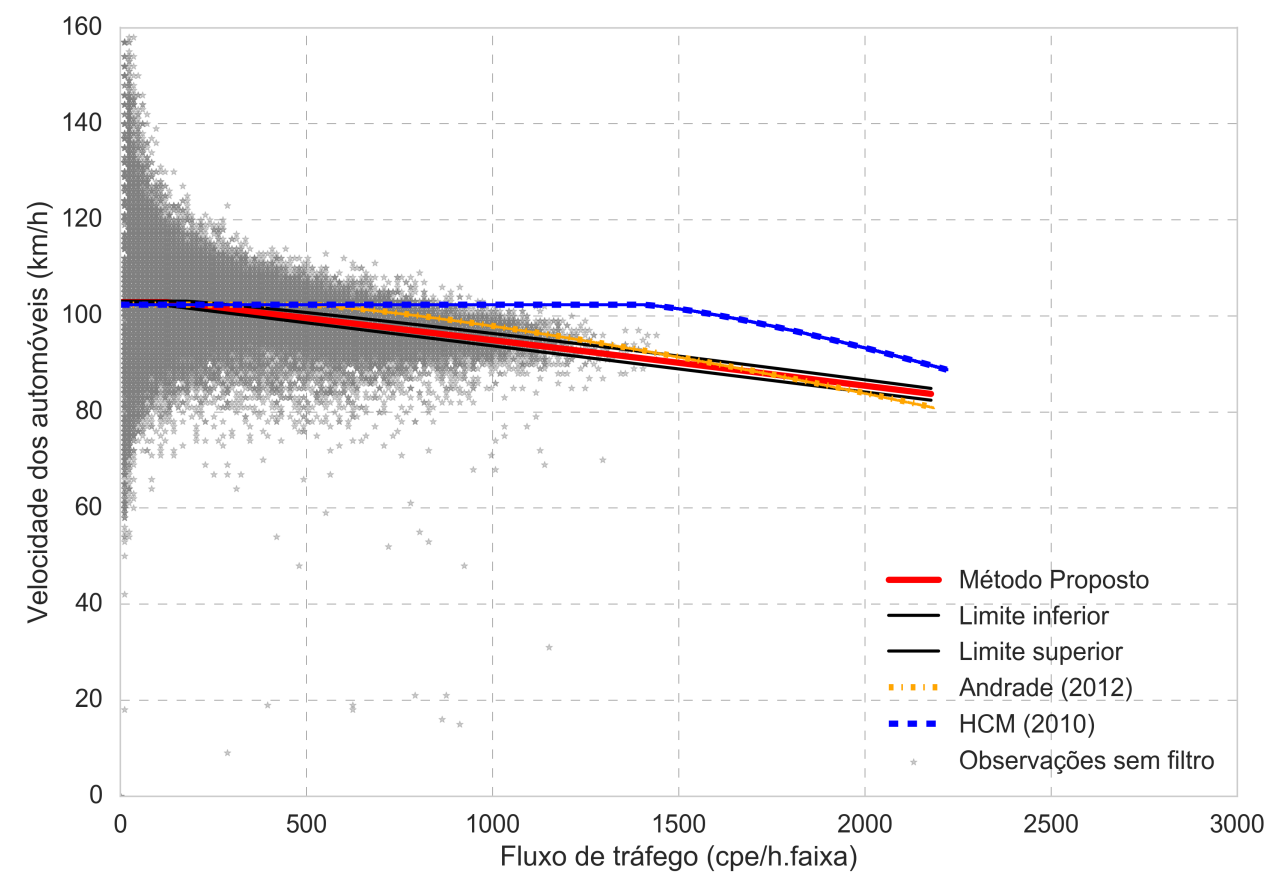

Figura A.4 - Curva fluxo-velocidade para a SP-280, km 16,0 oeste, faixa marginal, obtidas com o modelo proposto, HCM 2010 e Andrade (2012)

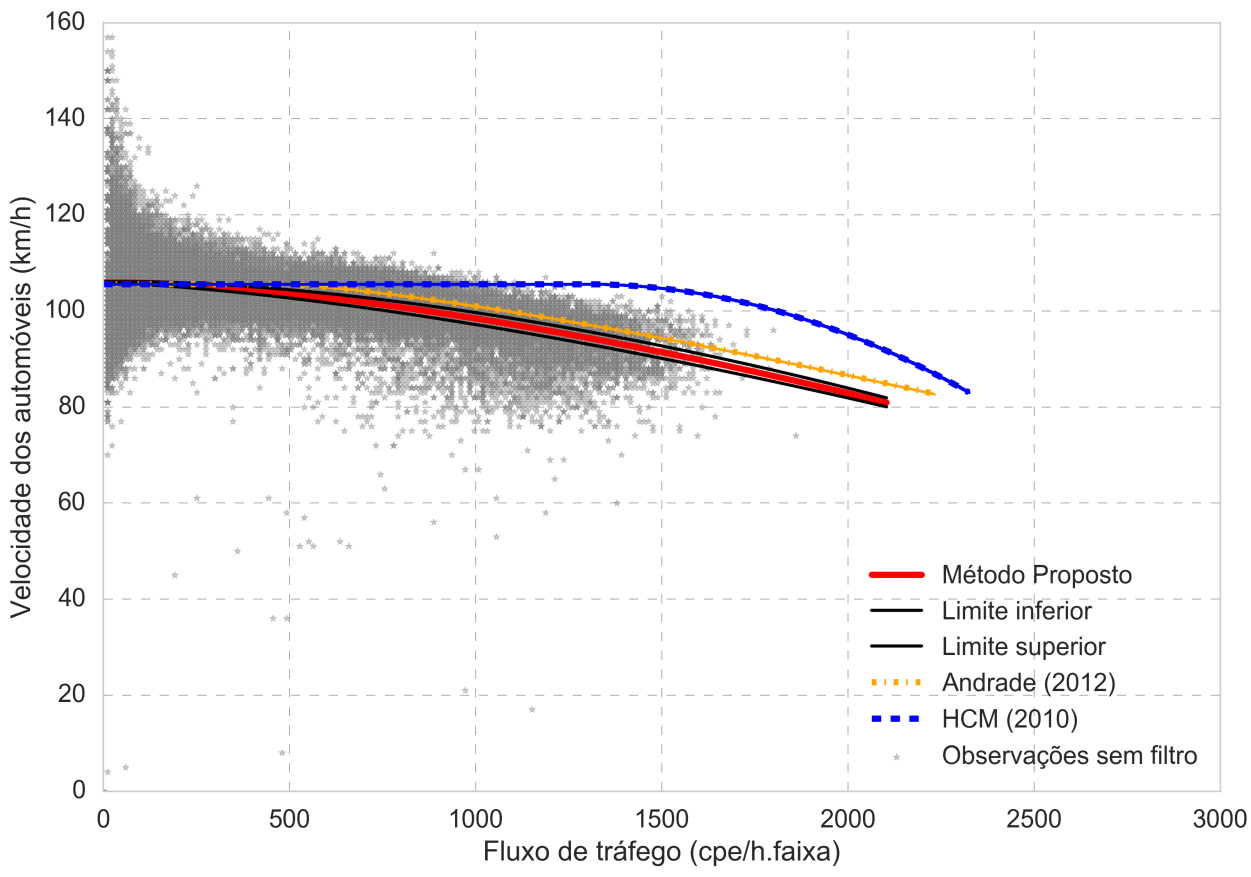

Figura A.5 - Curva fluxo-velocidade para a SP-280, km 22,4 leste, faixa expressa, obtidas com o modelo proposto, HCM 2010 e Andrade (2012) 


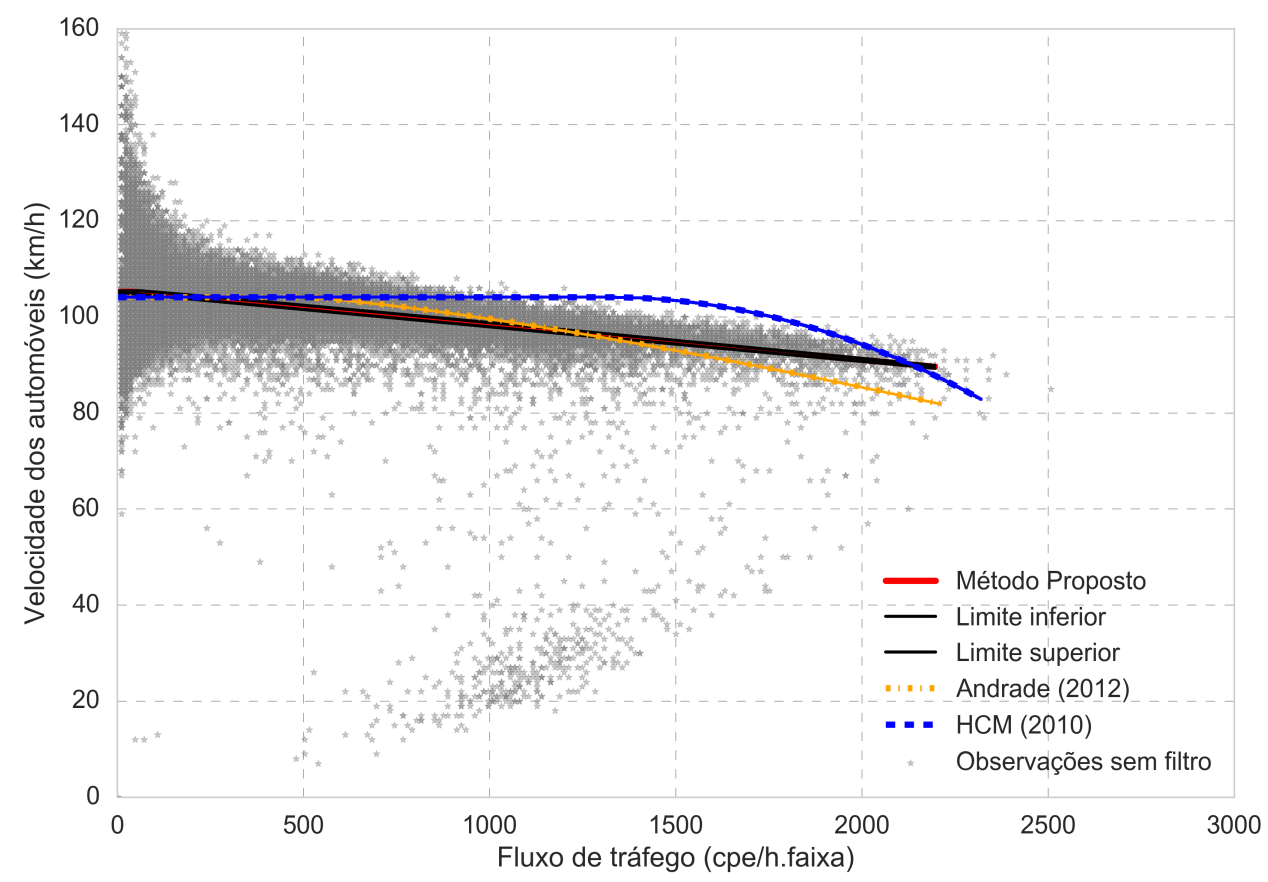

Figura A.6 - Curva fluxo-velocidade para a SP-280, km 22,4 oeste, faixa expressa, obtidas com o modelo proposto, HCM 2010 e Andrade (2012)

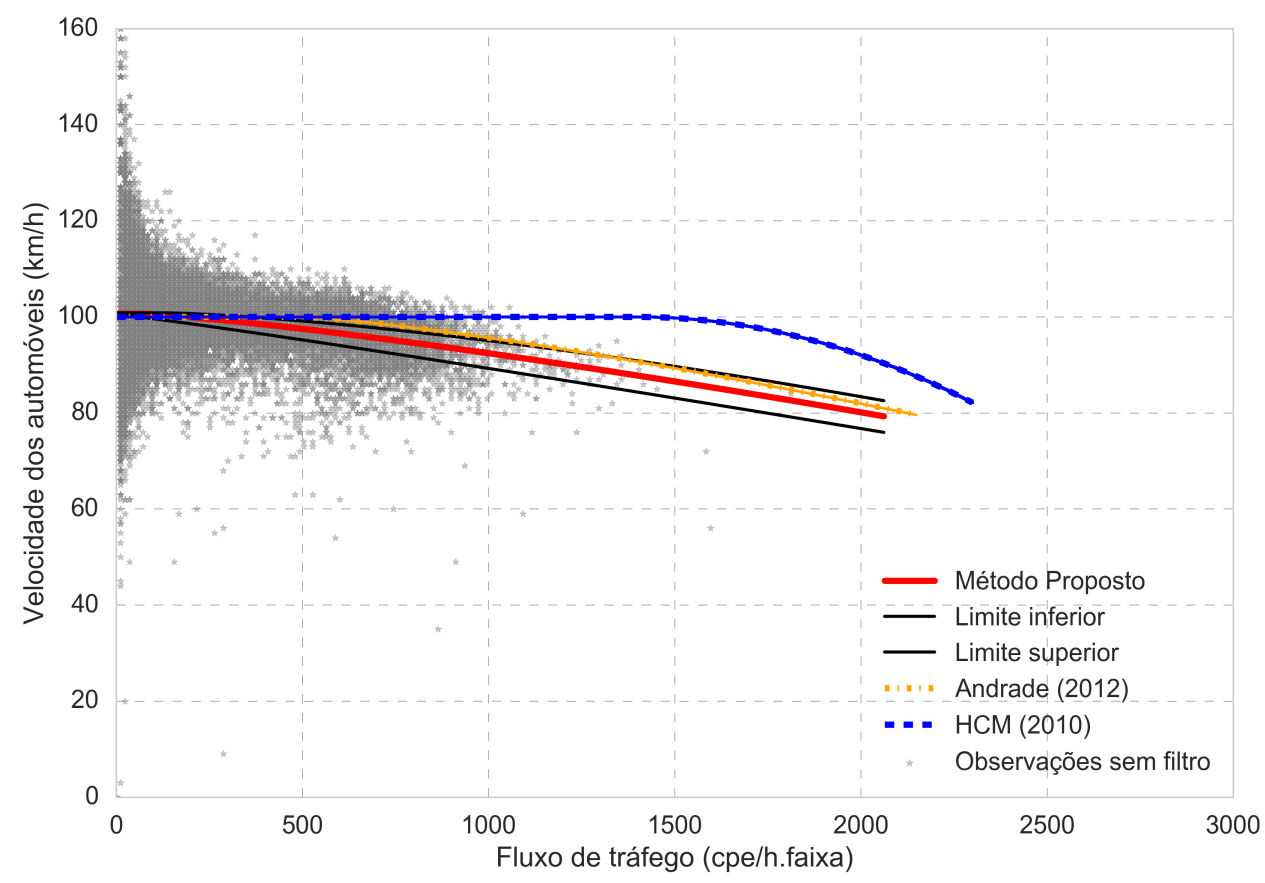

Figura A.7 - Curva fluxo-velocidade para a SP-280, km 22,4 leste, faixa marginal, obtidas com o modelo proposto, HCM 2010 e Andrade (2012) 


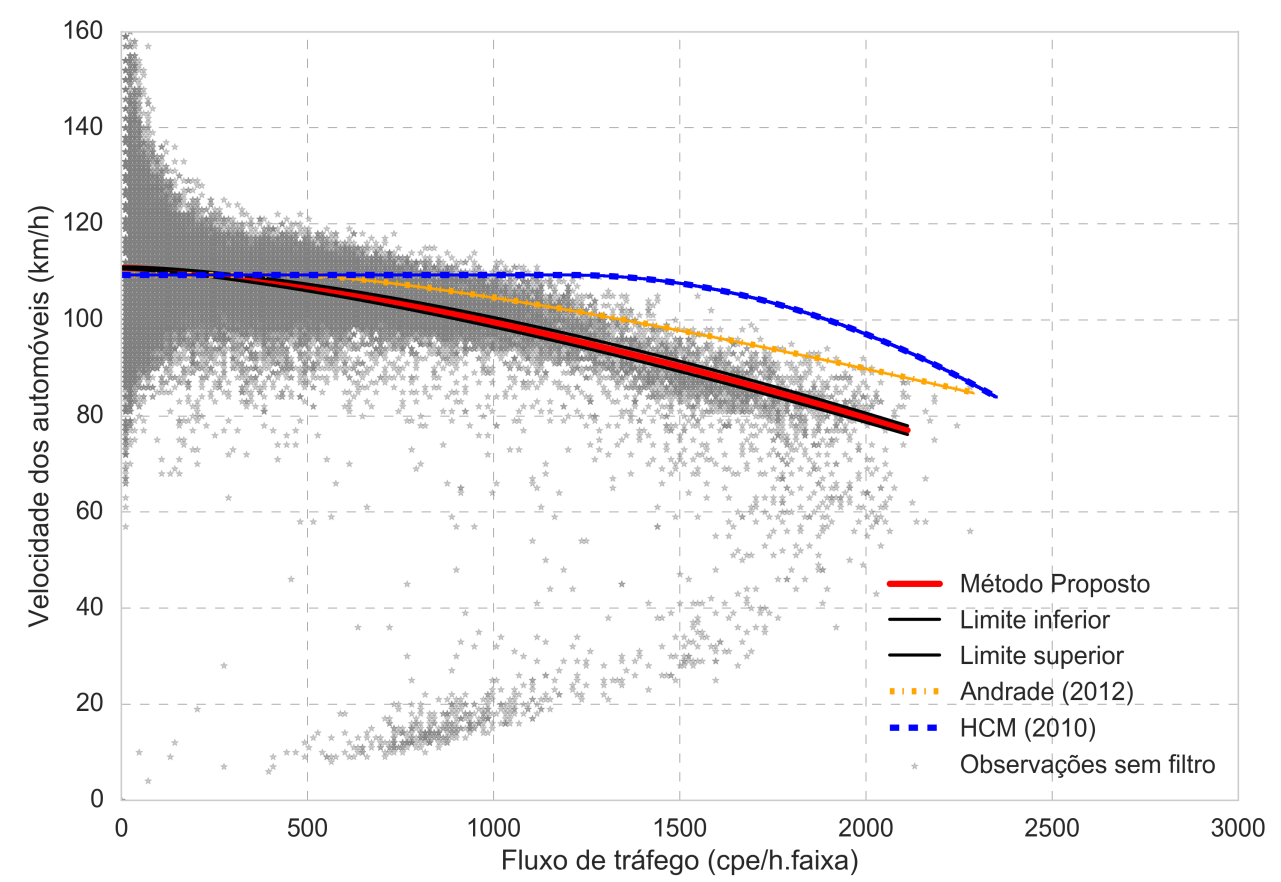

Figura A.8 - Curva fluxo-velocidade para a SP-280, km 22,4 oeste, faixa marginal, obtidas com o modelo proposto, HCM 2010 e Andrade (2012)

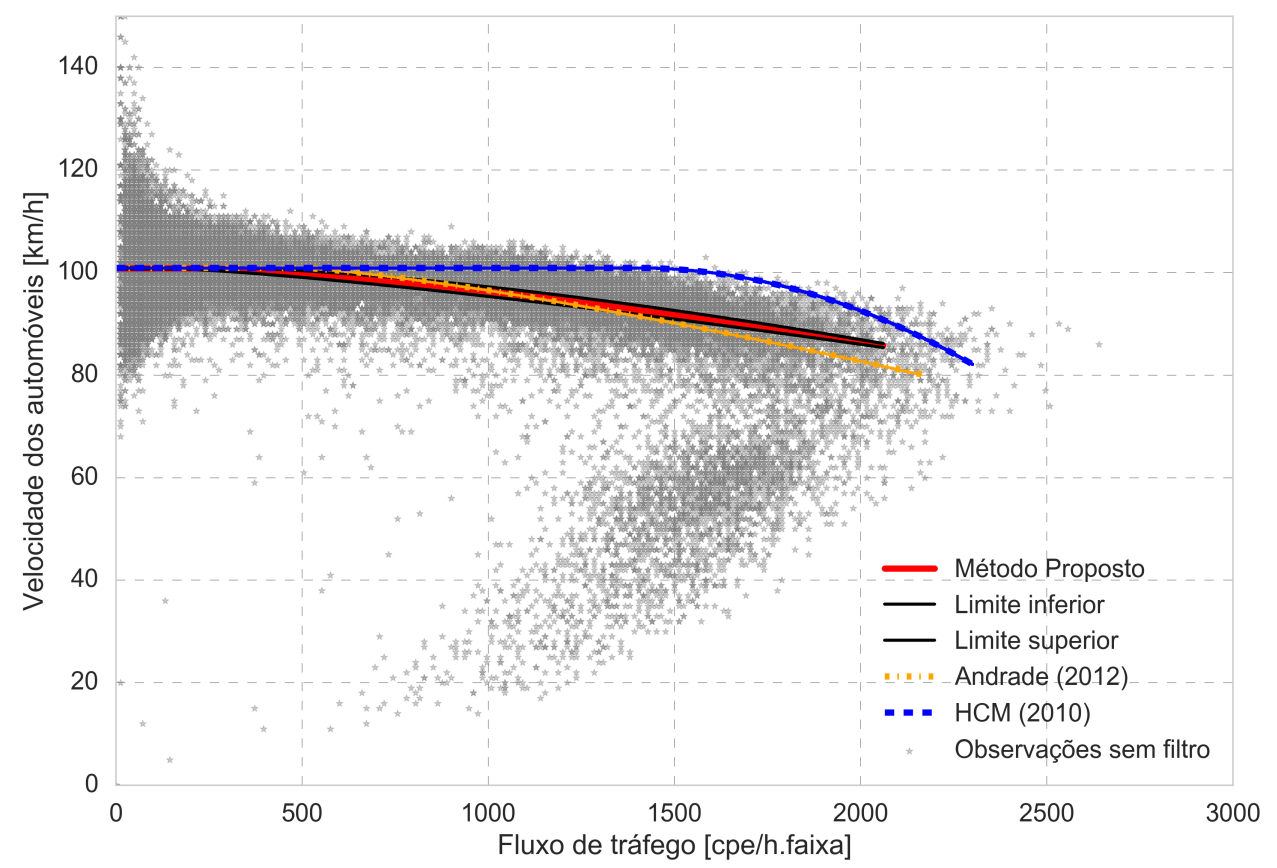

Figura A.9 - Curva fluxo-velocidade para a SP-280, km 29,5 leste, faixa expressa, obtidas com o modelo proposto, HCM 2010 e Andrade (2012) 


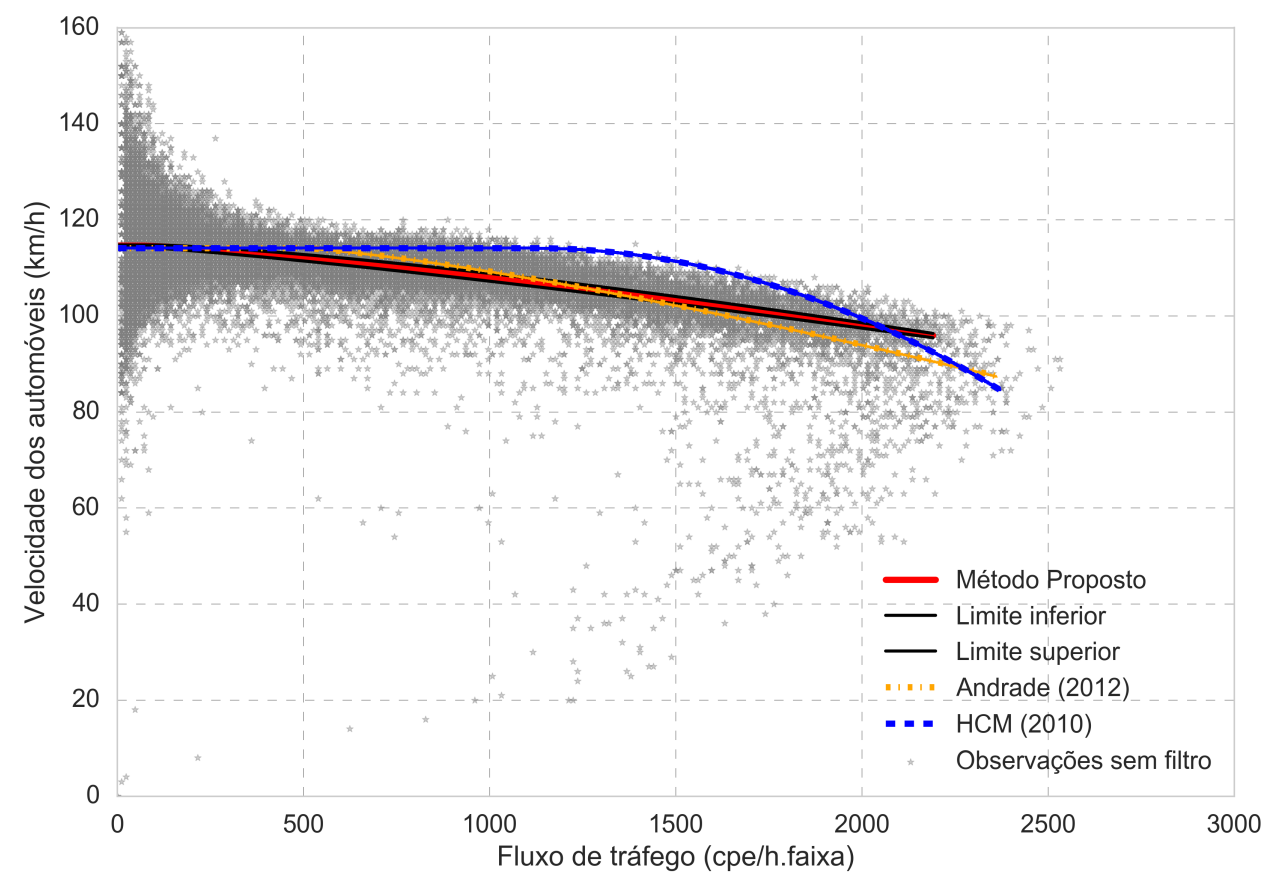

Figura A.10 - Curva fluxo-velocidade para a SP-280, km 29,5 oeste, faixa expressa, obtidas com o modelo proposto, HCM 2010 e Andrade (2012)

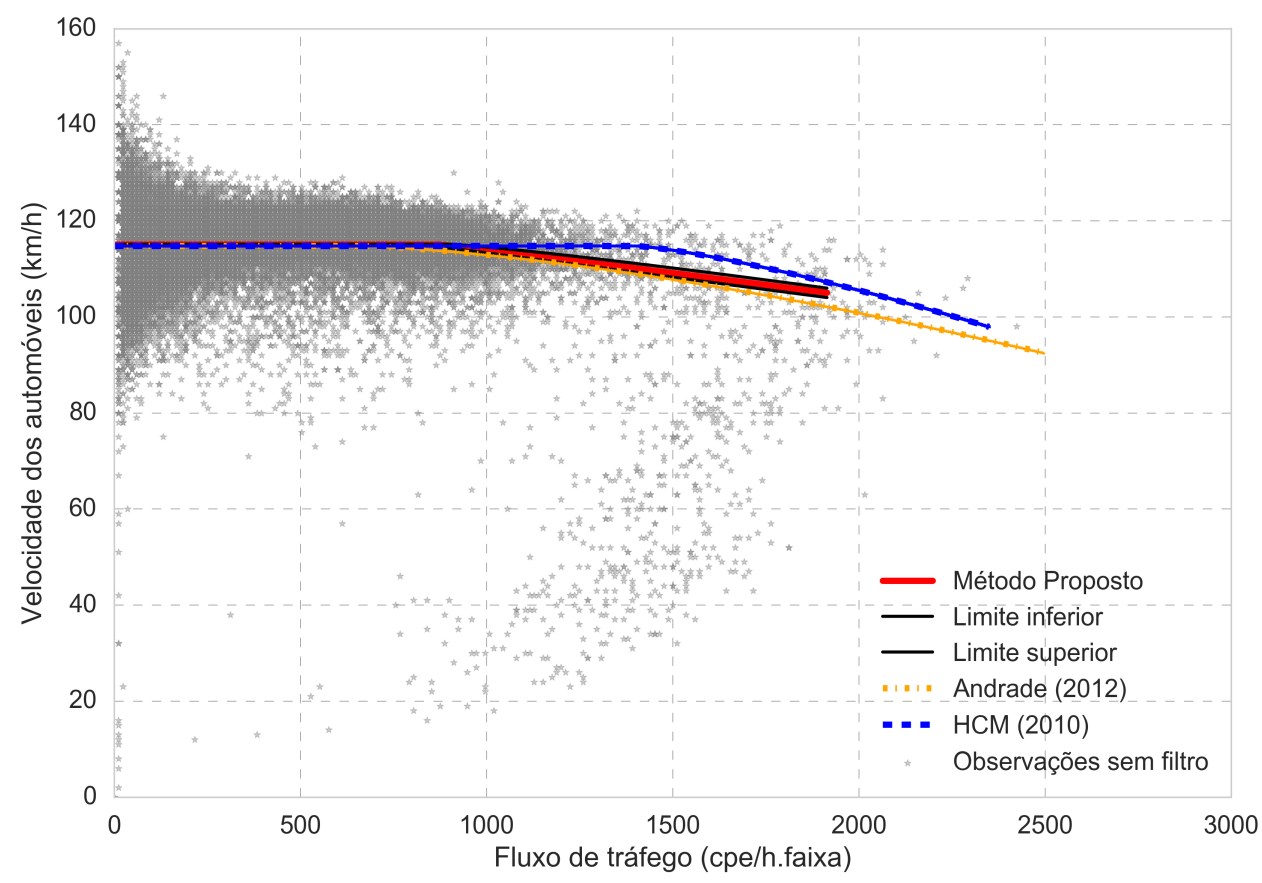

Figura A.11 - Curva fluxo-velocidade para a SP-280, km 37,0 leste, faixa expressa, obtidas com o modelo proposto, HCM 2010 e Andrade (2012) 


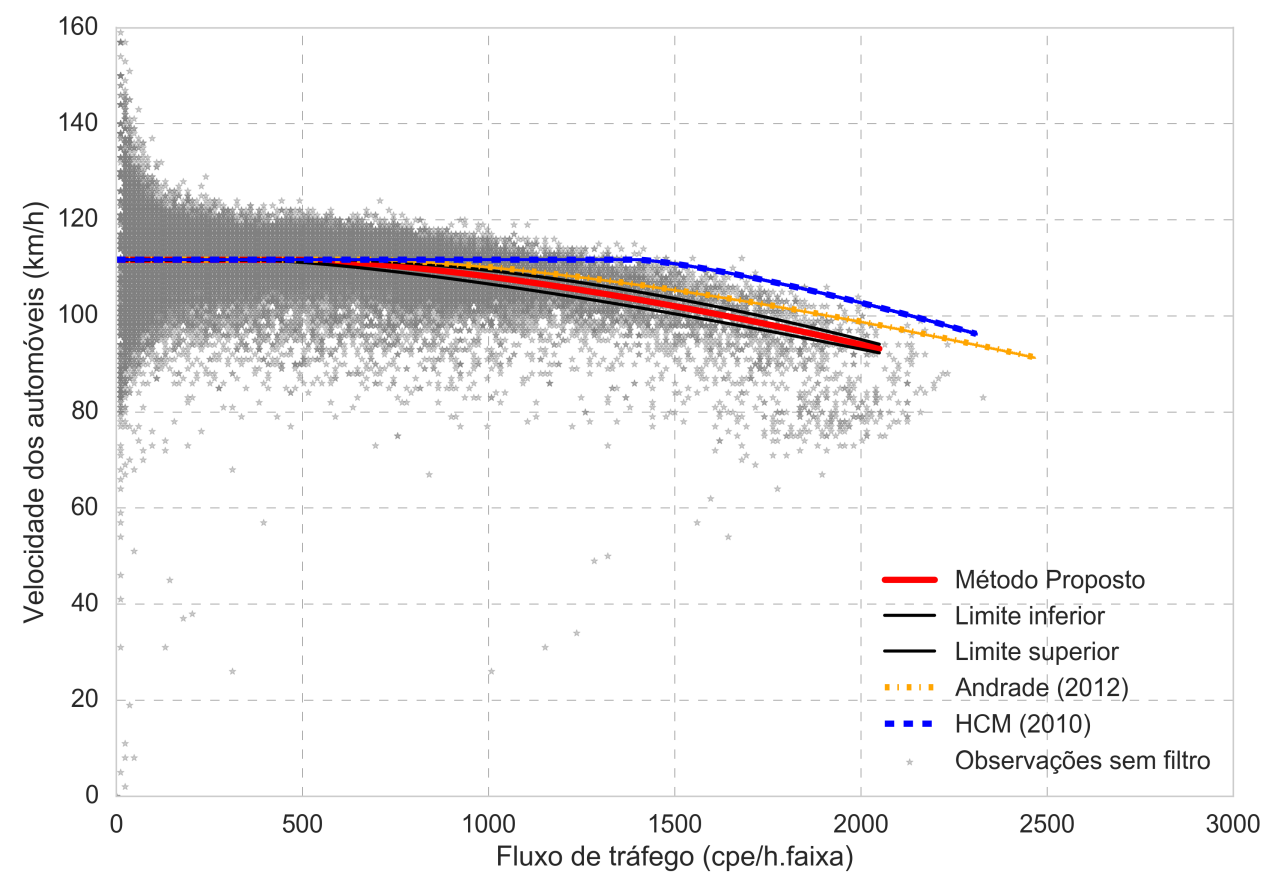

Figura A.12 - Curva fluxo-velocidade para a SP-280, km 37,0 oeste, faixa expressa, obtidas com o modelo proposto, HCM 2010 e Andrade (2012)

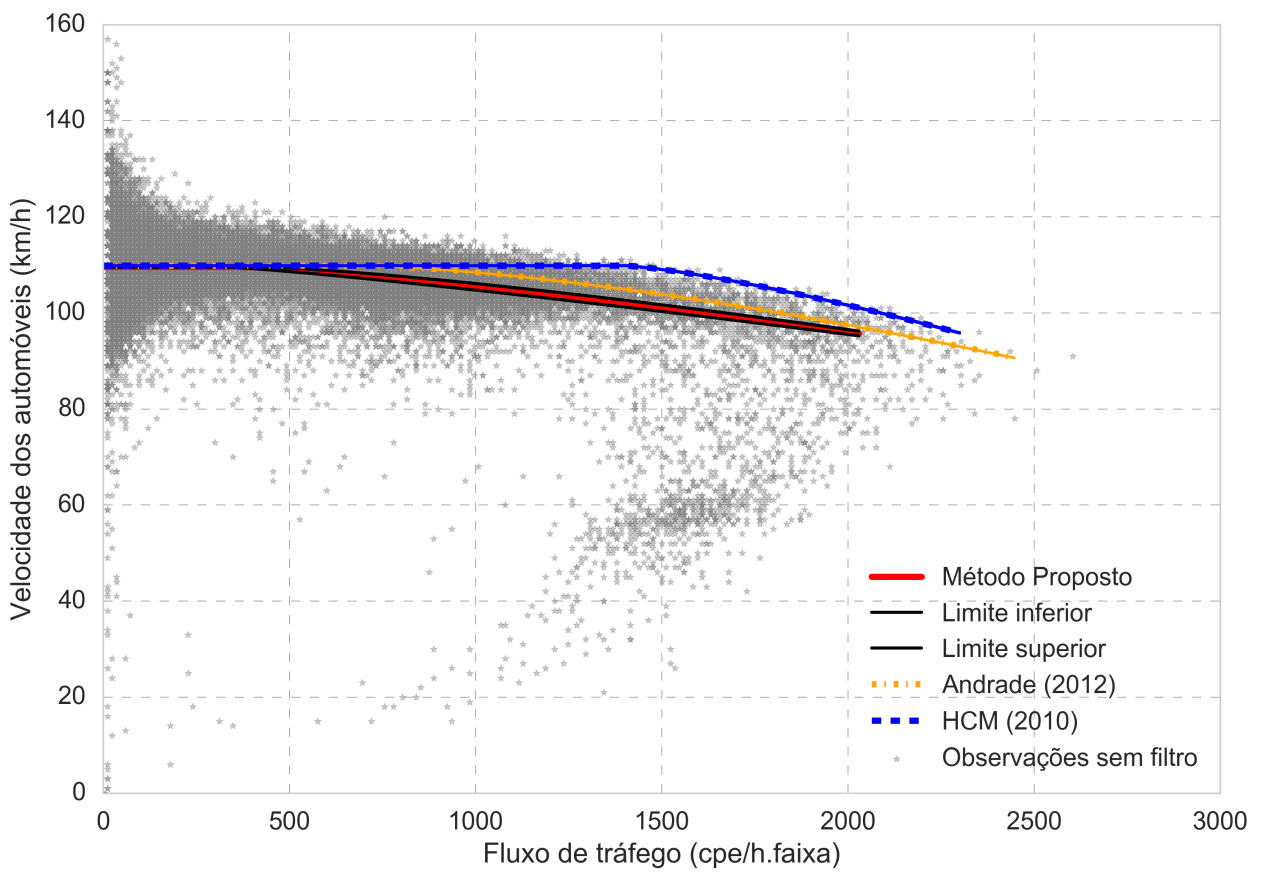

Figura A.13 - Curva fluxo-velocidade para a SP-280, km 51,9 leste, faixa expressa, obtidas com o modelo proposto, HCM 2010 e Andrade (2012) 


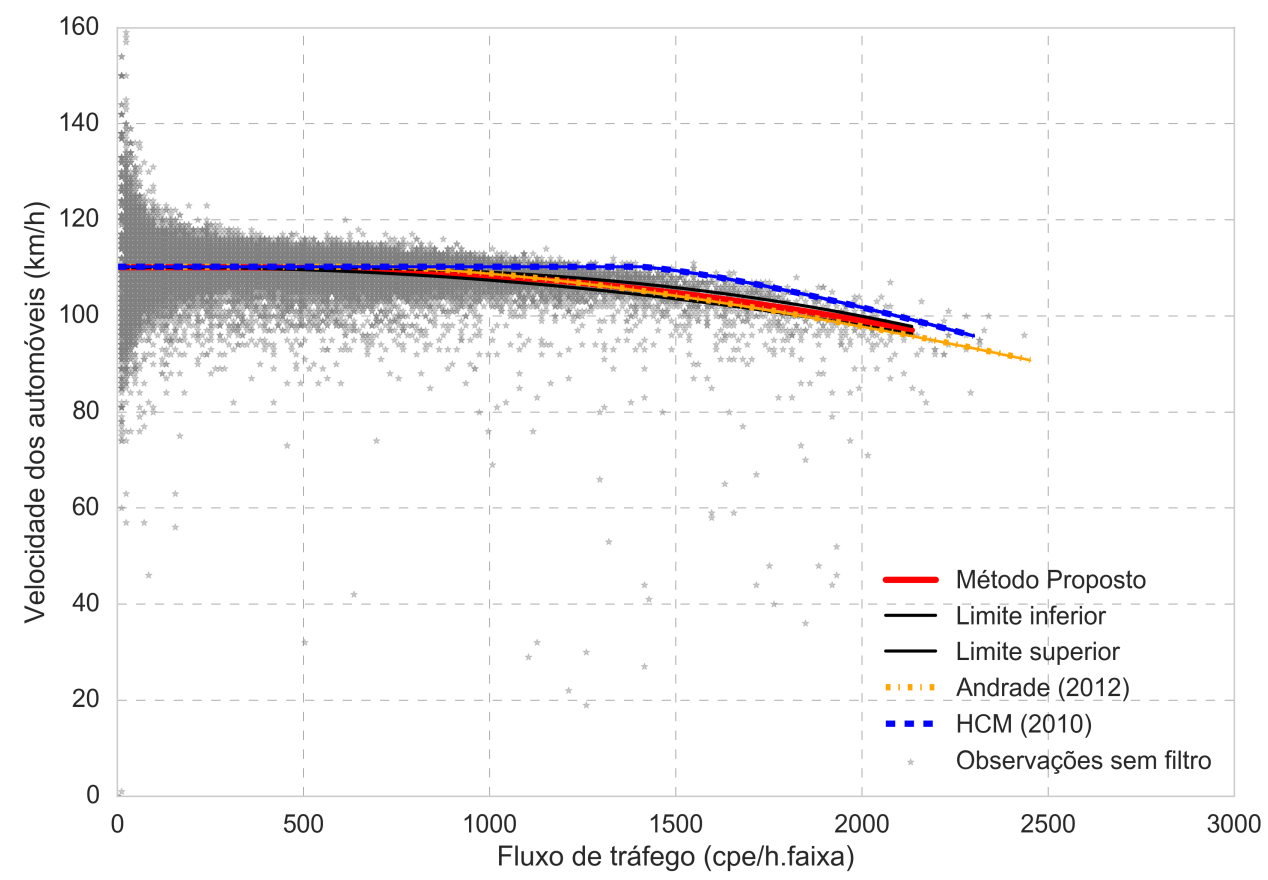

Figura A.14 - Curva fluxo-velocidade para a SP-280, km 51,9 oeste, faixa expressa, obtidas com o modelo proposto, HCM 2010 e Andrade (2012)

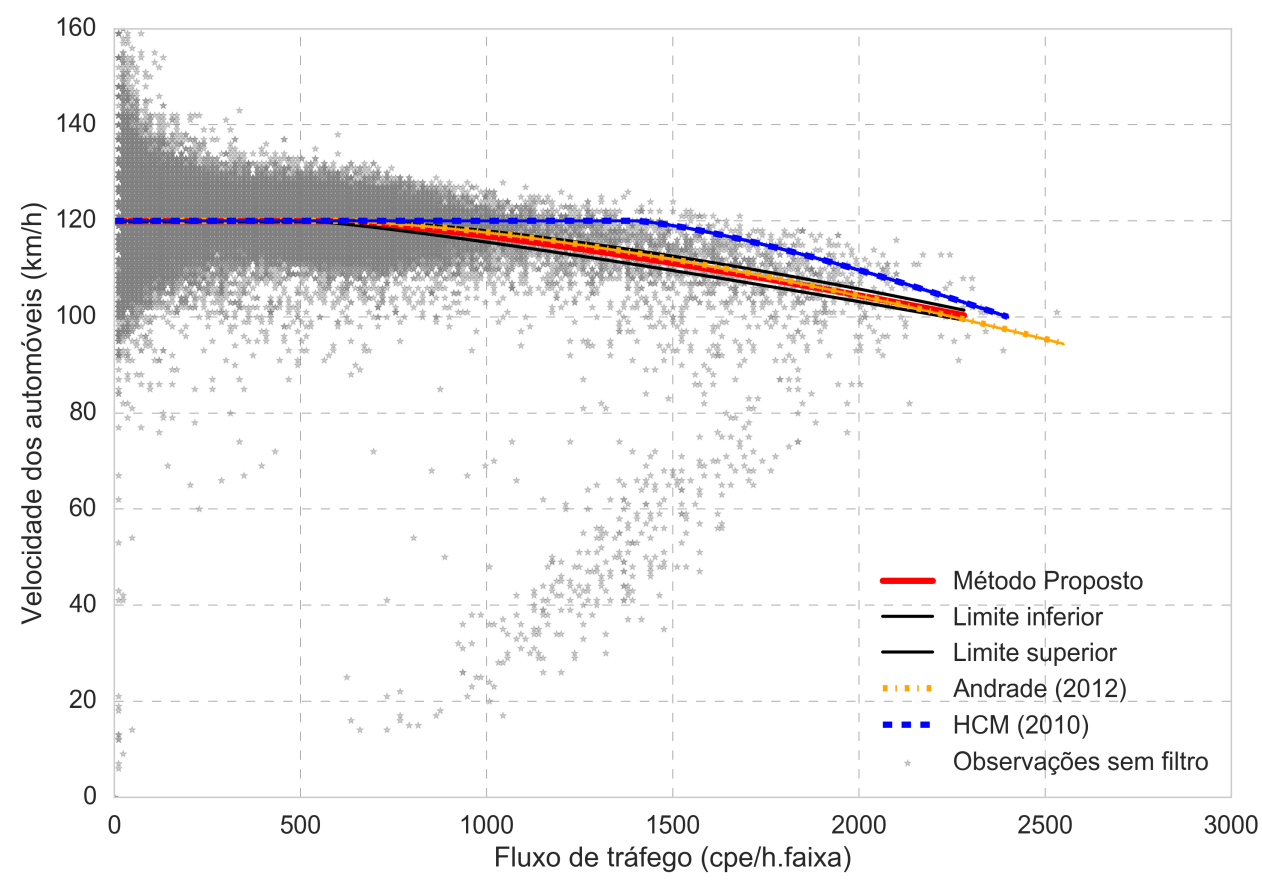

Figura A.15 - Curva fluxo-velocidade para a SP-280, km 59,6 leste, faixa expressa, obtidas com o modelo proposto, HCM 2010 e Andrade (2012) 


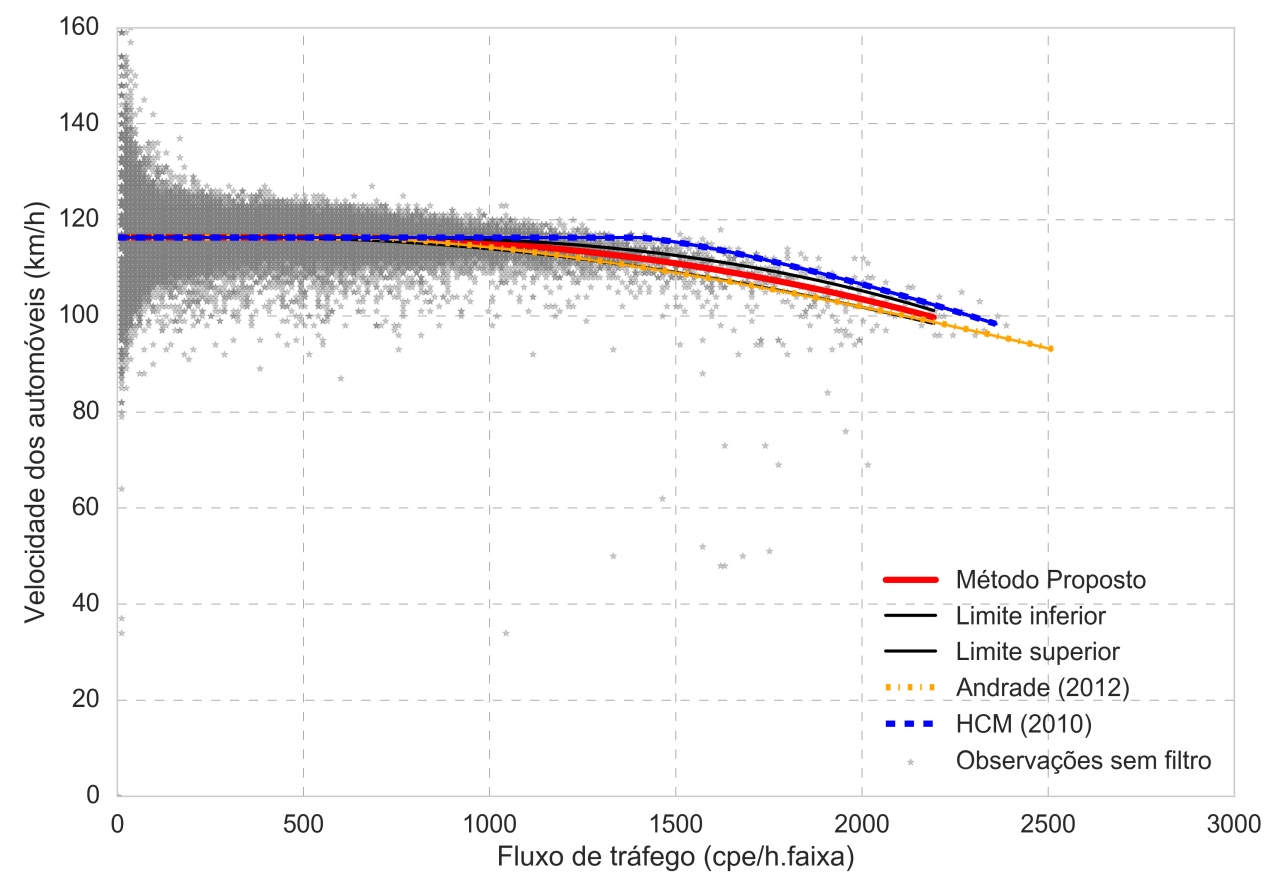

Figura A.16 - Curva fluxo-velocidade para a SP-280, km 59,6 oeste, faixa expressa, obtidas com o modelo proposto, HCM 2010 e Andrade (2012)

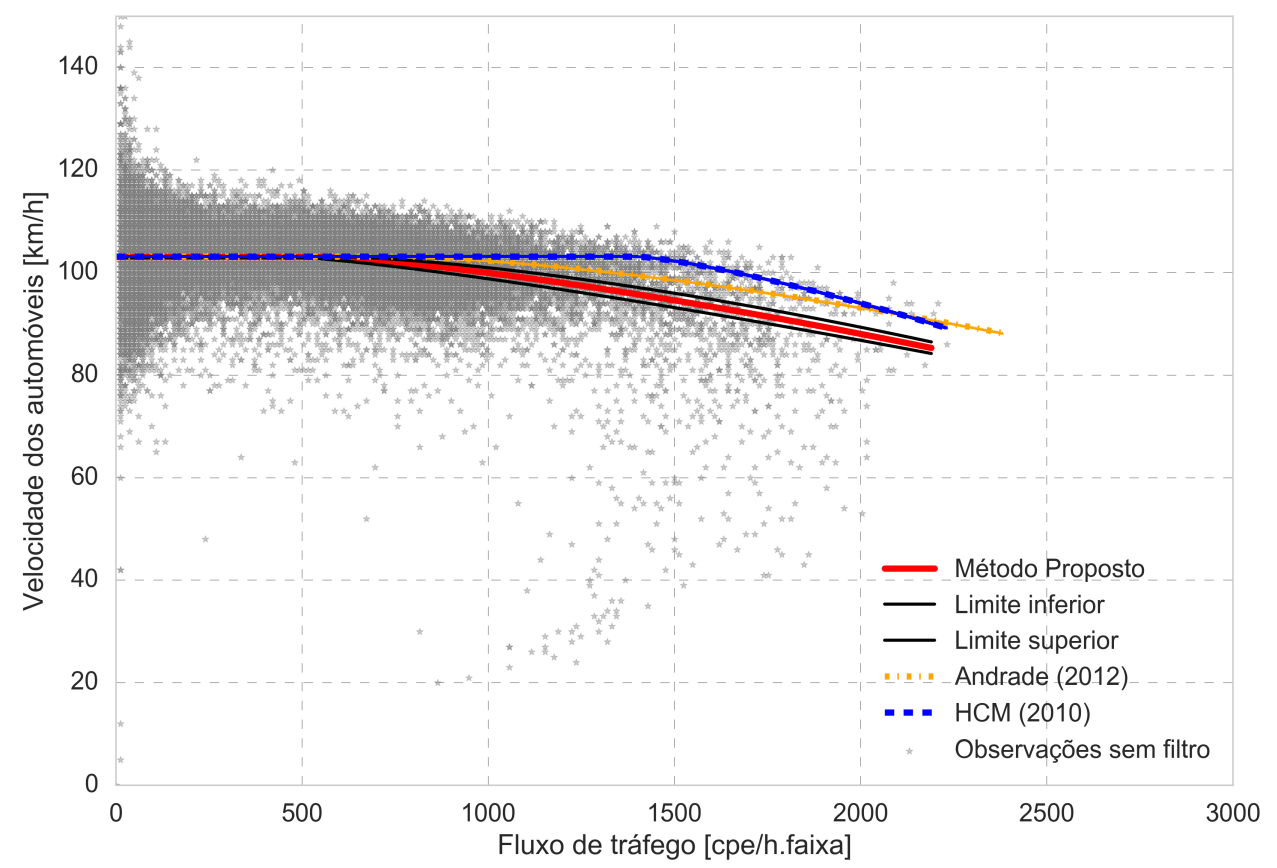

Figura A.17 - Curva fluxo-velocidade para a SP-280, km 75,9 leste, faixa expressa, obtidas com o modelo proposto, HCM 2010 e Andrade (2012) 


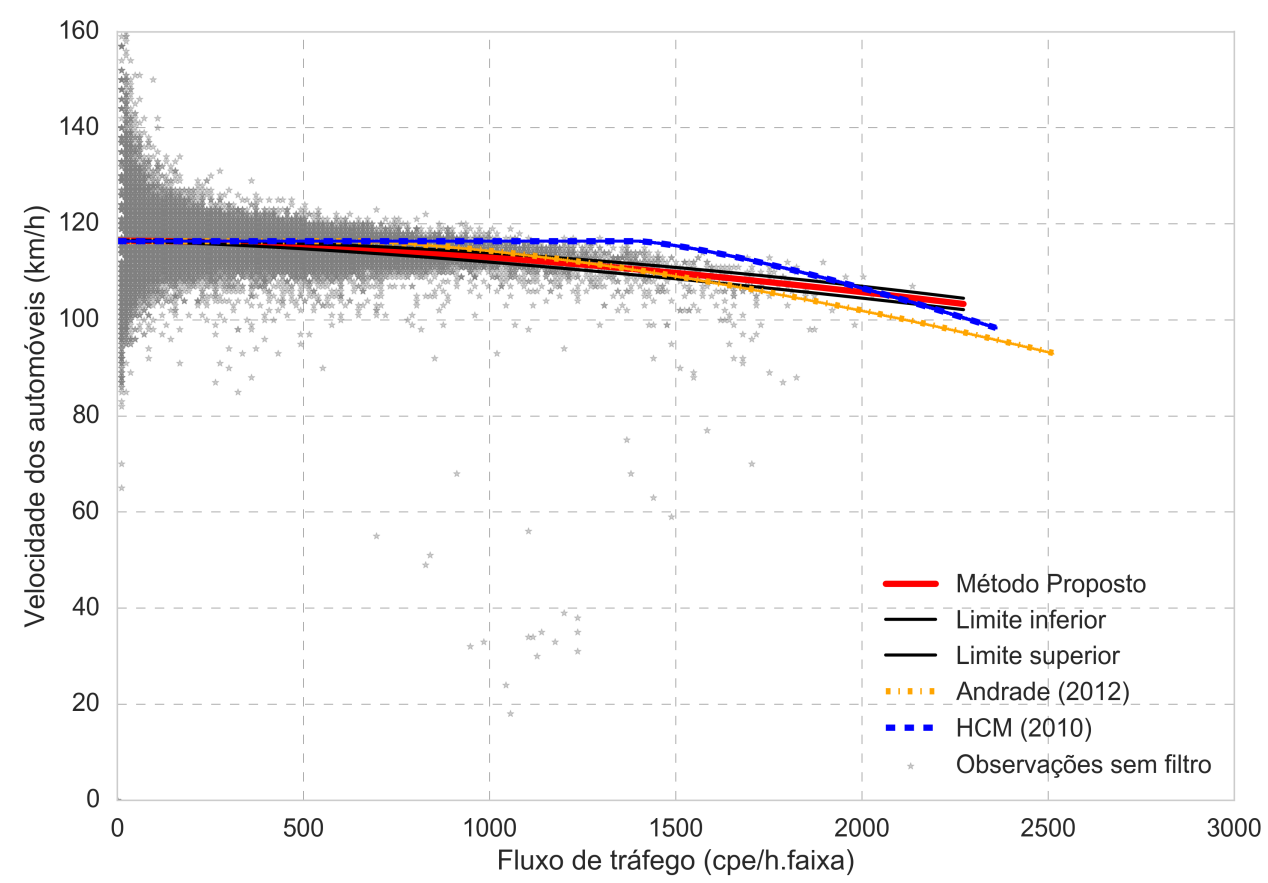

Figura A.18 - Curva fluxo-velocidade para a SP-280, km 75,9 oeste, faixa expressa, obtidas com o modelo proposto, HCM 2010 e Andrade (2012)

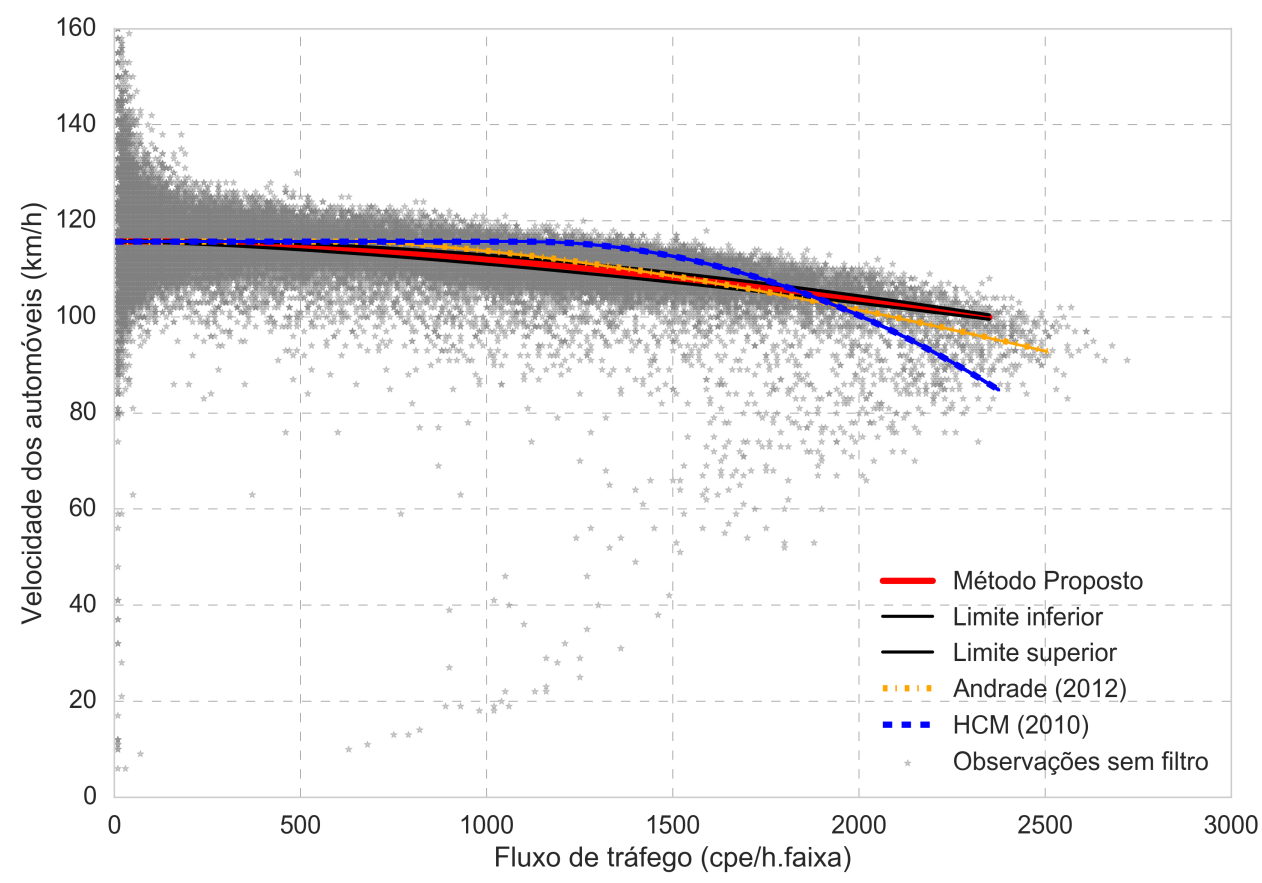

Figura A.19 - Curva fluxo-velocidade para a SP-348, km 32,0 norte, obtidas com o modelo proposto, HCM 2010 e Andrade (2012) 


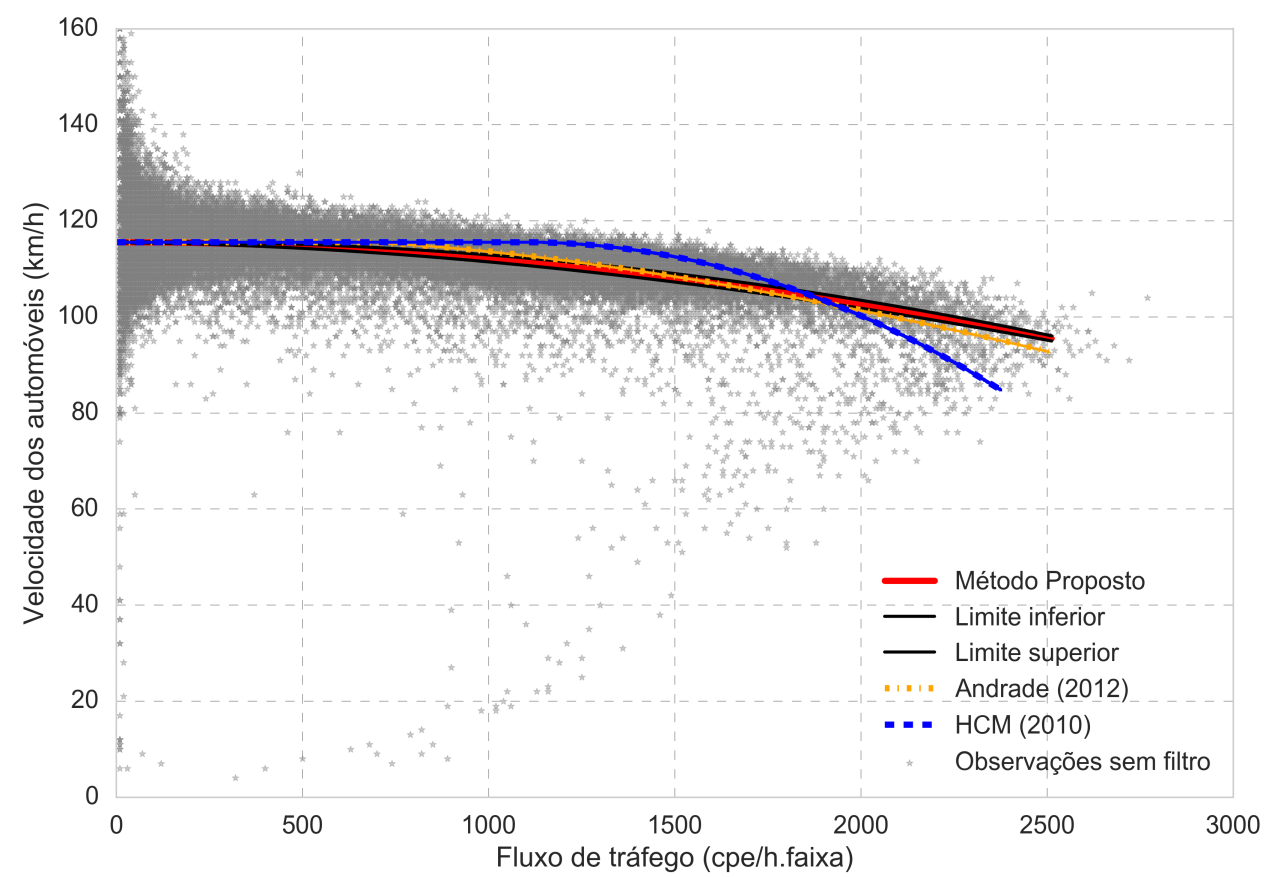

Figura A.20 - Curva fluxo-velocidade para a SP-348, km 32,0 sul, obtidas com o modelo proposto, HCM 2010 e Andrade (2012)

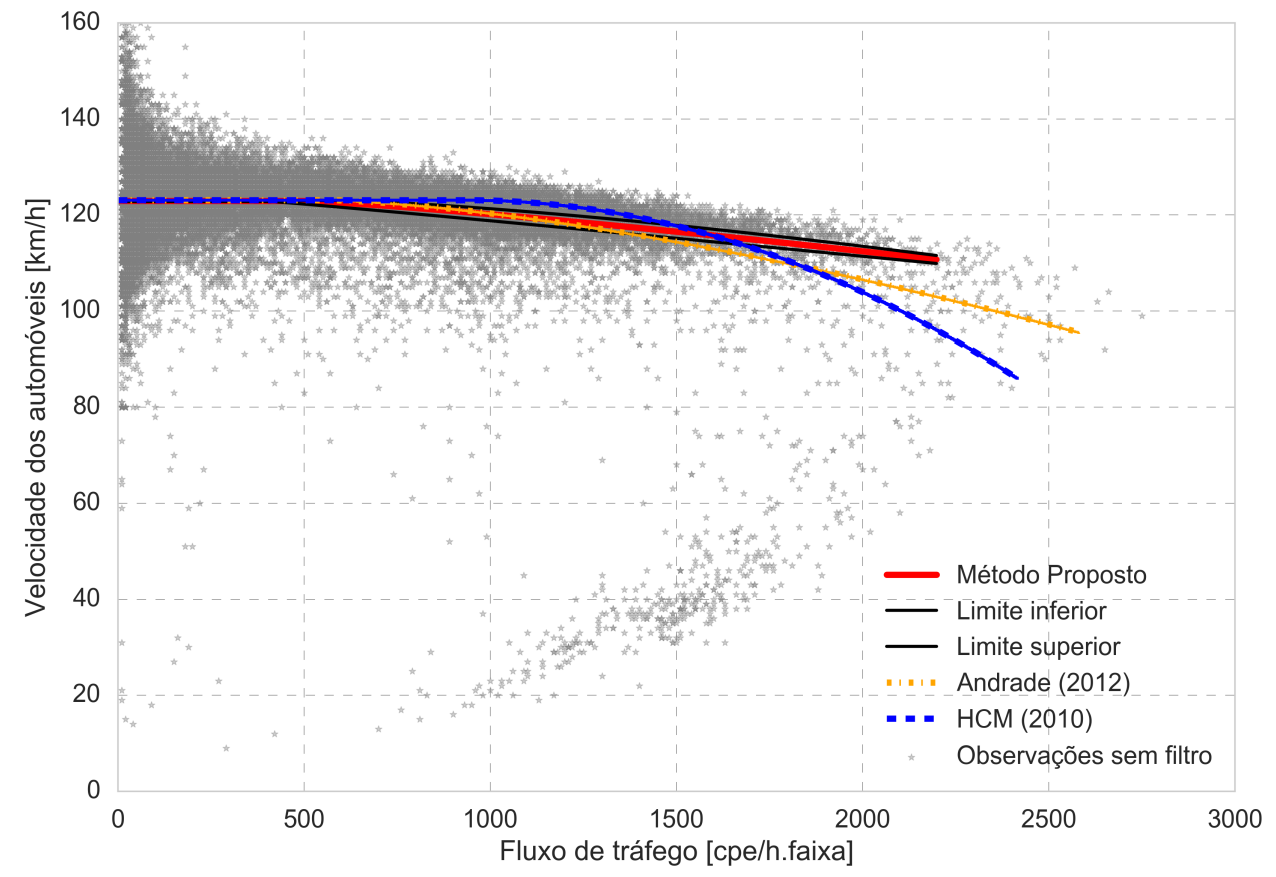

Figura A.21 - Curva fluxo-velocidade para a SP-348, km 50,0 norte, obtidas com o modelo proposto, HCM 2010 e Andrade (2012) 


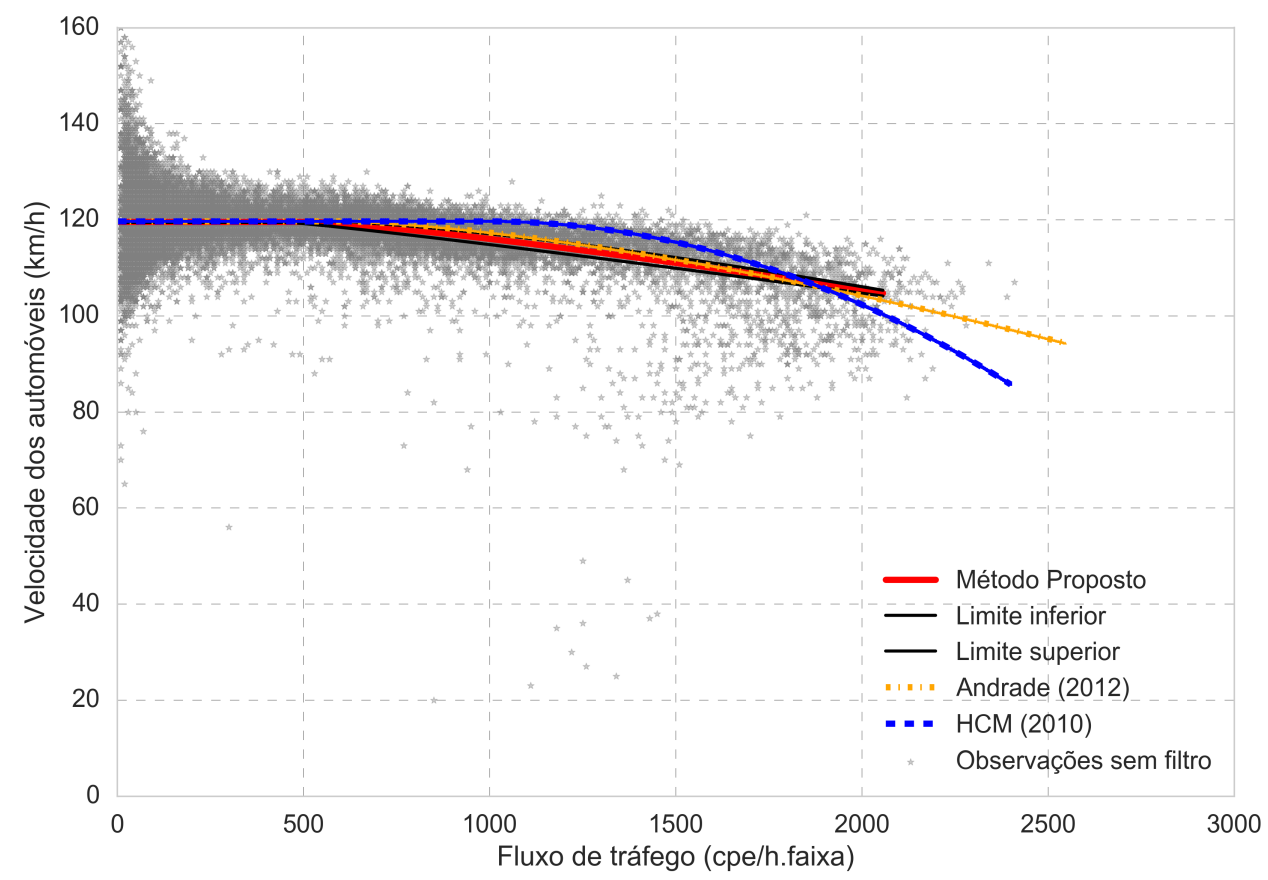

Figura A.22 - Curva fluxo-velocidade para a SP-348, km 50,0 sul, obtidas com o modelo proposto, HCM 2010 e Andrade (2012)

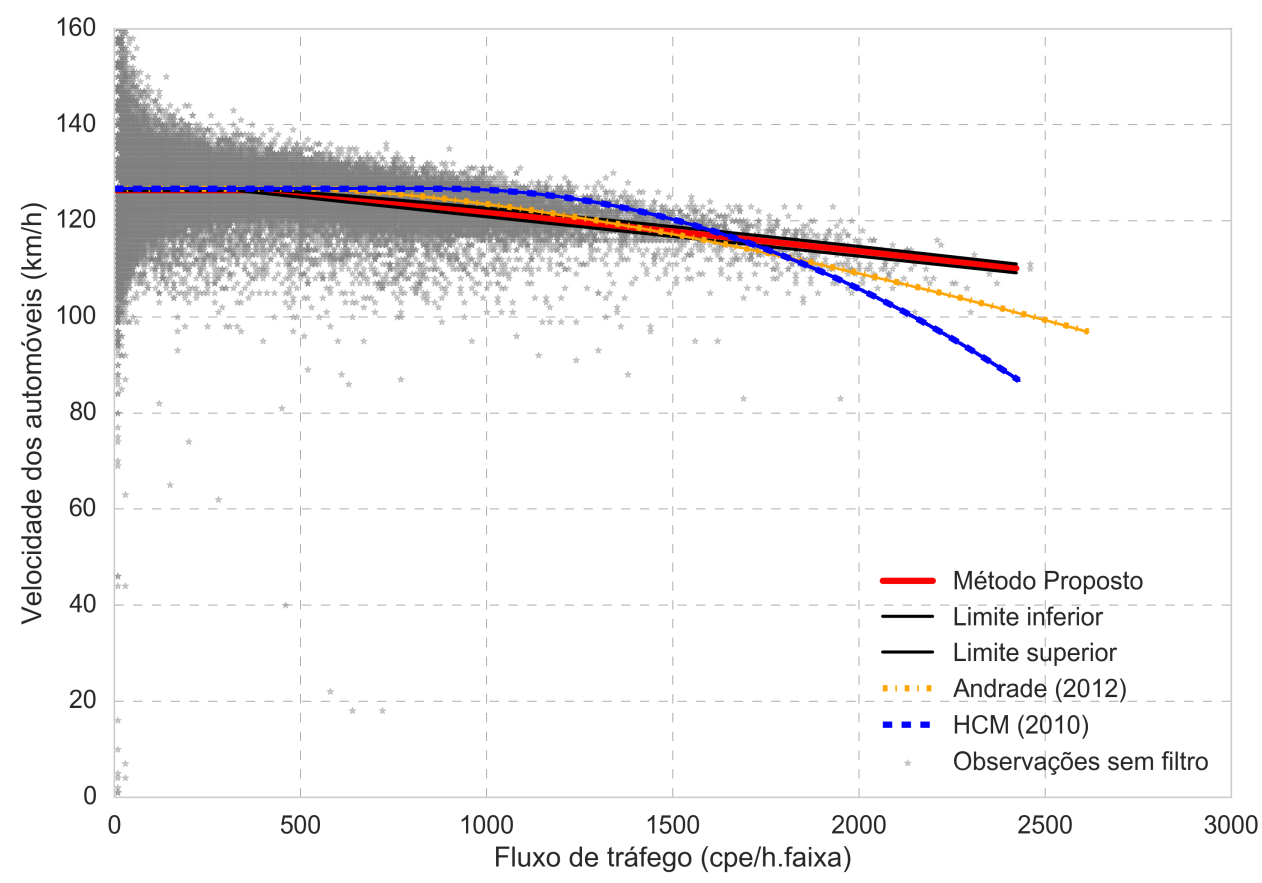

Figura A.23 - Curva fluxo-velocidade para a SP-348, km 65,0 norte, obtidas com o modelo proposto, HCM 2010 e Andrade (2012) 


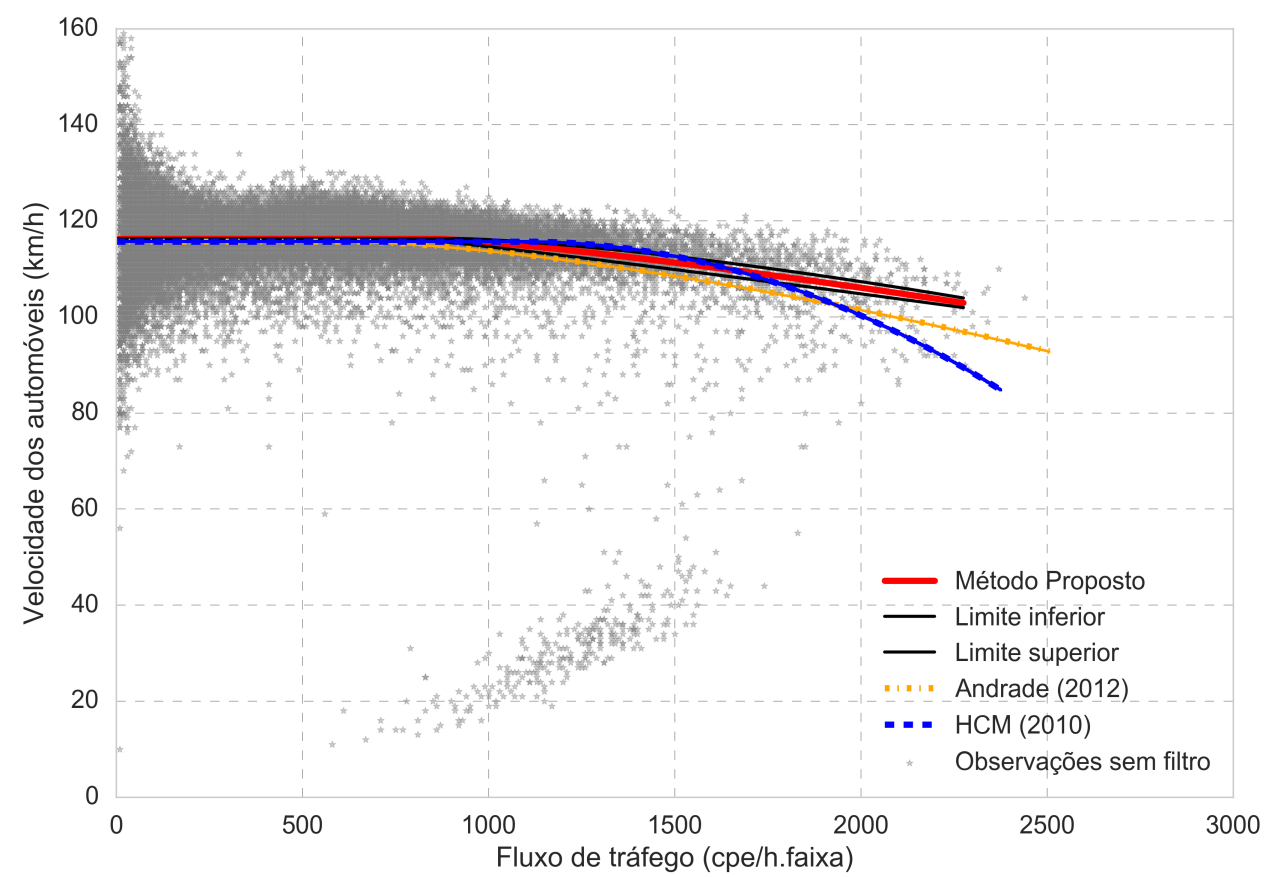

Figura A.24 - Curva fluxo-velocidade para a SP-348, km 65,0 sul, obtidas com o modelo proposto, HCM 2010 e Andrade (2012)

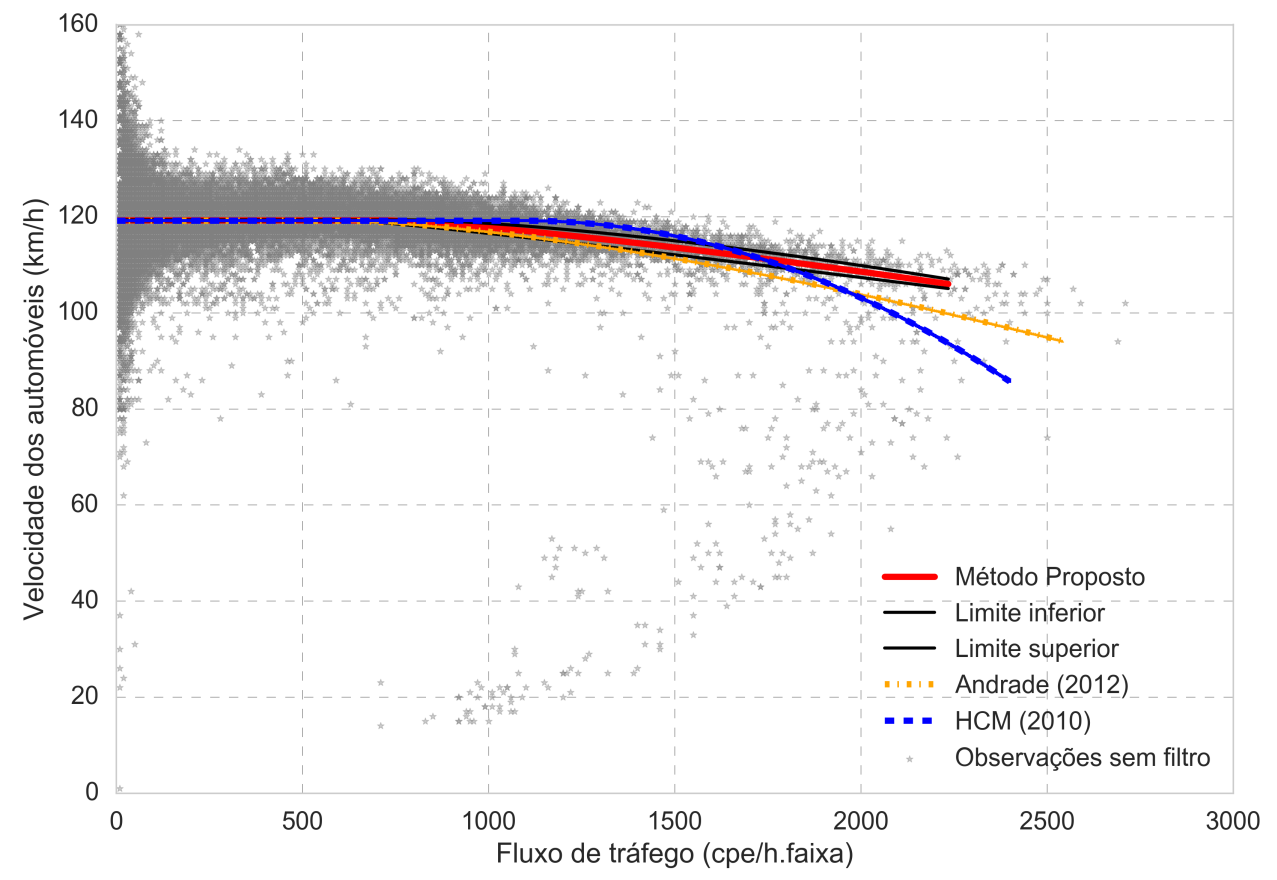

Figura A.25 - Curva fluxo-velocidade para a SP-348, km 87,0 norte, obtidas com o modelo proposto, HCM 2010 e Andrade (2012) 


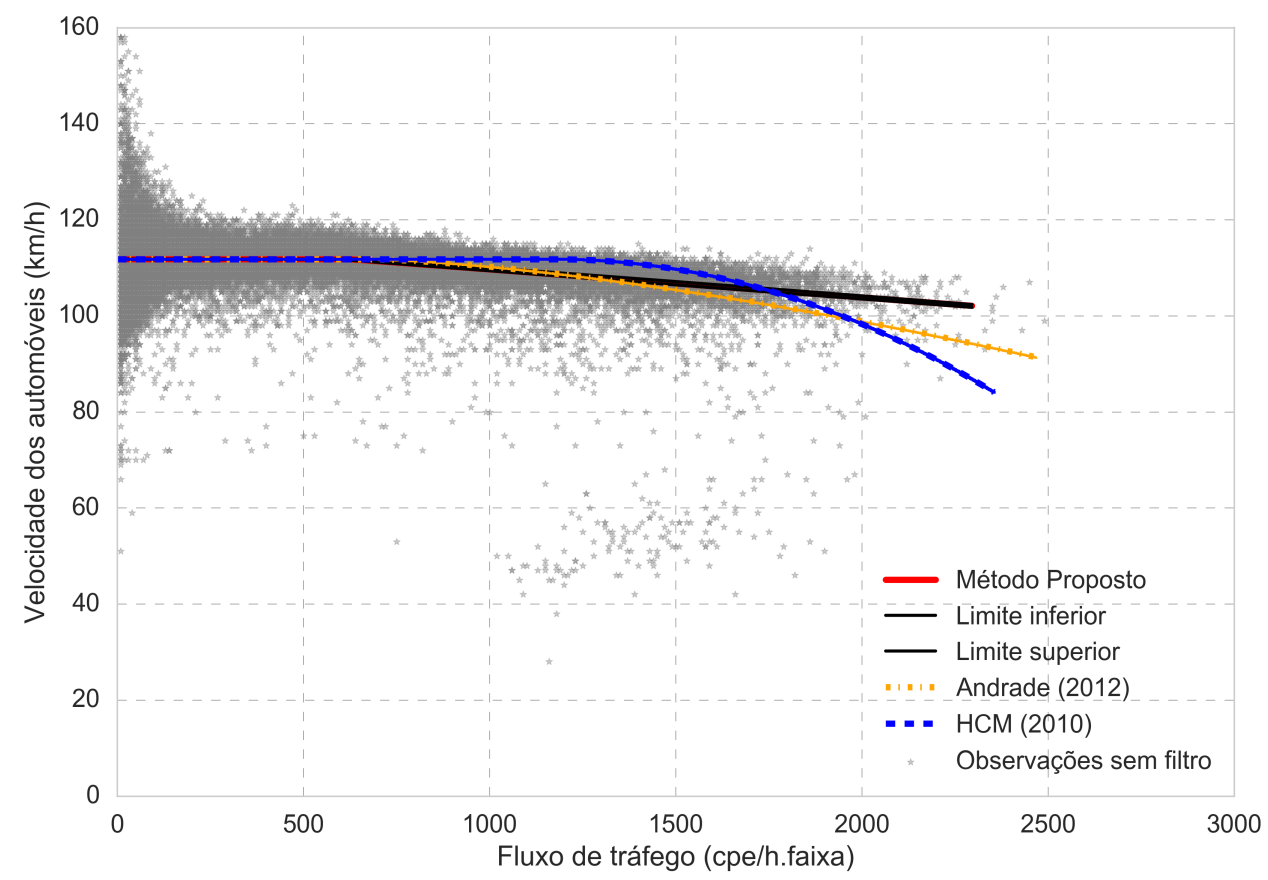

Figura A.26 - Curva fluxo-velocidade para a SP-348, km 87,0 sul, obtidas com o modelo proposto, HCM 2010 e Andrade (2012)

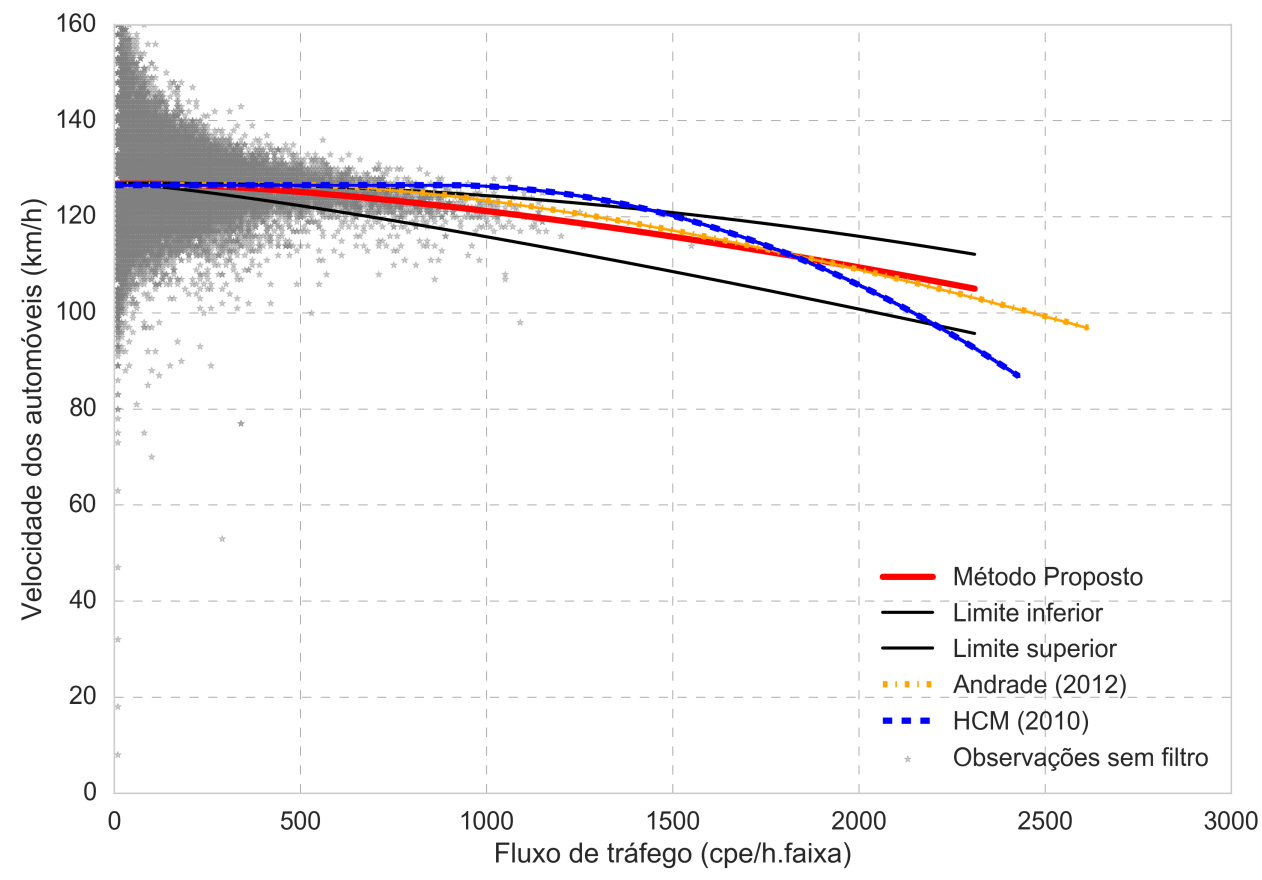

Figura A.27 - Curva fluxo-velocidade para a SP-348, km 131,7 norte, obtidas com o modelo proposto, HCM 2010 e Andrade (2012) 


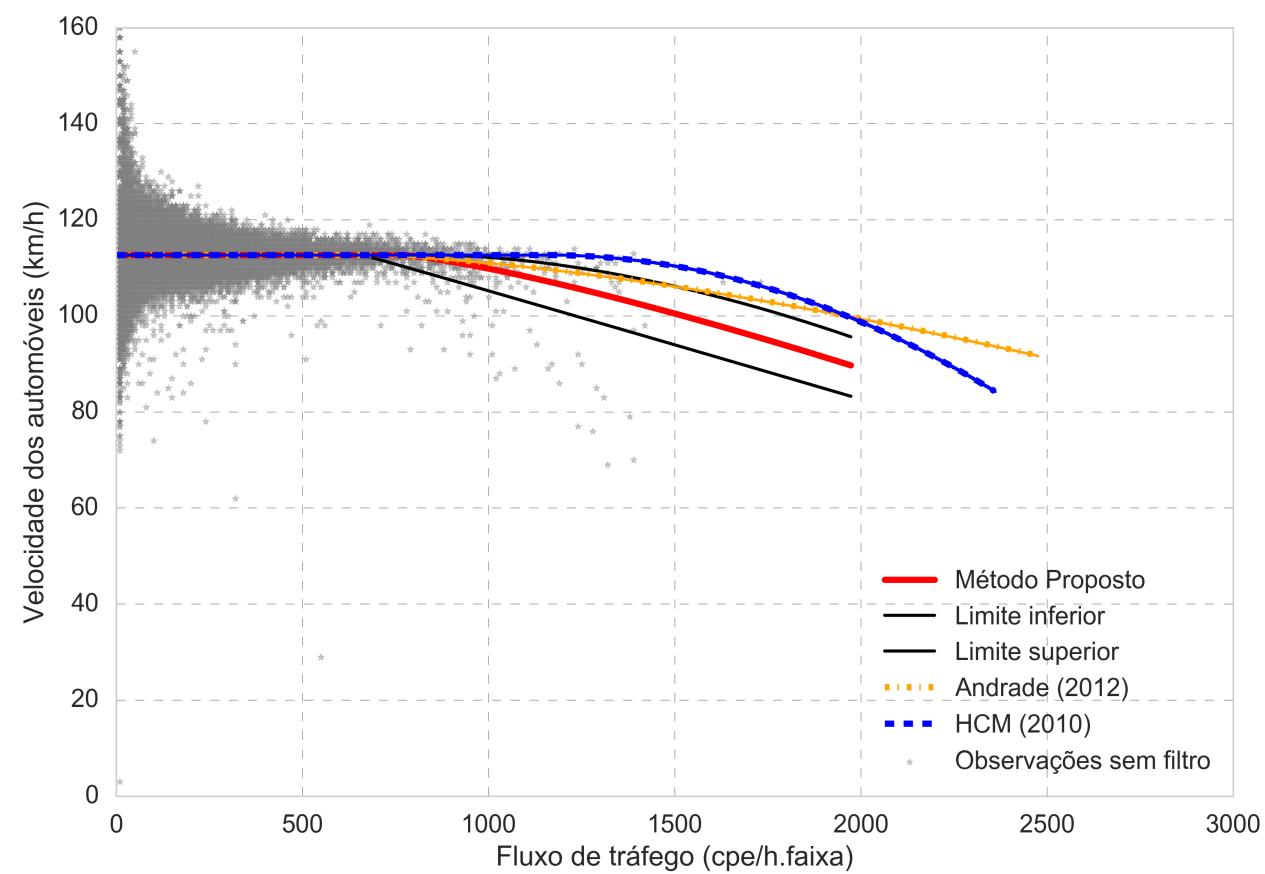

Figura A.28 - Curva fluxo-velocidade para a SP-348, km 131,7 sul, obtidas com o modelo proposto, HCM 2010 e Andrade (2012)

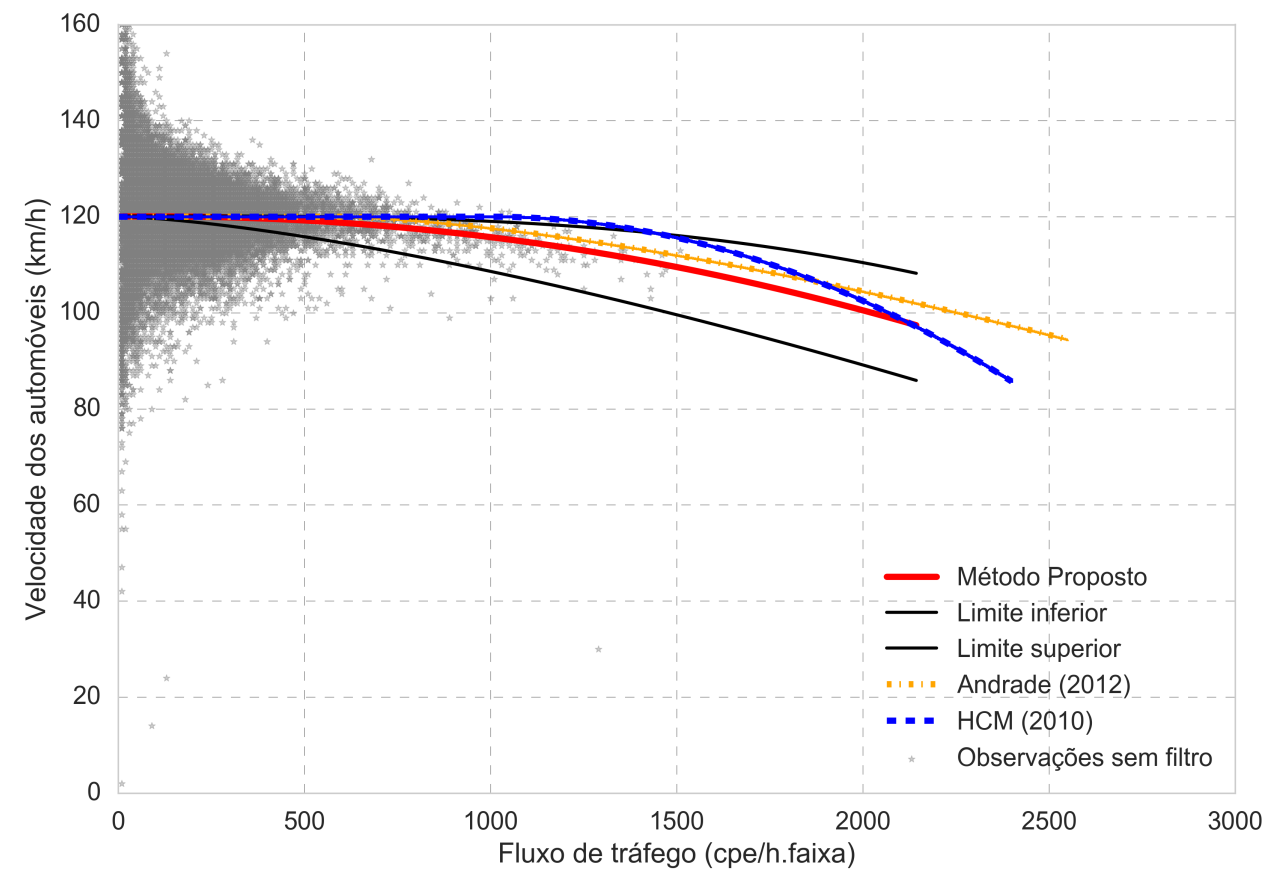

Figura A.29 - Curva fluxo-velocidade para a SP-348, km 149,6 norte, obtidas com o modelo proposto, HCM 2010 e Andrade (2012) 


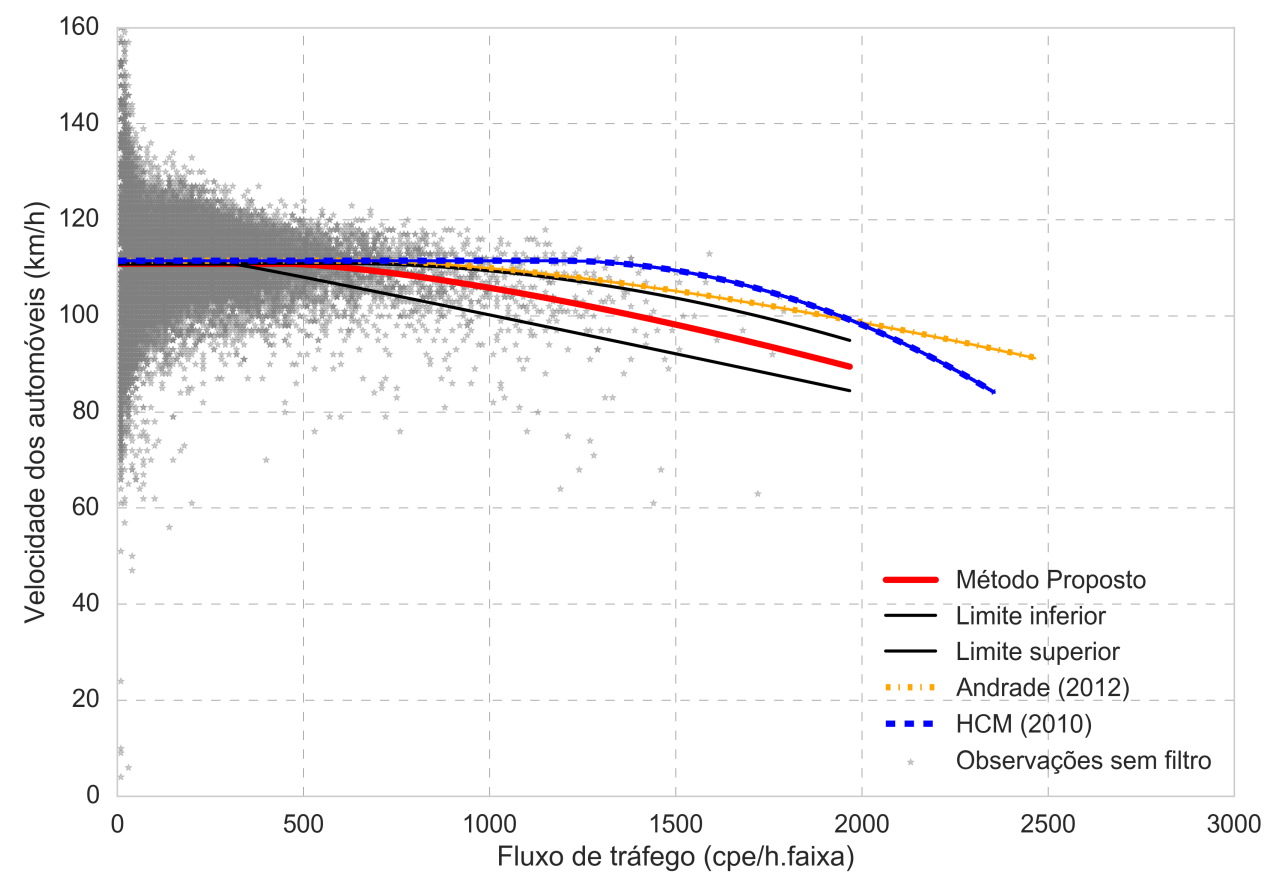

Figura A.30 - Curva fluxo-velocidade para a SP-348, km 149,6 sul, obtidas com o modelo proposto, HCM 2010 e Andrade (2012)

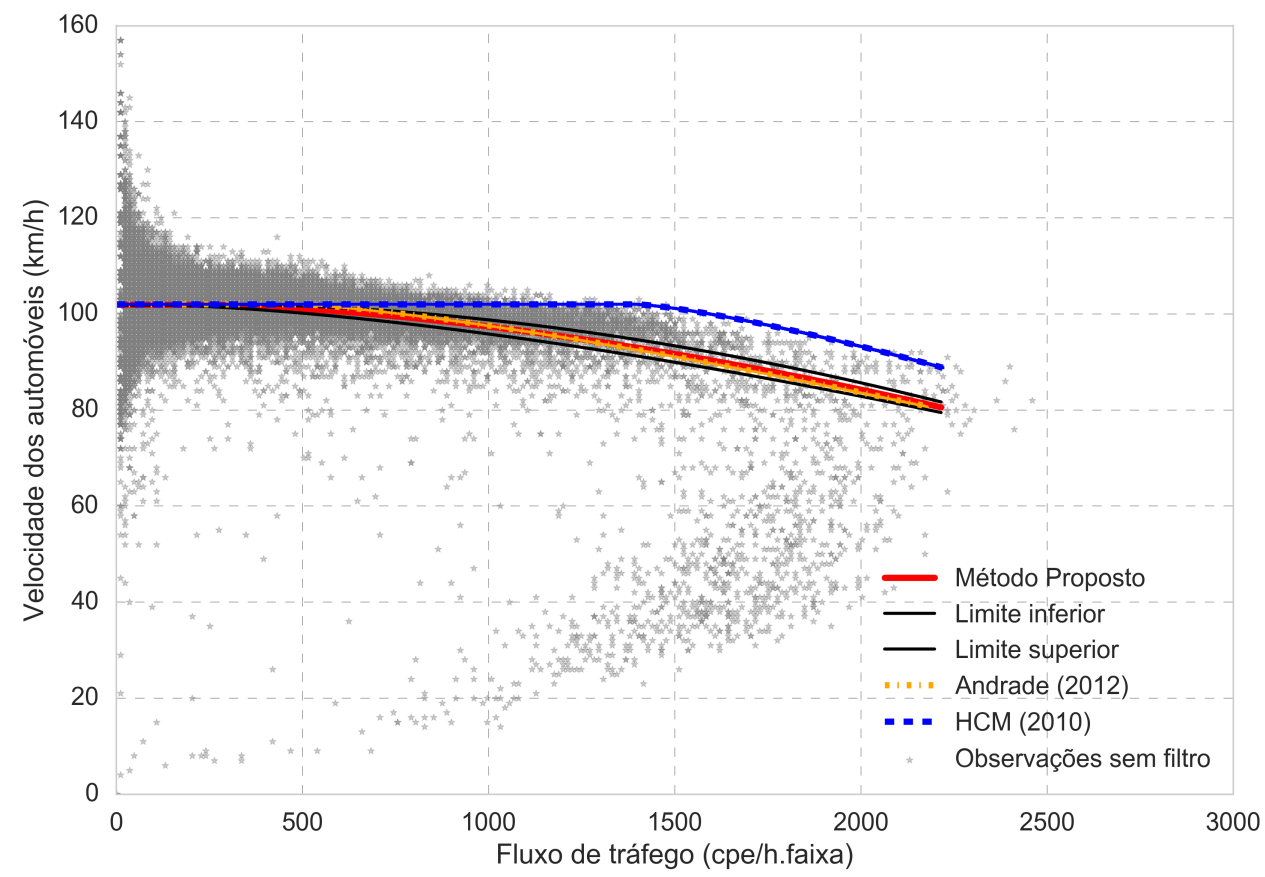

Figura A.31 - Curva fluxo-velocidade para a SP-021, km 18,3 norte, obtidas com o modelo proposto, HCM 2010 e Andrade (2012) 


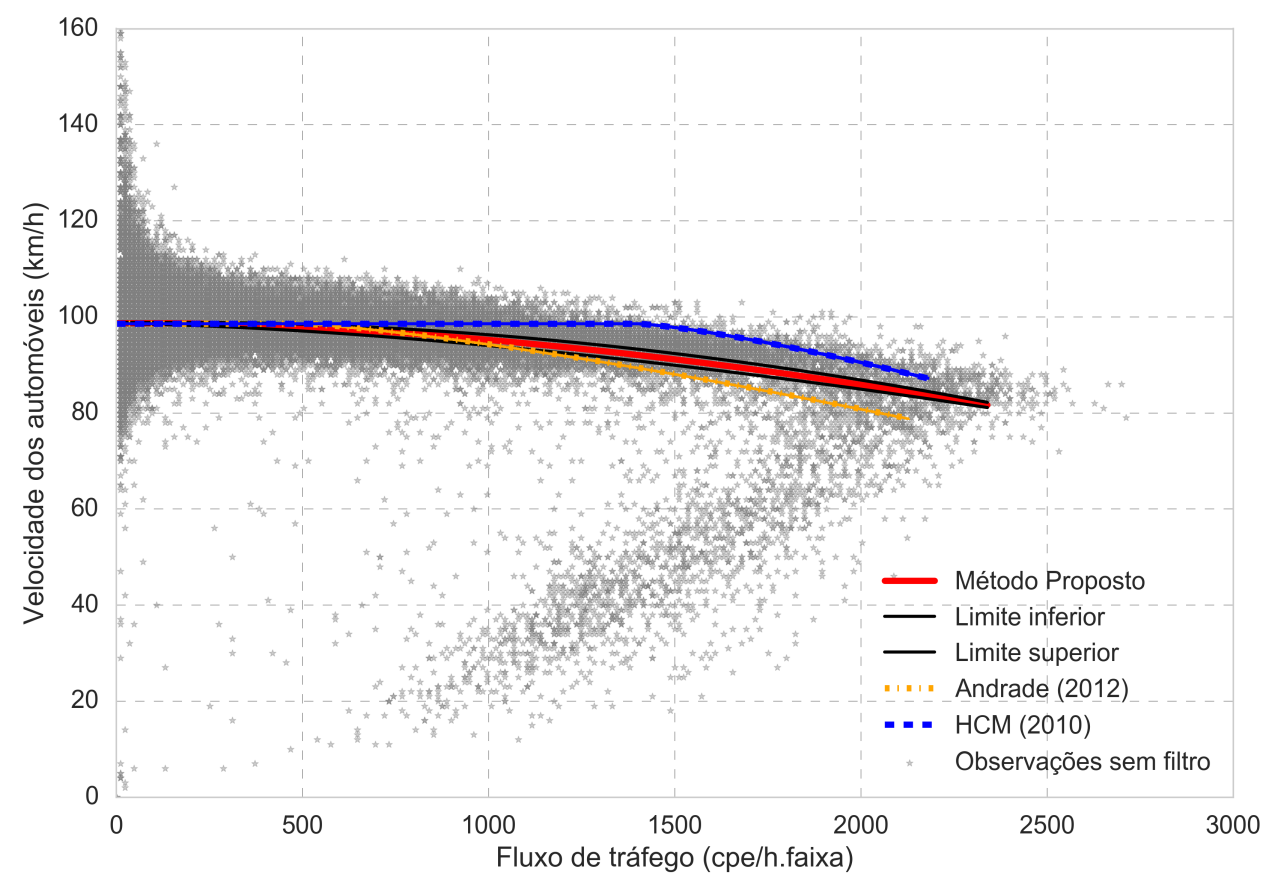

Figura A.32 - Curva fluxo-velocidade para a SP-021, km 22,3 sul, obtidas com o modelo proposto, HCM 2010 e Andrade (2012)

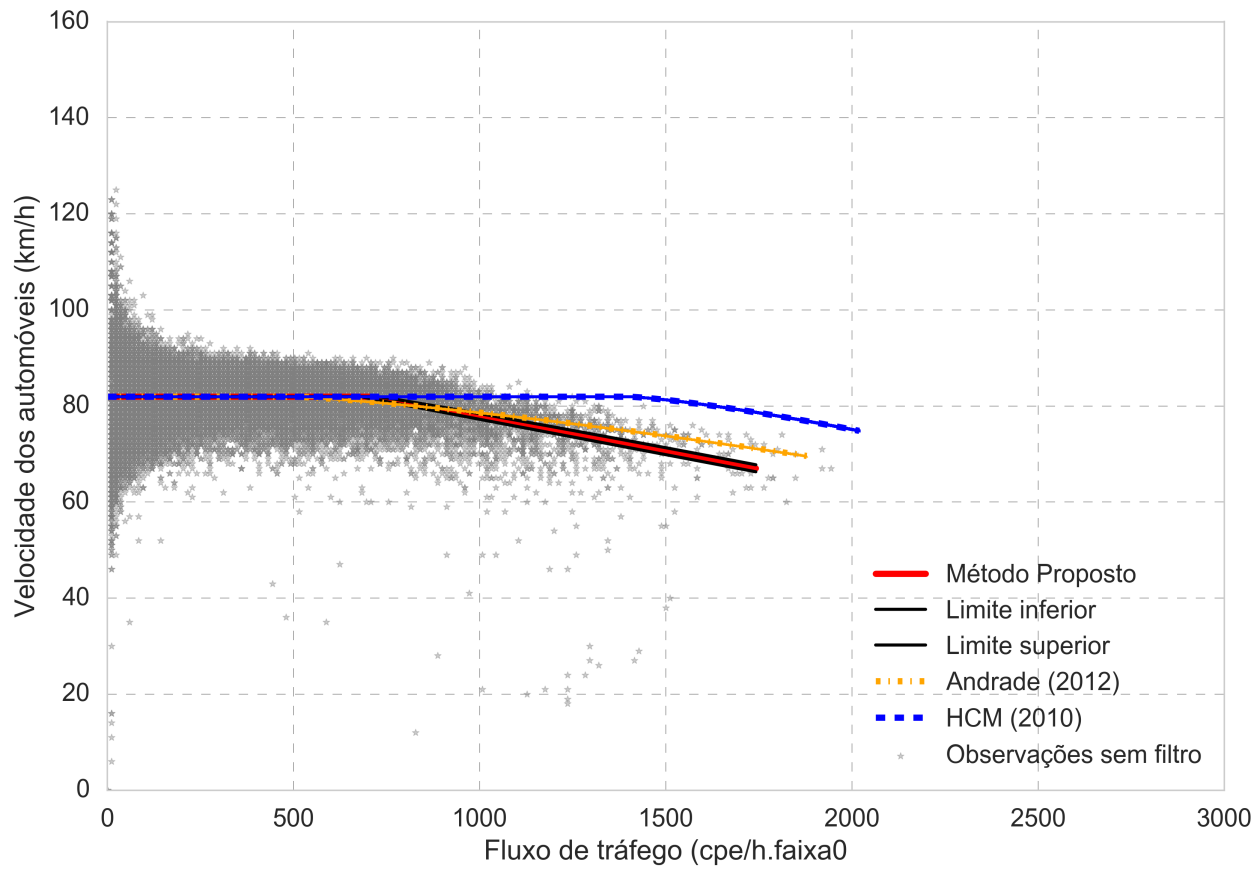

Figura A.33 - Curva fluxo-velocidade para a SP-270, km 39,9 leste, faixa expressa, obtidas com o modelo proposto, HCM 2010 e Andrade (2012) 


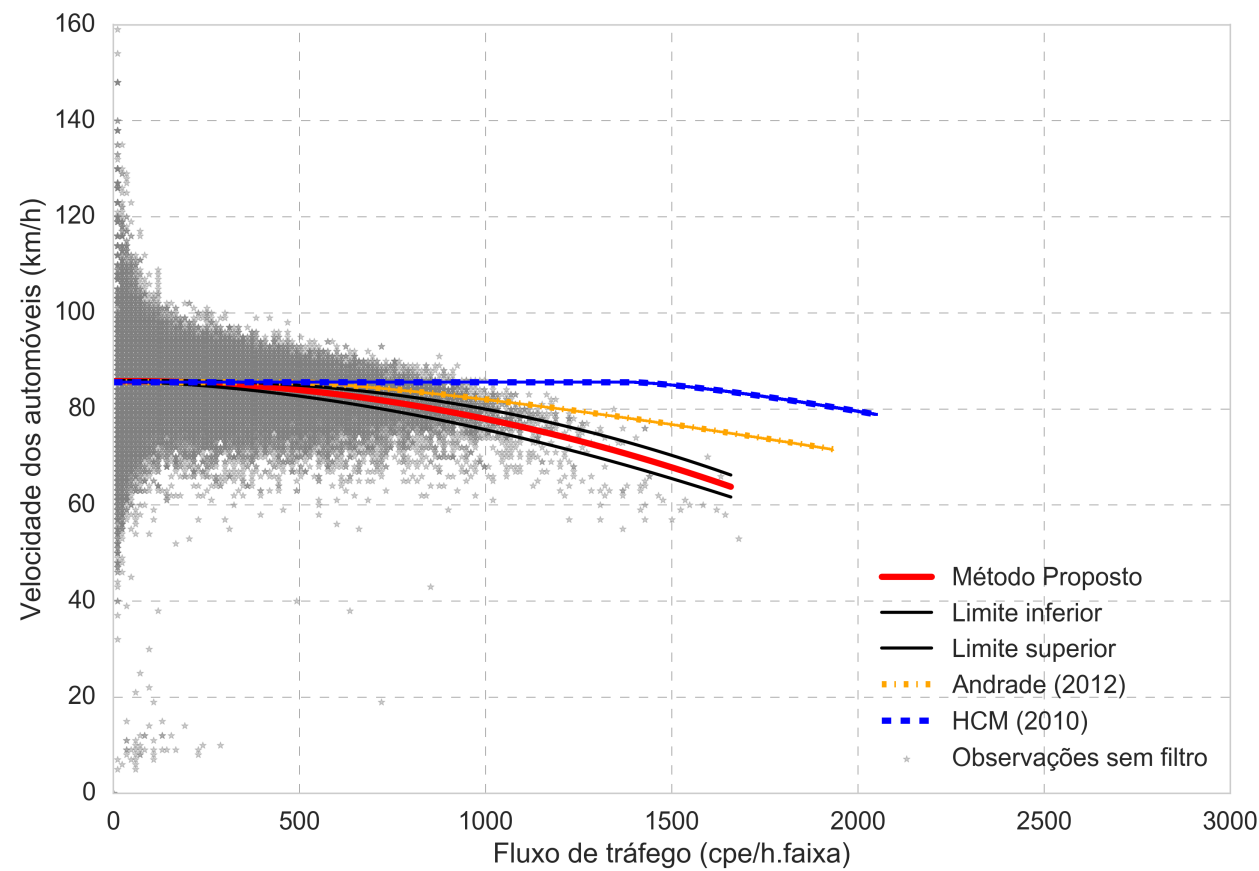

Figura A.34 - Curva fluxo-velocidade para a SP-270, km 39,9 oeste, faixa expressa, obtidas com o modelo proposto, HCM 2010 e Andrade (2012) 


\section{APÊNDICE}

\section{Teste de convergência MCMC}

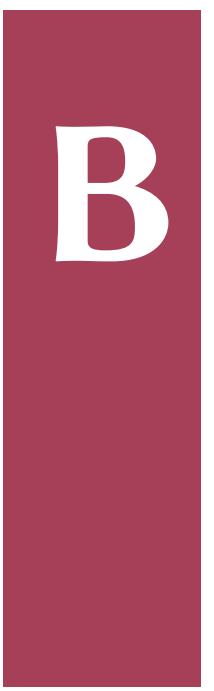

Esta seção apresenta os resultados do teste de Gelman e Rubin utilizado nos Capítulos 4 e 5 do para verificar a convergência do método de Monte Carlo via cadeias Markov. O MCMC foi empregado para estimar a distribuição posterior dos parâmetros do modelo proposto para capacidade, bem como para os parâmetros do modelo do HCM. 
Tabela B.1 - Teste de Gelman e Rubin para análise de convergência do MCMC dos parâmetros do modelo de capacidade

\begin{tabular}{|c|c|c|c|c|c|c|c|c|c|c|}
\hline \multirow[t]{2}{*}{$\mathrm{km}$} & \multirow[t]{2}{*}{ Sentido } & \multirow[t]{2}{*}{ Tipo de via } & \multirow[t]{2}{*}{ Ocupação lindeira } & \multicolumn{7}{|c|}{ Valores teste de Gelman e Rubin } \\
\hline & & & & $\tau$ & $\lambda_{2}$ & $\lambda_{2}$ & $u_{f}$ & $q_{c}$ & $b p$ & $\alpha$ \\
\hline \multicolumn{11}{|c|}{ SP-280 (Rodovia Castelo Branco) } \\
\hline 16,0 & Leste - Expresssa & Rodovia de pista dupla & Urbana & 1.0003 & 1,0006 & 1,0011 & 1,0333 & 1,0626 & 1,0807 & 1,0851 \\
\hline 16,0 & Oeste - Expressa & Rodovia de pista dupla & Urbana & & & & 1,0009 & 1,0009 & 1,0007 & 1,0021 \\
\hline 16,0 & Leste - Marginal & Rodovia de pista dupla & Urbana & & & & 1,0000 & 1,0001 & 1,0003 & 1,0005 \\
\hline 16,0 & Oeste - Marginal & Rodovia de pista dupla & Urbana & & & & 1,0002 & 1,0063 & 1,0001 & 1,0055 \\
\hline 22,4 & Leste - Expresssa & Autoestrada & Urbana & & & & 1,0061 & 1,0166 & 1,0150 & 1,0214 \\
\hline 22,4 & Oeste - Expressa & Autoestrada & Urbana & 1,0002 & 1,0001 & 1,0003 & 1,0025 & 1,0008 & 1,0007 & 1,0002 \\
\hline 22,4 & Leste - Marginal & Autoestrada & Urbana & & & & 1,0021 & 1,0006 & 1,0026 & 1,0000 \\
\hline 22,4 & Oeste - Marginal & Autoestrada & Urbana & 1,0012 & 1,0001 & 1,0001 & 1,0083 & 1,0081 & 1,0000 & 1,0100 \\
\hline 29,5 & Leste & Autoestrada & Urbana & 1,0013 & 1,0004 & 1.0007 & 1,0031 & 1,0005 & 1,0033 & 1,0016 \\
\hline 29,5 & Oeste & Autoestrada & Urbana & 1,0000 & 1,0028 & 1.0007 & 1,0027 & 1,0097 & 1,0073 & 1,0131 \\
\hline 37,0 & Leste & Rodovia de pista dupla & Rural & 1,0001 & 1,0002 & 1,0003 & 1,0011 & 1,0007 & 1,0017 & 1,0031 \\
\hline 37,0 & Oeste & Rodovia de pista dupla & Rural & & & & 1,0006 & 1,0010 & 1,0055 & 1,0033 \\
\hline 51,9 & Leste & Rodovia de pista dupla & Rural & 1,0066 & 1,0119 & 1,0006 & 1,0027 & 1,0134 & 1,0191 & 1,0192 \\
\hline 51,9 & Oeste & Rodovia de pista dupla & Rural & & & & 1,0026 & 1,0246 & 1,0353 & 1,0391 \\
\hline 59,6 & Leste & Rodovia de pista dupla & Rural & 1,0784 & 1,0044 & 1,0019 & 1,0083 & 1,0049 & 1,0229 & 1,0197 \\
\hline 59,6 & Oeste & Rodovia de pista dupla & Rural & & & & 1,0008 & 1,0015 & 1,0006 & 1,0010 \\
\hline 75,9 & Leste & Rodovia de pista dupla & Rural & 1,0080 & 1,0007 & 1,0005 & 1,0004 & 1,0413 & 1,0260 & 1,0436 \\
\hline 75,9 & Oeste & Rodovia de pista dupla & Rural & & & & 1,0041 & 1,0020 & 1,0094 & 1,0052 \\
\hline \multicolumn{11}{|c|}{ SP-348 (Rodovia dos Bandeirantes) } \\
\hline 32,0 & Norte & Autoestrada & Rural & 1,0449 & 1,0109 & 1,0023 & 1,0042 & 1,0229 & 1,0306 & 1,0360 \\
\hline 32,0 & Sul & Autoestrada & Rural & 1,0011 & 1,0001 & 1,0005 & 1,0039 & 1,0098 & 1,0159 & 1,0162 \\
\hline 50,0 & Norte & Autoestrada & Rural & 1,0003 & 1,0006 & 1,0005 & 1,0007 & 1,0006 & 1,0039 & 1,0029 \\
\hline 50,0 & Sul & Autoestrada & Rural & 1,0034 & 1,0000 & 1,0004 & 1,0024 & 1,0030 & 1,0070 & 1,0070 \\
\hline 65,0 & Norte & Autoestrada & Rural & & & & 1,0002 & 1,0051 & 1,0052 & 1,0084 \\
\hline 65,0 & Sul & Autoestrada & Rural & 1,0023 & 1,0001 & 1,0000 & 1,0002 & 1,0011 & 1,0017 & 1,0014 \\
\hline 87,0 & Norte & Autoestrada & Rural & 1,0025 & 1,0013 & 1,0012 & 1,0008 & 1,0119 & 1,0120 & 1,0164 \\
\hline 87,0 & Sul & Autoestrada & Rural & 1,0018 & 1,0001 & 1,0002 & 1,0005 & 1,0024 & 1,0021 & 1,0002 \\
\hline 131,7 & Norte & Autoestrada & Rural & & & & 1,0001 & 1,0071 & 1,0122 & 1,0104 \\
\hline 131,7 & Sul & Autoestrada & Rural & & & & 1,0006 & 1,0005 & 1,0000 & 1,0001 \\
\hline 149,6 & Norte & Autoestrada & Rural & & & & 1,0021 & 1,0058 & 1,0041 & 1,0071 \\
\hline 149,6 & Sul & Autoestrada & Rural & & & & 1,0003 & 1,0027 & 1,0043 & 1,0040 \\
\hline \multicolumn{11}{|c|}{ SP-021 (Rodoanel) } \\
\hline 18,3 & Norte (Externo) & Rodovia de pista dupla & Urbana & 1,0005 & 1,0003 & 1,0000 & 1,0009 & 1,0076 & 1,0069 & 1,0094 \\
\hline 22,3 & Sul (Interna) & Rodovia de pista dupla & Urbana & 1,0032 & 1,0002 & 1,0003 & 1,0090 & 1,0049 & 1,0151 & 1,0146 \\
\hline \multicolumn{11}{|c|}{ SP-270 (Raposo Tavares) } \\
\hline 39,9 & Leste & Rodovia de pista dupla & Urbana & & & & 1,0005 & 1,0018 & 1,0002 & 1,0003 \\
\hline 39,9 & Oeste & Rodovia de pista dupla & Urbana & & & & 1,0063 & 1,0254 & 1,0080 & 1,0255 \\
\hline
\end{tabular}




\section{APÊNDICE}

\section{Distribuição posterior}

Esta seção apresenta o tempo de processamento, o tipo de distribuição posterior dos parâmetros do modelo proposto para capacidade e dos parâmetros do HCM.

Tabela C.1 - Distribuição posterior dos parâmetros do modelo de capacidade e tempo de processamento

\begin{tabular}{|c|c|c|c|c|c|c|}
\hline \multirow[t]{2}{*}{$\mathrm{km}$} & \multirow[t]{2}{*}{ Sentido } & \multirow[t]{2}{*}{ Tipo de via } & \multirow{2}{*}{$\begin{array}{l}\text { Tempo de processa- } \\
\text { mento (s) }\end{array}$} & \multicolumn{3}{|c|}{ Distribuicão posteriror } \\
\hline & & & & $\tau$ & $\lambda_{1}$ & $\lambda_{2}$ \\
\hline \multicolumn{7}{|c|}{ SP-280 (Rodovia Castelo Branco) } \\
\hline 16,0 & Leste - Expresssa & Rodovia de pista dupla & 182,5 & Sem formato conhecido & Normal & Normal \\
\hline 22,4 & Oeste - Expressa & Autoestrada & 112,8 & Sem formato conhecido & Normal & Normal \\
\hline 22,4 & Oeste - Marginal & Autoestrada & 142,5 & Sem formato conhecido & Normal & Normal \\
\hline 29,5 & Leste & Autoestrada & 92,7 & Sem formato conhecido & Normal & Normal \\
\hline 29,5 & Oeste & Autoestrada & 92,8 & Sem formato conhecido & Normal & Normal \\
\hline 37,0 & Leste & Rodovia de pista dupla & 151,3 & Sem formato conhecido & Normal & Normal \\
\hline 51,9 & Leste & Rodovia de pista dupla & 194,9 & Sem formato conhecido & Normal & Normal \\
\hline 59,6 & Leste & Rodovia de pista dupla & 111,1 & Sem formato conhecido & Normal & Normal \\
\hline 75,9 & Leste & Rodovia de pista dupla & 89,3 & Sem formato conhecido & Normal & Normal \\
\hline \multicolumn{7}{|c|}{ SP-348 (Rodovia dos Bandeirantes) } \\
\hline 32,0 & Norte & Autoestrada & 91,0 & Sem formato conhecido & Normal & Normal \\
\hline 32,0 & Sul & Autoestrada & 96,8 & Sem formato conhecido & Normal & Normal \\
\hline 50,0 & Norte & Autoestrada & 65,8 & Sem formato conhecido & Normal & Normal \\
\hline 50,0 & Sul & Autoestrada & 48,1 & Sem formato conhecido & Normal & Normal \\
\hline 65,0 & Sul & Autoestrada & 76,4 & Sem formato conhecido & Normal & Normal \\
\hline 87,0 & Norte & Autoestrada & 57,4 & Sem formato conhecido & Normal & Normal \\
\hline 87.0 & Sul & Autoestrada & 96,7 & Sem formato conhecido & Normal & Normal \\
\hline \multicolumn{7}{|c|}{ SP-021 (Rodoanel) } \\
\hline 18,3 & Norte & Rodovia de pista dupla & 84,6 & Sem formato conhecido & Normal & Normal \\
\hline 22,3 & Sul & Rodovia de pista dupla & 104,0 & Sem formato conhecido & Normal & Normal \\
\hline
\end{tabular}


Tabela C.2 - Distribuição posterior dos parâmetros estimados do modelo HCM 2010 e tempo de processamento

\begin{tabular}{|c|c|c|c|c|c|c|c|}
\hline \multirow[t]{2}{*}{$\mathrm{km}$} & \multirow[t]{2}{*}{ Sentido } & \multirow[t]{2}{*}{ Tipo de via } & \multirow{2}{*}{$\begin{array}{l}\text { Tempo de processa- } \\
\text { mento (s) }\end{array}$} & \multicolumn{4}{|c|}{ Distribuição posterior } \\
\hline & & & & $u_{f}$ & $q_{c} \mathrm{c}$ & $b p$ & $\alpha$ \\
\hline \multicolumn{8}{|c|}{ SP-280 (Rodovia Castelo Branco) } \\
\hline 16,0 & Leste - Expresssa & Rodovia de pista dupla & 682,6 & Normal & Normal & Normal & Normal \\
\hline 16,0 & Oeste - Expressa & Rodovia de pista dupla & 565,8 & Normal & Normal & Exponecial & Exponencial \\
\hline 16,0 & Leste - Marginal & Rodovia de pista dupla & 892,1 & Normal & Normal & Normal & Exponencial \\
\hline 16,0 & Oeste - Marginal & Rodovia de pista dupla & 864,6 & Normal & Normal & Normal & Exponencial \\
\hline 22,4 & Leste - Expresssa & Autoestrada & 459,8 & Normal & Normal & Normal & Normal \\
\hline 22,4 & Oeste - Expressa & Autoestrada & 335,3 & Normal & Normal & Normal & Exponencial \\
\hline 22,4 & Leste - Marginal & Autoestrada & 325,1 & Normal & Normal & Exponecial & Normal \\
\hline 22,4 & Oeste - Marginal & Autoestrada & 375,8 & Normal & Normal & Normal & Exponencial \\
\hline 29,5 & Leste & Autoestrada & 499,1 & Normal & Normal & Normal & Normal \\
\hline 29,5 & Oeste & Autoestrada & 481,7 & Normal & Normal & Normal & Normal \\
\hline 37,0 & Leste & Rodovia de pista dupla & 636,7 & Normal & Normal & Normal & Exponencial \\
\hline 37,0 & Oeste & Rodovia de pista dupla & 670,1 & Normal & Normal & Normal & Normal \\
\hline 51,9 & Leste & Rodovia de pista dupla & 650,0 & Normal & Normal & Normal & Normal \\
\hline 51,9 & Oeste & Rodovia de pista dupla & 704,0 & Normal & Normal & Normal & Normal \\
\hline 59,6 & Leste & Rodovia de pista dupla & 576,2 & Normal & Normal & Normal & Normal \\
\hline 59,6 & Oeste & Rodovia de pista dupla & 461,4 & Normal & Normal & Normal & Normal \\
\hline 75,9 & Leste & Rodovia de pista dupla & 511,8 & Normal & Normal & Normal & Normal \\
\hline 75,9 & Oeste & Rodovia de pista dupla & 495,1 & Normal & Normal & Exponecial & Normal \\
\hline \multicolumn{8}{|c|}{ SP-348 (Rodovia dos Bandeirantes) } \\
\hline 32,0 & Norte & Autoestrada & 405,5 & Normal & Normal & Normal & Normal \\
\hline 32,0 & Sul & Autoestrada & 353,8 & Normal & Normal & Exponecial & Normal \\
\hline 50,0 & Norte & Autoestrada & 366,7 & Normal & Normal & Normal & Normal \\
\hline 50,0 & Sul & Autoestrada & 320,1 & Normal & Normal & Normal & Normal \\
\hline 65,0 & Norte & Autoestrada & 427,0 & Normal & Normal & Normal & Exponencial \\
\hline 65,0 & Sul & Autoestrada & 468,9 & Normal & Normal & Normal & Normal \\
\hline 87,0 & Norte & Autoestrada & 372,2 & Normal & Normal & Normal & Normal \\
\hline 87,0 & Sul & Autoestrada & 448,0 & Normal & Normal & Normal & Exponencial \\
\hline 131,7 & Norte & Autoestrada & 486,7 & Normal & Normal & Normal & Normal \\
\hline 131,7 & Sul & Autoestrada & 674,1 & Normal & Normal & Normal & Exponencial \\
\hline 149,6 & Norte & Autoestrada & 402,1 & Normal & Normal & Normal & Normal \\
\hline 149,6 & Sul & Autoestrada & 441,4 & Normal & Normal & Exponecial & Normal \\
\hline \multicolumn{8}{|c|}{ SP-021 (Rodoanel) } \\
\hline 18,3 & Norte & Rodovia de pista dupla & 416,8 & Normal & Normal & Normal & Normal \\
\hline 22,3 & Sul & Rodovia de pista dupla & 417,9 & Normal & Normal & Exponecial & Normal \\
\hline \multicolumn{8}{|c|}{ SP-270 (Raposo Tavares) } \\
\hline 39,9 & Leste & Rodovia de pista dupla & 564,4 & Normal & Normal & Normal & Exponencial \\
\hline 39,9 & Oeste & Rodovia de pista dupla & 352,7 & Normal & Normal & Exponecial & Normal \\
\hline
\end{tabular}

